\title{
Beyond the Antagonism: Self-Labeled Xanthone Inhibitors as Modeled "Two-in-One" Drugs in Cancer Therapy
}


Yu-Lu Ma, ${ }^{\dagger}$ Wen-Wen Qu, ${ }^{\S}$ Sheng-Jiao Yan, ${ }^{*}{ }^{\dagger}$ and Jun Lin ${ }^{* \dagger}{ }^{\dagger}$

${ }^{\dagger}$ Key Laboratory of Medicinal Chemistry for Natural Resource (Ministry of Education), Yunnan Provincial Engineering Research Center in University for Crude Drugs and Pharmaceutical Intermediates, School of Chemical Science and Technology, Yunnan University, Kunming 650091, P. R. China

${ }^{\ddagger}$ Faculty of Life Science and Technology and ${ }^{\S}$ Faculty of Science, Kunming University of Science and Technology, Kunming 650504, P. R. China

${ }^{\|}$Department of Chemistry and ${ }^{\perp}$ Department of Biomedical Engineering, Boston University, Boston, Massachusetts 02215, United States

\section{Supporting Information}

ABSTRACT: Self-labeled inhibitors (SLIs) are promising for creating links, ranging from cancer therapy and metastatic pathways to mechanistic elucidation. In this study, a new category of "two-in-one" fluorescent xanthone inhibitors was developed for the systematic evaluation of anticancer activity and the selective imaging of cytoplasm in vitro. These xanthone inhibitors presented high fluorescent brightness, working over a wide $\mathrm{pH}$ range enabled by a "switchable reaction" of the heterocyclic backbone. The strength and nature of fluorescence were probed via spectroscopic methods and density functional theory calculations on the molecular level, respectively. Along with the potent anticancer activity,

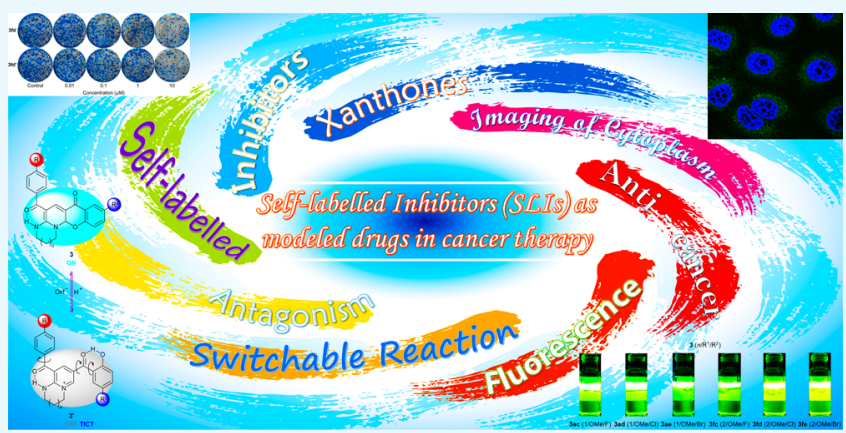
which was demonstrated using MTT and clonogenic assays with high fluorescent brightness in the cytoplasm, SLI $3 \mathrm{fd}$ could be established as a modeled self-monitoring drug in cancer therapy.

\section{INTRODUCTION}

Enabled by the advancement of fluorescent spectroscopic and microscopic technologies, monitoring the real-time behavior of drug molecules inside of living cells has been well-established. ${ }^{1}$ Traditionally, tracking drug molecules and their corresponding behavior (e.g., the alternation of the molecular structure and informational feedback) was dependent on the output of signals from the fluorescent label attached to the drug molecules. ${ }^{2-5}$ However, extraneous fluorescent labels or drug delivery media could pose potential risks such as toxicity, residue, and metabolism, which would interfere with the normal cellular function. ${ }^{6}$ Therefore, it is highly desired to design self-labeled inhibitors (SLIs) that not only play the role of antagonists but also report their own trace in cells and further potentially convey the information of intracellular delivery, metastatic pathways, and even mechanistic elucidation (Figure 1).

Xanthones represent a valuable category of natural products $^{7-12}$ because of their prominent pharmacological activities. They are known to serve as inhibitors for various targets such as tumors, ${ }^{13,14}$ bacteria, ${ }^{15,16}$ viruses, ${ }^{17}$ fungi, ${ }^{18}$ and others. ${ }^{19-21}$ Recently, the fluorescence of xanthones has been investigated for selective labeling and recognition of multiscale chemical or biological species. $^{22,23}$ For example, Maity et al. developed a two-photon probe based on the xanthone framework for the selective detection of $\mathrm{Cu}^{+}$in a physiologically reducing environment; ${ }^{24}$ Umemoto et al. used a series of xanthone and thioxanthone derivatives to study the binding process of small molecules to $\mathrm{RNA}^{25}$ and Gosh et al. used acetylated xanthones to serve as fluorescent probes for embryonic stem cells. ${ }^{26}$ However, to the best of our knowledge, no information is available about an SLI that couples at least two functions, viz., antagonism and fluorescence in one xanthone molecule, to inhibit cancer cells, track drug delivery, and report the response of intracellular homeostasis.

Given these considerations, we envisioned that an SLI model can be established based on a rational design, stepwise screening, and functional combination. Herein, we report a sequential approach to discover, characterize, and evaluate "two-in-one" fluorescent inhibitors, which includes three stages: (i) xanthone derivatives (3) were initially screened using fluorescent calorimetry, after which the strength and nature of fluorescence were meticulously probed using spectroscopic

Received: January 3, 2017

Accepted: February 28, 2017

Published: March 13, 2017 


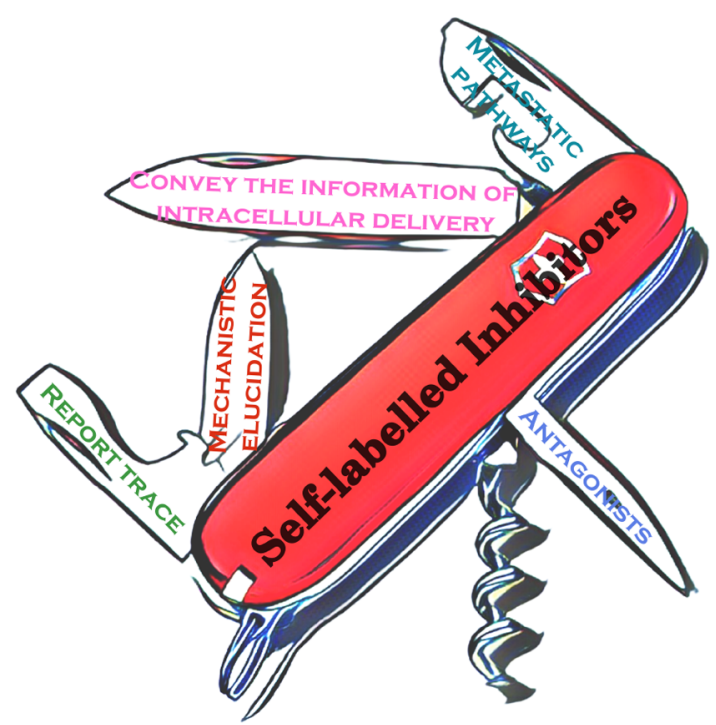

Figure 1. Functionalized SLIs.

methods and density functional theory (DFT) calculations; (ii) the screened fluorescent molecules and quenched counterparts were subjected to MTT and clonogenic assays that shed light on the anticancer activity both in the short- and long-term; and (iii) in order to demonstrate the self-monitoring in cancer cells, the potent inhibitor $3 \mathrm{fd}$ was investigated using cell imaging to observe the subcellular localization.

\section{RESULTS AND DISCUSSION}

In the first stage, synthetic efforts have been made to establish xanthone-based fluorescent compounds (3) (Figure 2a). The remarkable tolerance of the functional groups $\left(R^{1}\right.$ and $R^{2}$ ) enabled the facile transfer of electrons across the $\pi$-conjugated fused rings, and different-sized diazaheterocycles $(n)$ modulated the flexibility of the molecular skeleton. Accordingly, the rational preintroduction of electron withdrawing or donating groups in synthons $\mathbf{1}$ and $\mathbf{2}$ should tremendously affect the fluorescent performance of 3 . Once the xanthone-based compounds (3) have been constructed, first-stage screening was carried out (Table S1). After rigorous calorimetry, six molecules (Figure 2b) with the highest fluorescent intensity were selected as candidates for the development of SLIs.

For the sake of maximally dissolving the target compounds 3 in the deuterated solvent, a drop of perchloric acid was added when the nuclear magnetic resonance (NMR) characterization was carried out. Unexpectedly, we found that with the disappearance of fluorescence, all of the compounds (3) were transformed into the ring-opened counterparts $\left(3^{\prime}\right)$ (Figure $2 c)$. Moreover, this accidental phenomenon encouraged us to tackle at least two important questions, viz.: (i) is the transformation reversible? and (ii) how can the essential relationship and the mechanism between the structural and fluorescent changes be demonstrated and confirmed?

As a result, an integrated investigation of fluorescent molecules 3ac-3ae and $3 \mathrm{fc}-3 \mathrm{fe}$, which included spectroscopic properties, NMR, X-ray crystallographic analysis, DFT calculations, and electrochemistry was conducted. Ultraviolet-visible (UV-vis) absorption spectra (Figure $3 a$ and Table 1, col. 2) and calculated electronic transitions (Table 1, col. 3) revealed that shifting the substitution groups $\left(\mathrm{R}^{2}\right)$ from a more to a less electron-withdrawing state $(\mathrm{F} \rightarrow \mathrm{Cl} \rightarrow \mathrm{Br})$ and increasing the size $(n)$ of diazaheterocycles $(1 \rightarrow 2)$ lead to a small but a discernible red shift. At the same time, the fluorescence of these molecules was also examined. Several solvents were used to probe the effects of increased polarity on the emission wavelengths $\left(\lambda_{\text {em }}\right)$ of 3ae (Figure S2). It was found that an apparent red shift will occur when the polarity of the solvents increases. The best excitation wavelengths $\left(\lambda_{\mathrm{ex}}\right)$ and $\lambda_{\mathrm{em}}$ ranged from $449-470$ to $519-526 \mathrm{~nm}$ (Figure $3 \mathrm{~b}$ and Table 1, col. 4), respectively (Figures S3-S8). Importantly, the combination of electron donors and acceptors in the xanthone framework released most of its potential fluorescent properties, for example, large Stokes shifts $(\sim 80 \mathrm{~nm})$ (Figure 3c and Table 1 , col. 5), high quantum yields (up to 0.671), and excellent fluorescent brightness (up to $74.72 \mathrm{~mL} \mathrm{mg}^{-1} \mathrm{~cm}^{-1}$ ) (Table 1,

(a)

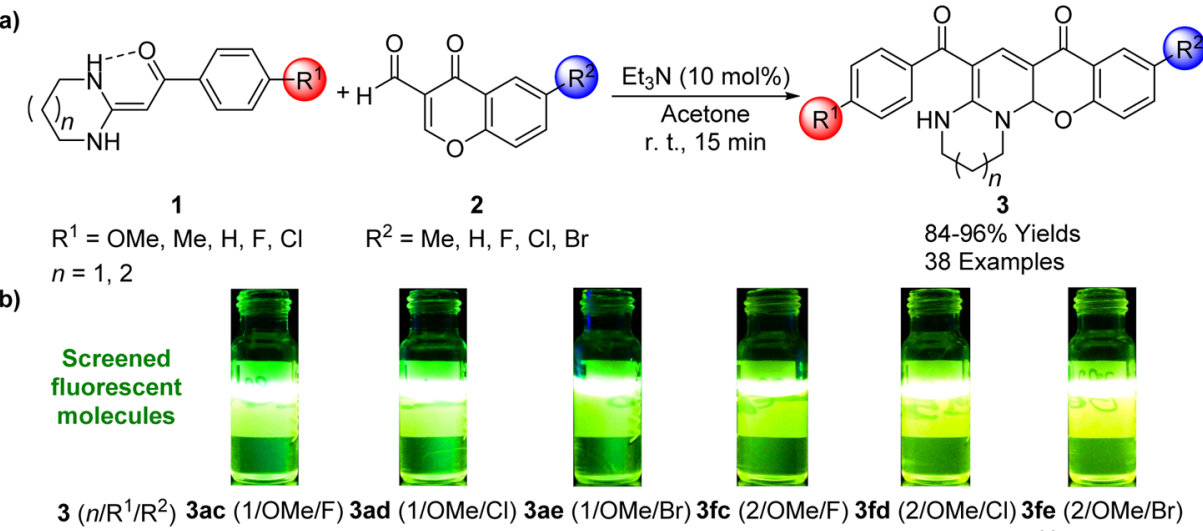

(c)
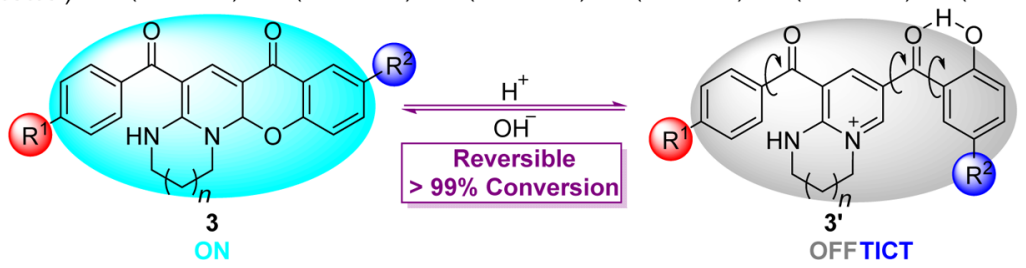

Figure 2. (a) Synthesis of xanthone-based compounds; (b) candidates with the highest light-emitting intensity; and (c) accidental discovery of the $\mathrm{pH}$-tuned, switchable reaction-dependent fluorescent molecules. 
(a)

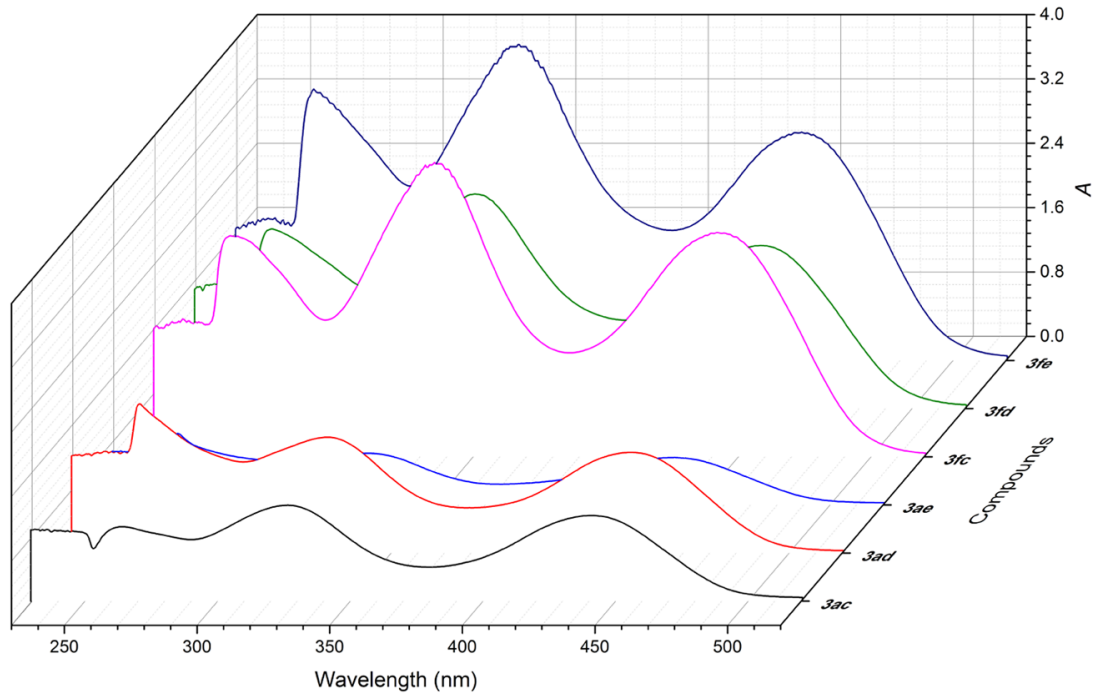

(b)

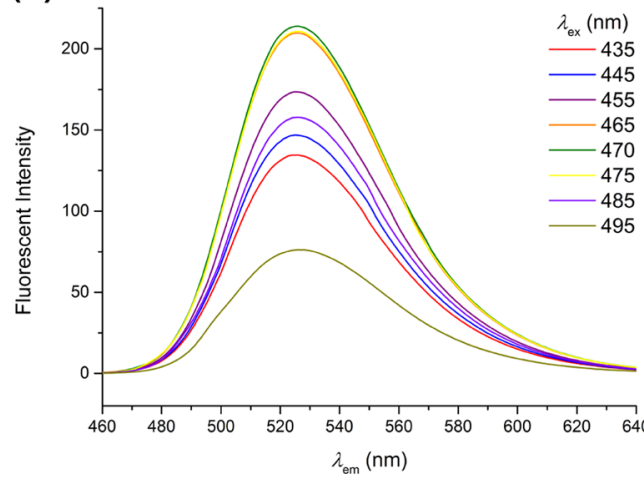

(c)

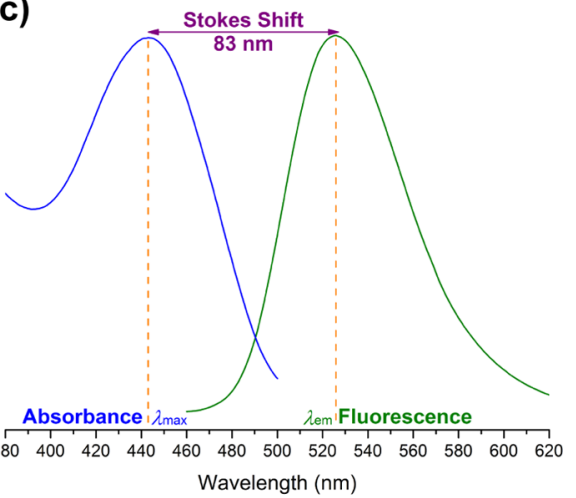

Figure 3. (a) UV-vis absorption spectra of the fluorescent molecules; (b) fluorescent spectra of compound 3fd under specific excitation wavelengths; and (c) Stokes shift of compound 3fd.

Table 1. Experimental and Calculated Electronic Transitions for Fluorescent Molecues ${ }^{a}$

$\begin{array}{ccccccc}\text { compd } & \lambda_{\text {abs }}(\mathrm{nm})^{b} & \lambda_{\text {abs }}^{\text {cal }} / \lambda_{\text {em }}^{\text {cal }}(\mathrm{nm})^{c} & \lambda_{\text {ex }} / \lambda_{\text {em }}(\mathrm{nm}) & \lambda_{\text {em }}-\lambda_{\text {abs }}(\mathrm{nm})^{d} & \Phi^{e} & \varepsilon / \varepsilon \times \Phi\left(\mathrm{mL} \mathrm{mg}^{-1} \mathrm{~cm}^{-1}\right)^{f} \\ \text { 3ac } & 440.5 & 421.9 / 514.3 & 464.0 / 519.5 & 79.0 & 0.476 & 42.64 / 19.91 \\ \text { 3ad } & 440.0 & 421.0 / 514.4 & 449.0 / 520.0 & 80.0 & 0.464 & 50.07 / 23.23 \\ \text { 3ae } & 441.5 & 421.4 / 515.9 & 466.0 / 520.5 & 79.0 & 0.428 & 23.56 / 10.08 \\ \text { 3fc } & 442.0 & 424.3 / 514.6 & 461.0 / 525.5 & 83.5 & 0.671 & 111.53 / 74.72 \\ \text { 3fd } & 443.0 & 424.1 / 514.5 & 470.0 / 526.0 & 83.0 & 0.663 & 81.07 / 53.75 \\ \text { 3fe } & 443.5 & 423.6 / 516.6 & 470.0 / 526.0 & 82.5 & 0.329 & 113.48 / 37.33\end{array}$

${ }^{a}$ Ethanol as the solvent. ${ }^{b} \lambda_{\text {abs }}$ : maximal absorption wavelength. ${ }^{c}$ Calculated transitions $\left(\lambda_{\mathrm{abs}}^{\mathrm{cal}} / \lambda_{\mathrm{em}}^{\mathrm{cal}}\right)$ were performed using the time-dependent DFT (TD-DFT) method on the B3LYP/6-311+G(2d,2p) level, and the polarizable continuum model (PCM) was used with ethanol as the solvent. ${ }^{d} \lambda_{\mathrm{em}}-\lambda_{\mathrm{abs}}$ : Stokes shift. ${ }^{e} \Phi$ : quantum yield, rhodamine as the reference. ${ }^{f} \mathcal{E}$ : absorption coefficient; $\varepsilon \times \Phi$ : fluorescent brightness.

col. 7). Consequently, these molecules could avoid selfquenching and enhance the number of labels that can be attached to a biological entity.

Having completed this preliminary study of spectroscopic properties, it is time to point out the proposed fluorescence mechanism. A combined method has been adopted to confirm the reversibility of the transformation illustrated in Figure 2c. When two drops of $\mathrm{KOH}$ solution were dropped into compounds $3^{\prime}$, the disappeared fluorescence of 3 reproduced in $10 \mathrm{~s}$. The contrasting in situ ${ }^{13} \mathrm{C}$ and ${ }^{1} \mathrm{H}$ NMR spectra (for original data, see Supporting Information) between $3 \mathrm{fd}$ and $3 \mathbf{f d}^{\prime}$ revealed that once the transformation occurred, the chemical shifts of $\mathrm{C} 1(\mathrm{H} 1), \mathrm{C} 2, \mathrm{C} 4(\mathrm{H} 4), \mathrm{C} 5, \mathrm{C} 7$, and $\mathrm{C} 8$ moved to a lower field, whereas those of $\mathrm{C} 3$ and $\mathrm{C} 6$ moved to a higher field. The newly generated hydroxyl group (H9) introduced a chemical shift at $9.57 \mathrm{ppm}$ (Figure 4a). These alterations in the characteristic peaks could partially verify that the transformation is reversible. In addition, clear evidence from the X-ray crystallographic interpretation of $\mathbf{3} \mathbf{c b}$ and $\mathbf{3} \mathbf{c b}$ solidified the previous deduction (Figure 4b).

To demonstrate the essential relationship between the structural and fluorescent changes, we next sought to use the DFT calculation of frontier molecular orbitals (FMOs) to elucidate the mechanism of fluorescence quenching (Figure 5). For all molecules 3, an excellent agreement between the experimental and theoretical maximal absorptions or emissions was observed (Table 1, col. 3). The main absorption bands were due to three excitations with a high oscillator strength $(f$ $\approx 0.40$ ), viz., HOMO $\rightarrow$ LUMO, HOMO $-1 \rightarrow$ LUMO, and $\mathrm{HOMO} \rightarrow \mathrm{LUMO}+1$, mainly of the $\pi \rightarrow \pi^{*}$ or $n \rightarrow \pi^{*}$ 

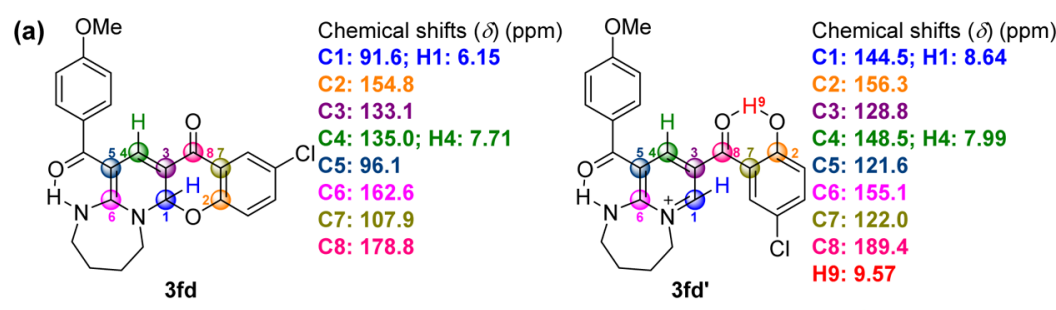

(b)

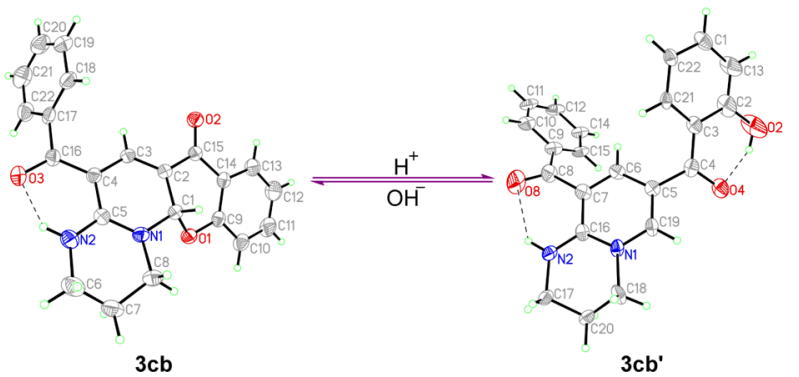

Figure 4. (a) Contrasting ${ }^{13} \mathrm{C}$ and ${ }^{1} \mathrm{H}$ NMR spectra of compounds $3 \mathbf{f d}$ and $3 \mathbf{f d}^{\prime}$ and (b) X-ray crystal structures of compounds $3 \mathbf{c b}$ and $3 \mathbf{c b}$. Thermal ellipsoids are drawn at $30 \%$ probability.

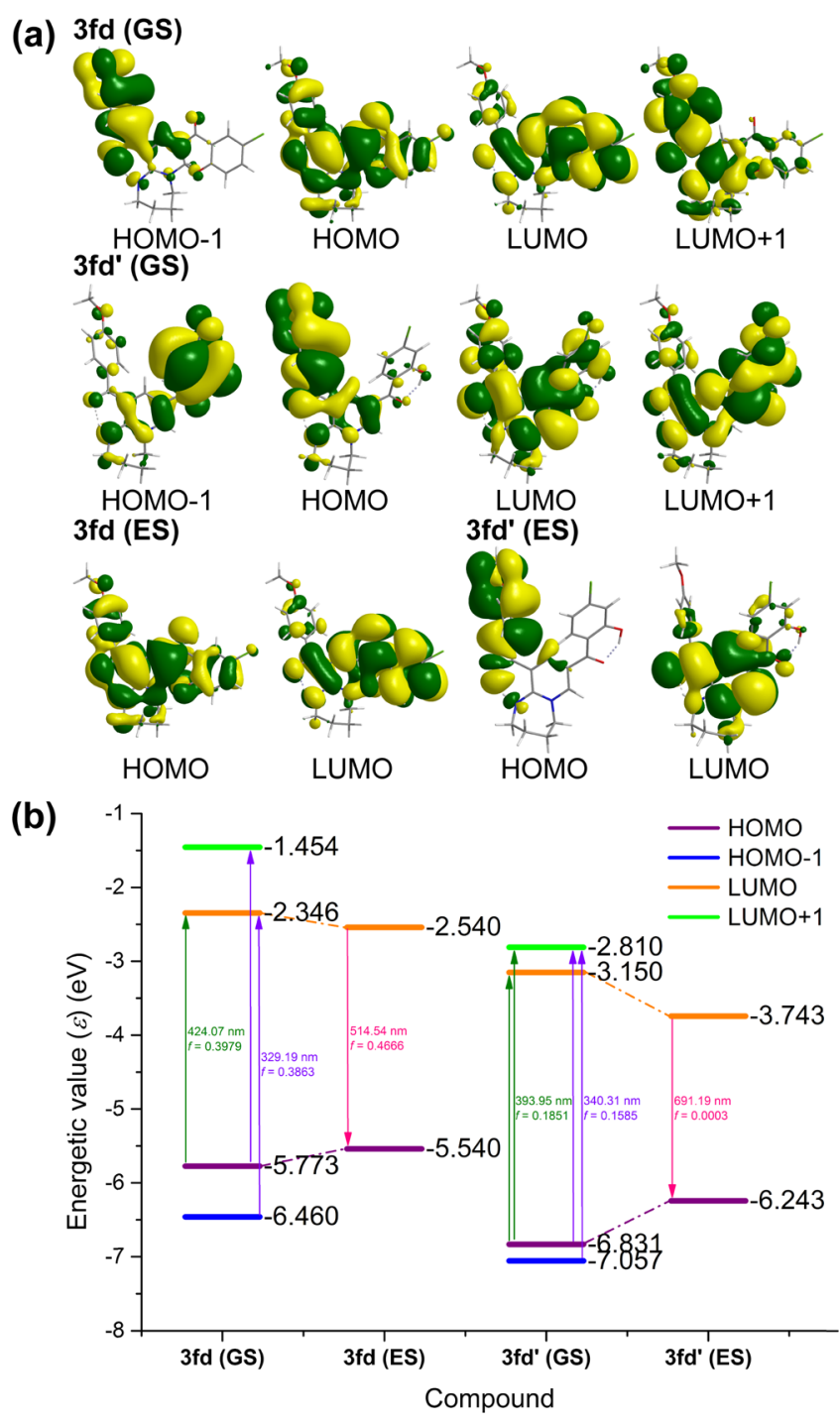

Figure 5. (a) FMOs and (b) their energetic values $(\varepsilon)$ of compounds $3 \mathbf{f d}$ and $3 \mathbf{f d}^{\prime}$. GS: ground state and ES: excited state. intramolecular charge transfer (ICT) characteristic. The emission band with a high oscillator strength $(f \approx 0.45)$, which was responsible for the fluorescence, lay on the $\pi^{*} \rightarrow \pi$ ICT of LUMO $\rightarrow$ HOMO. It was obviously reflected in the population of the FMOs. For the ring-opening counterparts $3^{\prime}$, a higher energy $(\sim 0.25 \mathrm{eV})$ needed to be supplied for the absorption, but the oscillator strength $(f \approx 0.20)$ was only half that of 3 . In addition, once the rigid molecular framework was broken, the emission band of $3^{\prime}$ (LUMO $\rightarrow$ HOMO) shifted to the longer wavelength region $(\sim 690 \mathrm{~nm})$ with an extremely small oscillator strength $(f \approx 0.0002)$; meanwhile, the flexible structure restricted the ICT. On the other hand, the electrostatic potential also offered apparent evidence for the direction of electron mobility (Figure 6a). Therefore, the fluorescence quenching was caused by the ICT block, which was derived from a twisted ICT (TICT) via the rotation of C$\mathrm{C}$ single bonds $(\mathrm{C} 1-\mathrm{C} 2, \mathrm{C} 2-\mathrm{C} 3$, and $\mathrm{C} 4-\mathrm{C} 5)$ (Figure 6a). Afterward, the electrochemical property was also tested using cyclic voltammetry (Figure 6b). For instance, 3fd presented only one reversible reduction potential. The first onset of reduction was at $-1.04 \mathrm{~V}$, with a reversible reduction wave at $-1.19 \mathrm{~V}$. It was revealed that the molecules are electrondeficient and therefore can be considered as electron acceptors.

Having illustrated the fluorescent nature of the selected molecules, we next performed a second-stage screening. The anticancer activity in MTT and clonogenic assays was evaluated to identify the most promising fluorescent inhibitors in several human cell lines. For compounds that showed $>50 \%$ inhibition, half-maximal inhibitory concentrations $\left(\mathrm{IC}_{50}\right)$ were determined. For short-term treatment effects (Table 2), we found that except for 3ac, all compounds presented definite cytotoxicity to many cancer cell lines $\left(\mathrm{IC}_{50}<50 \mu \mathrm{M}\right)$. In particular, compounds $3 \mathbf{f e}, 3 \mathbf{f c}^{\prime}$, and $3 \mathbf{f d}^{\prime}$ demonstrated potent anticancer activity, with $\mathrm{IC}_{50}<10 \mu \mathrm{M}$ in HepG2 liver carcinoma cells. It is also worth noting that the cytotoxicity of all molecules for embryonic lung fibroblasts MRC-5 is lower than that for the positive control cisplatin (DDP) (Table 2, entry 10), indicating that the screened inhibitors are effective against cancer cells (e.g., T47D and U251), yet have lower cytotoxicity to normal cells (e.g., MRC-5).

To investigate the long-term treatment effects of inhibitors $3 \mathbf{f d}$ and $\mathbf{3 f d}$, a clonogenic assay was also performed in HepG2 
(a)

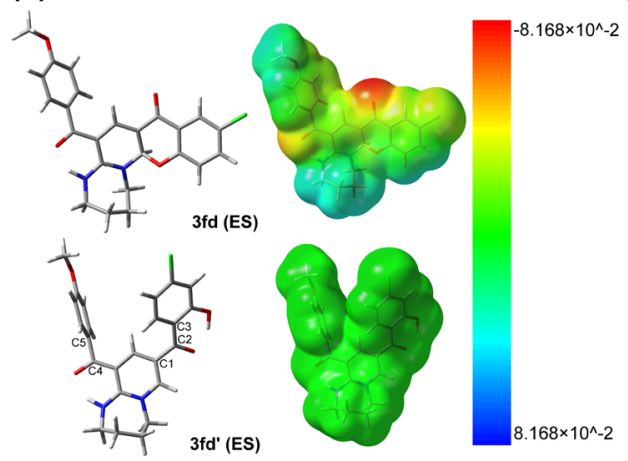

(b)

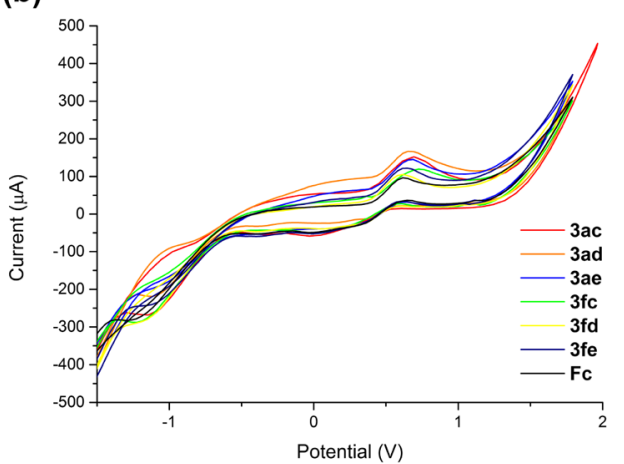

Figure 6. (a) Electrostatic potential map of compounds $3 \mathbf{f d}$ and $\mathbf{3} \mathbf{f d}^{\prime}$ and (b) cyclic voltammogram (CV) of the fluorescent molecules in anhydrous ethanol $\left(1.0 \times 10^{-4} \mathrm{M}\right)$. $\mathrm{Fc} / \mathrm{Fc}^{+}$couple was used as an internal standard.

Table 2. MTT Assay for Short-Term Anticancer Activity

\begin{tabular}{|c|c|c|c|c|c|c|}
\hline \multirow[b]{2}{*}{ entry } & \multirow[b]{2}{*}{ compd } & \multicolumn{5}{|c|}{ anticancer activity $\left(\mathrm{IC}_{50}\right)(\mu \mathrm{M})$} \\
\hline & & MRC- $5^{a}$ & HepG $2^{b}$ & $\mathrm{HT} 29^{c}$ & SGC7901 $^{d}$ & $\mathrm{~A} 549^{\circ}$ \\
\hline 1 & $3 a c$ & & $>100$ & & $>100$ & $>100$ \\
\hline 2 & 3ad & 34.9 & 30.9 & 26.9 & 18.7 & 34.3 \\
\hline 3 & $3 a e$ & 31.3 & 15.4 & 18.8 & 17.8 & 27.5 \\
\hline 4 & $3 \mathrm{fc}$ & 48.0 & 18.9 & 29.8 & 26.7 & 39.6 \\
\hline 5 & $3 \mathrm{fd}$ & 33.1 & 11.2 & 26.8 & 14.8 & 33.5 \\
\hline 6 & $3 \mathrm{fe}$ & 34.8 & 9.5 & 13.3 & 13.5 & 27.5 \\
\hline 7 & $3 \mathrm{fc}^{\prime}$ & 35.3 & 9.2 & 21.8 & 15.0 & 33.7 \\
\hline 8 & $3 \mathrm{fd}^{\prime}$ & 34.0 & 7.7 & 14.1 & 10.5 & 26.4 \\
\hline 9 & $3 \mathrm{fe}^{\prime}$ & 45.8 & 15.2 & 25.1 & 25.8 & 27.6 \\
\hline $10^{f}$ & DDP & 8.2 & 3.0 & 14.3 & 2.3 & 8.4 \\
\hline
\end{tabular}

${ }^{a}$ Diploid fibroblasts. ${ }^{b}$ Liver carcinoma cells. ${ }^{c}$ Colorectal cancer cells. ${ }^{d}$ Gastric carcinoma cells. ${ }^{e}$ Cancerous alveolar epithelial cells. $f_{\text {Cisplatin: positive control. }}$

liver carcinoma cells. This assay is used to determine the ability of a cell to proliferate indefinitely. $\mathrm{IC}_{50}$ values of $3 \mathbf{f d}$ and $3 \mathrm{fd}^{\prime}$ were estimated by dividing the mean number of colonies following compound treatment by the mean number of colonies in the absence of a compound. Compared with untreated controls, the number of colonies declined after treatment with a series of concentrations of $3 \mathrm{fd}$ and $3 \mathrm{fd}^{\prime}$ (Figure 7a), with $\mathrm{IC}_{50}$ values of 5.99 and $5.55 \mu \mathrm{M}$ (Figure $7 \mathrm{~b}$ ), respectively. In any case, the perfect match for short-term (MTT assay) and long-term (clonogenic assay) treatments showed stable and continued activities in cancerous resistance.

In view of the above scenario, the assembly of potent anticancer activity with inherent high fluorescent brightness in an inhibitor shows promise. Hence, we finally proposed a cell imaging program to validate the feasibility of inhibitor $3 \mathrm{fd}$ through the observation of the subcellular localization in HepG2 cells. The experiment was carried out with increasing concentrations of $3 \mathrm{fd}$ and staining of the nucleus with 4,6diamidino-2-phenylindole (DAPI). The results demonstrated that the accumulation of blue fluorescence in the nuclear compartment contrasts with the extensive green fluorescent inhibitor 3fd sequestered in the cytoplasm (Figure 8). Increasing the incubation concentration of $3 \mathrm{fd}$ does not change its subcellular localization. Therefore, $3 \mathrm{fd}$ is preferentially localized to the cytoplasm. So far, as an antagonist, 3fd has presented extraordinary potency in several cancer cell lines; as a fluorescein, it has afforded extreme brightness; most

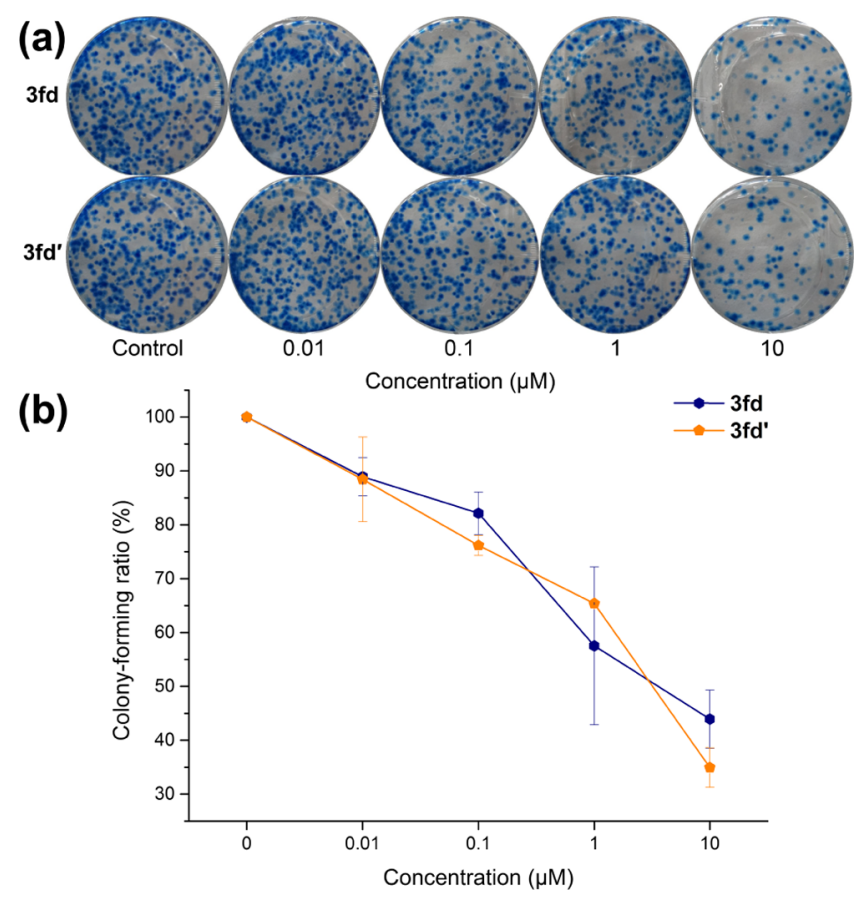

Figure 7. (a) Clonogenic assay for long-term anticancer activity and (b) colony-forming ratio of inhibitors $3 \mathbf{f d}$ and $3 \mathrm{fd}^{\prime}$.

importantly, as a model SLI, it lights up the way to the cell, reports where it is, and ultimately kills the cancerous enemy.

\section{CONCLUSIONS}

In summary, we have successfully developed the first model of an SLI in cancer therapy via an assembly line pathway that includes the systematic screening of fluorescent xanthone derivatives, the multidimensional evaluation of anticancer activity, and the functional embedment of the two inherent properties. The present results with SLI $3 \mathrm{fd}$ indicate that the fluorescent properties can avoid self-quenching and enhance the number of labels; simultaneously, the coherent short- and long-term resistance can ensure excellent anticancer activity. Importantly, the functional combination reveals a promising idea for tracking drug molecules on the micron scale. Moreover, with the tunable fluorescent intensity over a wide $\mathrm{pH}$ range, it also provides a new impetus for probing the effects of homeostasis to antagonism. It is worth pointing out that the SLI concept suggests in-depth insights into the informational feedback of intracellular delivery, metastatic pathways, mech- 


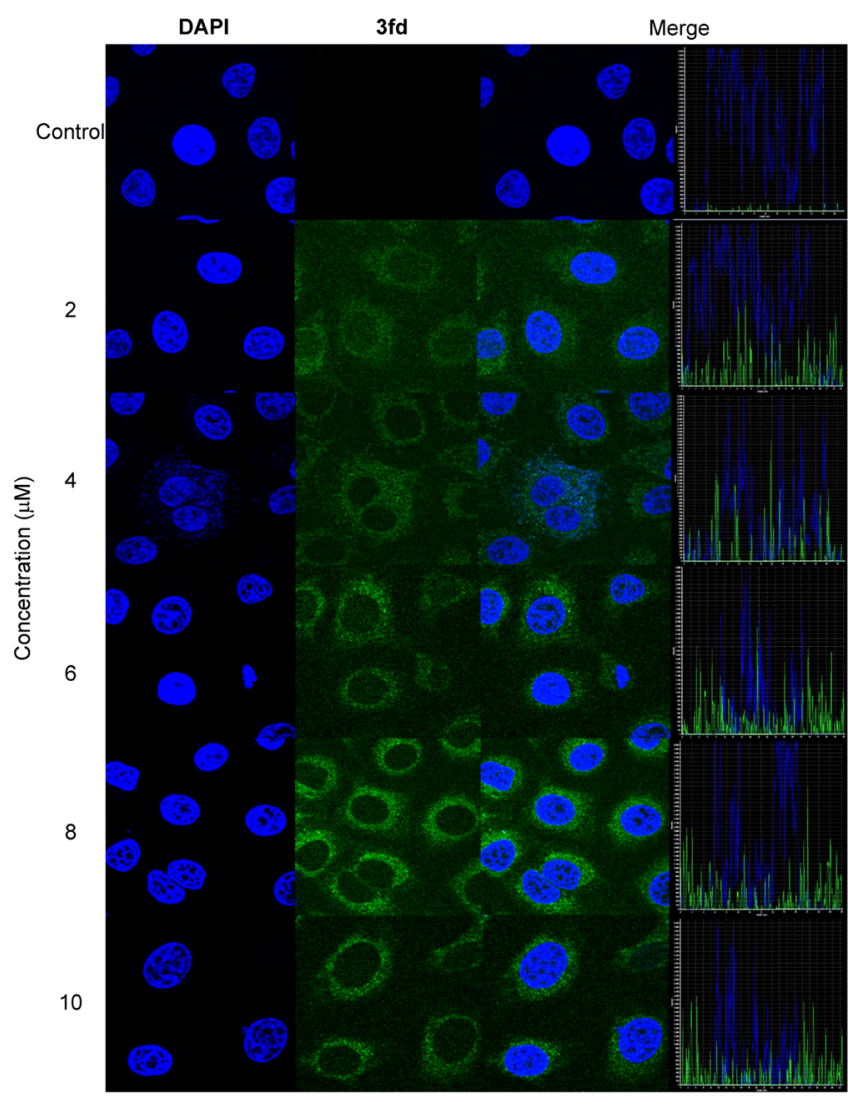

Figure 8. Confocal fluorescent images of HepG2 cells incubated with fluorescent inhibitor 3fd (green) or DAPI (blue).

anistic elucidation, and so forth. Further investigations into the quantitative $\mathrm{pH}$-fluorescence response for cancer cells and the real-time imaging of an enzymatic target on the nanoscale are currently under way.

\section{EXPERIMENTAL SECTION}

General Methods. All commercially available reagents were purchased from Adamas Reagent Co. Ltd. and used without further purification unless otherwise stated. Melting points were determined using a melting point apparatus and are uncorrected. ${ }^{1} \mathrm{H}\left({ }^{13} \mathrm{C}\right)$ NMR spectra were recorded at 500 (125) $\mathrm{MHz}$ using $\mathrm{CDCl}_{3}, \mathrm{DMSO}-d_{6}$, or their combination as the solvent. The chemical shifts $(\delta)$ are expressed in parts per million relative to the residual deuterated solvent signal, and coupling constants $(J)$ are given in hertz. Infrared (IR) spectra were recorded on a Fourier transform infrared (FT-IR) spectrometer using $\mathrm{KBr}$ pellets. High-resolution mass spectrometry (HRMS) data were obtained in the electron impact (EI) mode at $70 \mathrm{eV}$. Anhydrous ethanol was used throughout the process of absorption and fluorescence determination. All samples were prepared at room temperature. Dilute hydrochloric acid or sodium hydroxide was used for tuning the $\mathrm{pH}$ values. UV-vis absorption spectra were obtained using $1.0 \mathrm{~cm}$ quartz cells. An ethanolic solution of compounds $3(25 \mu \mathrm{g}$ $\mathrm{mL}^{-1}$ ) was added to a $10 \mathrm{~mL}$ volumetric flask. The ethanolic solution was equilibrated for $2 \mathrm{~min}$ before measurement. The excitation slit was set to $5.0 \mathrm{~nm}$. Fluorescent emission spectra were obtained using a xenon lamp and $1.0 \mathrm{~cm}$ quartz cells. An ethanolic solution of compounds $3\left(25 \mu \mathrm{g} \mathrm{mL}^{-1}\right)$ was added to a $10 \mathrm{~mL}$ volumetric flask. After dilution with different buffer solutions, the mixture was equilibrated for $2 \mathrm{~min}$ before measurement. The excitation and emission slits were set to 5.0 $\mathrm{nm}$. The quantum yields of compounds $\mathbf{3}$ in anhydrous ethanol were determined by comparing the integrated fluorescence spectra of the samples with that of a standard (rhodamine 6G in anhydrous ethanol, $5.0 \mu \mathrm{g} \mathrm{mL}^{-1}$ ).

Computational Methods. All calculations were carried out using the Gaussian 03 program. ${ }^{27}$ Geometry optimizations were performed with the B3LYP functional ${ }^{28-30}$ and the 6$311+G(2 d, 2 p)$ basis set $^{31}$ for the ground states. UV-vis absorptions (vertical excitation) were calculated using the TDDFT method based on the optimized ground state geometry (GS, $\mathrm{S}_{0}$ state). For fluorescent emissions, the light emission was calculated based on the optimized excited states (ES, $S_{1}$ state). The default self-consistent reaction field (SCRF) PCM was used with ethanol (dielectric constant $\varepsilon=24.852$ ) as the solvent, while universal force field (UFF) radii were chosen as the atomic radii to define the molecular cavity. Vibrational frequencies were calculated for all stationary points to verify that each was a minimum (no imaginary frequencies) on the potential energy surface.

Cyclic Voltammetry. CVs were recorded on a Zahner IM6e electrochemical workstation using a Pt foil as the working electrode, a $\mathrm{Pt}$ wire as the counter electrode, and a $\mathrm{Ag} / \mathrm{AgCl}$ electrode as the reference. Cyclic voltammetry curves run at a scan rate of $50 \mathrm{mV} \mathrm{s}^{-1}$ in anhydrous ethanol with $1.0 \times 10^{-4} \mathrm{M}$ substrate and $0.1 \mathrm{M}\left[\mathrm{NBu}_{4}\right]^{+}\left[\mathrm{PF}_{6}\right]^{-}$as the supporting electrolyte. $\mathrm{Fc} / \mathrm{Fc}^{+}$couple was used as an internal standard.

MTT Assay. Four carcinoma cell lines and one normal cell line, that is, diploid fibroblasts (MRC-5), liver carcinoma cells (HepG2), colorectal cancer cells (HT29), gastric carcinoma cells (SCG7910), and cancerous alveolar epithelial cells (A549) were obtained from the American Type Culture Collection (Manassas, VA). All cells were incubated at $37{ }^{\circ} \mathrm{C}$ under $5 \%$ $\mathrm{CO}_{2}$ and humidified air. The growth inhibition of human cancer cells by compounds 3 (3ac-3ae and $3 \mathrm{fc}-3 \mathrm{fe}$ ) was assessed using the MTT assay, along with dimethyl sulfoxide (DMSO) as a control. Different human cancer cell lines were treated with compounds at various concentrations. After a $96 \mathrm{~h}$ incubation, MTT [3-(4,5-dimethylthiazol-2-yl)-2,5-diphenyltetrazolium bromide] was added to the wells $(50 \mathrm{~mL} ; 0.4 \mathrm{mg}$ $\mathrm{mL}^{-1}$ ) and incubated for another $4 \mathrm{~h}$. The medium was aspirated, and DMSO $(150 \mathrm{~mL})$ was added to each well. Absorbance was measured at $490 \mathrm{~nm}$ using a 2030 Multilabel Reader (Perkin-Elmer Victor X5, US). Compound concentrations causing 50\% growth inhibition (IC50) were calculated.

Clonogenic Assay. Exponentially growing HepG2 cells were seeded at a density of $2 \times 10^{5}$ cells per well in 6-well plates and allowed to attach overnight; then, the cells were exposed to different concentrations of $3 \mathbf{f d}$ and $3 \mathrm{fd}^{\prime}$ (0.01, 0.1, $1,10 \mu \mathrm{M}$ ) for $18 \mathrm{~h}$, whereas control wells received the vehicle alone. Afterward, the vehicle and the compound-treated cells were replated into 6-well plates (700 cells/well) in triplicate. The plates were incubated for 10 days at $37{ }^{\circ} \mathrm{C}$ in an atmosphere of $5 \% \mathrm{CO}_{2}$. The cells were washed [three times in ice-cold phosphate buffered saline (PBS)], fixed with prechilled methanol $(20 \mathrm{~min})$, stained with $0.5 \%$ methylene blue for $30 \mathrm{~min}$, washed thoroughly in distilled $\mathrm{H}_{2} \mathrm{O}$, and airdried. Cell colonies containing more than 50 cells were counted. $\mathrm{IC}_{50}$ values of $\mathbf{3} \mathbf{f d}$ and $\mathbf{3} \mathbf{f d}^{\prime}$ were estimated by dividing the mean number of colonies following compound treatment by the mean number of colonies in the absence of the compound. 
In Vitro Cell Imaging. The HepG2 cells $\left(1.5 \times 10^{5}\right.$ cells/ well) were incubated at $37{ }^{\circ} \mathrm{C}$ with different concentrations of 3fd $(2,4,6,8$, and $10 \mu \mathrm{M})$ and treated for $15 \mathrm{~h}$. The medium was removed, and the cells were rinsed with ice-cold PBS before the fixation with fixative (5\% paraformaldehyde/ sucrose $/ \mathrm{PBS}=6: 1: 3$ ) for $10 \mathrm{~min}$ at room temperature. After washing, the cells were incubated with DAPI $\left(1 \mathrm{mg} \mathrm{mL}^{-1}\right)$ for $20 \mathrm{~min}$ at room temperature in the dark. A drop of antifade solution was added, and the treated portion of the slide was covered with a glass coverslip. The fluorescence of the compound was detected and localized using a confocal microscope (Olympus FV1000) with a 100 oil objective. The optical sections were obtained in the $Z$ axis and stored in the computer with a scanning mode.

Noncommercially Available Compounds. Heterocyclic ketene aminals (HKAs) 1 were prepared according to a procedure described in the literature. ${ }^{32}$ The identity of the materials was confirmed using ${ }^{1} \mathrm{H}$ and ${ }^{13} \mathrm{C}$ NMR and by their spectra from mass spectrometry.

General Procedure for the Synthesis of Compounds 3. HKAs (1) (1.0 mmol) and 3-formylchromones (2) (1.0 $\mathrm{mmol})$ were combined and dissolved in acetone $(15 \mathrm{~mL})$, followed by the addition of trimethylamine (10 $\mathrm{mol} \%)$. Subsequently, the reaction mixture was stirred in a roundbottom flask $(25 \mathrm{~mL})$ at room temperature for $15 \mathrm{~min}$. After the completion of the reaction as indicated by thin-layer chromatography (TLC), the mixture was filtered and washed with ethanol $(3 \times 5 \mathrm{~mL})$. The crude solid was then dried and recrystallized from acetone to afford the pure products 3 .

General Procedure for the Synthesis of Compounds $3^{\prime}$. One to eight drops of pure acid were dropped into compounds $3(0.5 \mathrm{mmol})$. Subsequently, the reaction mixture was stirred in a round-bottom flask $(5 \mathrm{~mL})$ for $8-25$ seconds (s) (Scheme 1). After the completion of the reaction as

Scheme 1. Transformative Synthesis of Compounds 3 and 3'

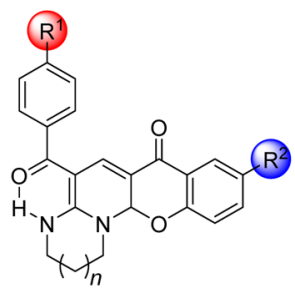

3
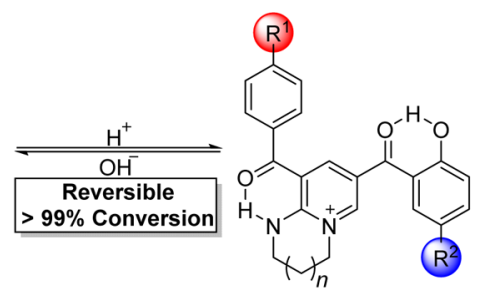

3'
Acid (Conc.): $\mathrm{HClO}_{4} \mathrm{H}_{2} \mathrm{SO}_{4} \mathrm{HCl} \mathrm{HOAc}$ Base (1.0 M): $\mathrm{KOH} \mathrm{NaOH} \mathrm{Na} \mathrm{CO}_{3} \mathrm{NH}_{3} \cdot \mathrm{H}_{2} \mathrm{O}$

$\begin{array}{llllllllll}\text { Drop: } & 1 & 2 & 5 & 8 & \text { Drop: } & 2 & 2 & 8 & >10\end{array}$

$\begin{array}{llllllllll}\text { Time (s): } & 8 & 15 & 20 & 25 & \text { Time (s): } & 10 & 12 & 20 & -\end{array}$

indicated by TLC, the mixture was filtered and washed in succession with $\mathrm{H}_{2} \mathrm{O}(2 \times 5 \mathrm{~mL})$ and $\mathrm{EtOH}(2 \times 5 \mathrm{~mL})$. The residue was then dried to afford the pure products $3^{\prime}$.

General Procedure for the Transformative Synthesis of Compounds 3 from $\mathbf{3}^{\prime}$. Two to eight drops of basic solution $(1.0 \mathrm{M})$ were dropped into compounds $3^{\prime}(0.5 \mathrm{mmol})$. Subsequently, the reaction mixture was stirred in a roundbottom flask $(5 \mathrm{~mL})$ for $10-20 \mathrm{~s}$. After the completion of the reaction as indicated by TLC, the mixture was filtered and washed in succession with $\mathrm{H}_{2} \mathrm{O}(2 \times 5 \mathrm{~mL})$ and $\mathrm{EtOH}(2 \times 5$ $\mathrm{mL})$. The residue was then dried to afford the pure products 3 .

Characterization Data of Compounds 3. 5-(4-Methoxybenzoyl)-9-methyl-2,3,4,12a-tetrahydro- $1 \mathrm{H}, 7 \mathrm{H}$-chromeno$\left[3^{\prime}, 2^{\prime}: 5,6\right]$ pyrido[1,2-a]pyrimidin-7-one (3aa). Isolated yield
95\%; yellow solid, mp $234-235{ }^{\circ} \mathrm{C}$; IR ( $\left.\mathrm{KBr}\right)\left(\nu_{\max } \mathrm{cm}^{-1}\right)$ : 3429, 1583, 1498, 1415, 1250, 1167, 1082, 608; ${ }^{1} \mathrm{H}$ NMR (500 $\left.\mathrm{MHz} \mathrm{CDCl}_{3}\right)(\delta, \mathrm{ppm}): 2.02-2.17\left(\mathrm{~m}, 1 \mathrm{H}, \mathrm{CH}_{2}\right), 2.31(\mathrm{~s}, 3 \mathrm{H}$, $\left.\mathrm{ArCH}_{3}\right), 3.38-3.52\left(\mathrm{~m}, 3 \mathrm{H}, \mathrm{NCH}_{2}\right.$ and $\left.\mathrm{CH}_{2} \mathrm{~N}\right), 3.84(\mathrm{~s}, 3 \mathrm{H}$, $\left.\mathrm{OCH}_{3}\right), 3.93-4.00\left(\mathrm{~m}, 1 \mathrm{H}, \mathrm{NCH}_{2}\right), 6.10(\mathrm{~s}, 1 \mathrm{H}, \mathrm{CH}), 6.84(\mathrm{~d}$, $J=8.3 \mathrm{~Hz}, 1 \mathrm{H}, \mathrm{ArH}), 6.90(\mathrm{~d}, J=8.5 \mathrm{~Hz}, 2 \mathrm{H}, \mathrm{ArH}), 7.23-7.28$ (m, 1H, ArH), 7.41 (d, $J=8.5 \mathrm{~Hz}, 2 \mathrm{H}, \operatorname{ArH}), 7.70-7.74(\mathrm{~m}$, $2 \mathrm{H}, \mathrm{ArH}), 12.02$ (br, $1 \mathrm{H}, \mathrm{NH}) ;{ }^{13} \mathrm{C}$ NMR $\left(125 \mathrm{MHz} \mathrm{CDCl}_{3}\right)$ $(\delta, \mathrm{ppm}): 19.9,20.9,38.8,44.9,55.8,88.4,93.3,107.9,113.9$, $117.8,124.3,127.6,130.4,132.3,133.4,136.2,137.6,154.3$, 156.4, 161.4, 180.6, 191.9; HRMS (ESI-TOF, $[\mathrm{M}]^{+}$): calcd for $\mathrm{C}_{24} \mathrm{H}_{22} \mathrm{~N}_{2} \mathrm{O}_{4}, 402.1574$; found, 402.1576 .

5-(4-Methoxybenzoyl)-2,3,4, 12a-tetrahydro- $1 \mathrm{H}, 7 \mathrm{H}$ chromeno[3', $\left.2^{\prime}: 5,6\right]$ pyrido[1,2-a]pyri-midin-7-one (3ab). Isolated yield $94 \%$; yellow solid, $\mathrm{mp} 210-213{ }^{\circ} \mathrm{C}$; IR $(\mathrm{KBr})\left(\nu_{\max }\right.$ $\left.\mathrm{cm}^{-1}\right): 3436,1644,1600,1498,1422,1384,1341,1295,1251$, $1169,1126,1021,812,755 ;{ }^{1} \mathrm{H}$ NMR $\left(500 \mathrm{MHz}, \mathrm{DMSO}-d_{6}+\right.$ $\left.\mathrm{HClO}_{4}\right)(\delta, \mathrm{ppm}): 1.95-2.05\left(\mathrm{~m}, 2 \mathrm{H}, \mathrm{CH}_{2}\right), 3.45-3.47(\mathrm{~m}$, $3 \mathrm{H}, \mathrm{NCH}_{2}$ and $\left.\mathrm{CH}_{2} \mathrm{~N}\right), 3.68-3.73\left(\mathrm{~m}, 1 \mathrm{H}, \mathrm{NCH}_{2}\right), 3.83(\mathrm{~s}$, $\left.3 \mathrm{H}, \mathrm{OCH}_{3}\right), 6.32(\mathrm{~s}, 1 \mathrm{H}, \mathrm{CH}), 7.00-7.05(\mathrm{~m}, 3 \mathrm{H}, \mathrm{ArH}), 7.09-$ $7.12(\mathrm{~m}, 1 \mathrm{H}, \mathrm{ArH}), 7.36(\mathrm{~d}, J=7.7 \mathrm{~Hz}, 2 \mathrm{H}, \mathrm{ArH}), 7.44-7.55$ (m, 2H, ArH), 7.74 (d, J = 7.6 Hz, 1H, ArH), $11.63(\mathrm{br}, 1 \mathrm{H}$, $\mathrm{NH}) ;{ }^{13} \mathrm{C}$ NMR $\left(125 \mathrm{MHz}, \mathrm{DMSO}-d_{6}+\mathrm{HClO}_{4}\right)(\delta, \mathrm{ppm})$ : 19.3, 36.7, 44.8, 55.7, 88.1, 92.6, 107.0, 113.8, 118.3, 122.5, $124.3,127.0,129.9,133.3,135.5,136.4,155.5,156.2,160.7$, 179.1, 190.4; HRMS (ESI-TOF, $[M]^{+}$): calcd for $\mathrm{C}_{23} \mathrm{H}_{20} \mathrm{~N}_{2} \mathrm{O}_{4}$, 388.1418; found, 388.1420.

9-Fluoro-5-(4-methoxybenzoyl)-2,3,4, 12a-tetrahydro$1 \mathrm{H}, 7 \mathrm{H}$-chromeno $\left[3^{\prime}, 2^{\prime}: 5,6\right]$ pyrido-[1,2-a]pyrimidin-7-one (3ac). Isolated yield 90\%; yellow solid, mp $252-254{ }^{\circ} \mathrm{C}$; IR $(\mathrm{KBr})\left(\nu_{\max } \mathrm{cm}^{-1}\right): 3419,1646,1598,1494,1433,1354,1306$, $1254,1177,1125,1027,842 ;{ }^{1} \mathrm{H}$ NMR $\left(500 \mathrm{MHz}, \mathrm{DMSO}-d_{6}+\right.$ $\left.\mathrm{HClO}_{4}\right)(\delta, \mathrm{ppm}): 2.04-2.10\left(\mathrm{~m}, 2 \mathrm{H}, \mathrm{CH}_{2}\right), 3.44-3.46(\mathrm{~m}$, $\left.2 \mathrm{H}, \mathrm{CH}_{2} \mathrm{~N}\right), 3.69-3.73\left(\mathrm{~m}, 2 \mathrm{H}, \mathrm{NCH}_{2}\right), 3.84\left(\mathrm{~s}, 3 \mathrm{H}, \mathrm{OCH}_{3}\right)$, $6.32(\mathrm{~s}, 1 \mathrm{H}, \mathrm{CH}), 7.00-7.03(\mathrm{~m}, 2 \mathrm{H}, \mathrm{ArH}), 7.09-7.11(\mathrm{~m}, 1 \mathrm{H}$, $\operatorname{ArH}), 7.35-7.42(\mathrm{~m}, 4 \mathrm{H}, \operatorname{ArH}), 7.46-7.48(\mathrm{~m}, 1 \mathrm{H}, \operatorname{ArH})$, 11.60 (br, $1 \mathrm{H}, \mathrm{NH}) ;{ }^{13} \mathrm{C}$ NMR (125 MHz, DMSO-d $d_{6}+$ $\left.\mathrm{HClO}_{4}\right)(\delta, \mathrm{ppm}): 19.3,24.6,36.9,44.8,55.7,88.3,93.0,104.3$, $106.2,112.1,113.9,120.4,122.5$ (d, $J=23.8 \mathrm{~Hz}), 129.9,133.2$, 137.1, 152.4, 155.5, 160.8, 178.0, 190.6; HRMS (ESI-TOF, $\left.[\mathrm{M}]^{+}\right)$: calcd for $\mathrm{C}_{23} \mathrm{H}_{19} \mathrm{FN}_{2} \mathrm{O}_{4}, 406.1323$; found, 406.1329.

9-Chloro-5-(4-methoxybenzoyl)-2,3,4,12a-tetrahydro$1 \mathrm{H}, 7 \mathrm{H}$-chromeno[3',2':5,6]pyrido-[1,2-a]pyrimidin-7-one (3ad). Isolated yield 92\%; yellow solid, mp $235-236{ }^{\circ} \mathrm{C}$; IR $(\mathrm{KBr})\left(\nu_{\max } \mathrm{cm}^{-1}\right): 3429,1654,1601,1503,1386,1340,1293$, 1256, 1229, 1132, 1071, 1020, 758, 701; ${ }^{1} \mathrm{H}$ NMR (500 MHz, DMSO- $\left.d_{6}+\mathrm{HClO}_{4}\right)(\delta, \mathrm{ppm}): 2.01-2.07\left(\mathrm{~m}, 2 \mathrm{H}, \mathrm{CH}_{2}\right)$, 3.50-3.55 (m, 2H, CH $\left.\mathrm{C}_{2} \mathrm{~N}\right), 3.67-3.73\left(\mathrm{~m}, 2 \mathrm{H}, \mathrm{NCH}_{2}\right), 3.88(\mathrm{~s}$, $\left.3 \mathrm{H}, \mathrm{OCH}_{3}\right), 6.34(\mathrm{~s}, 1 \mathrm{H}, \mathrm{CH}), 7.01(\mathrm{~d}, J=7.2 \mathrm{~Hz}, 2 \mathrm{H}, \mathrm{ArH})$, $7.08(\mathrm{~d}, J=8.1 \mathrm{~Hz}, 1 \mathrm{H}, \operatorname{Ar} H), 7.36(\mathrm{~d}, J=7.0 \mathrm{~Hz}, 2 \mathrm{H}, \operatorname{Ar} H)$, 7.47 (s, 1H, ArH), 7.55-7.57 (m, 1H, ArH), 7.65 (s, 1H, ArH), 11.59 (br, $1 \mathrm{H}, \mathrm{NH}) ;{ }^{13} \mathrm{C}$ NMR $\left(125 \mathrm{MHz}, \mathrm{DMSO}-d_{6}+\right.$ $\left.\mathrm{HClO}_{4}\right)(\delta, \mathrm{ppm}): 19.2,38.5,44.9,55.7,88.4,93.0,105.9$, $113.9,120.6,126.0,126.7,129.9,133.2,134.9,137.3,145.5$, 154.8, 155.5, 160.8, 177.7, 190.6; HRMS (ESI-TOF, $[\mathrm{M}]^{+}$): calcd for $\mathrm{C}_{23} \mathrm{H}_{19} \mathrm{ClN}_{2} \mathrm{O}_{4}, 422.1028$; found, 422.1030 .

9-Bromo-5-(4-methoxybenzoyl)-2,3,4,12a-tetrahydro$1 \mathrm{H}, 7 \mathrm{H}$-chromeno $\left[3^{\prime}, 2^{\prime}: 5,6\right]$ pyrido-[1,2-a]pyrimidin-7-one (3ae). Isolated yield 93\%; yellow solid, mp $232-234{ }^{\circ} \mathrm{C}$; IR $(\mathrm{KBr})\left(\nu_{\max } \mathrm{cm}^{-1}\right): 3428,1641,1595,1498,1419,1354,1251$, $1175,1132,604 ;{ }^{1} \mathrm{H}$ NMR $\left(500 \mathrm{MHz}, \mathrm{DMSO}-d_{6}+\mathrm{HClO}_{4}\right)(\delta$, ppm): $2.12-2.20\left(\mathrm{~m}, 2 \mathrm{H}, \mathrm{CH}_{2}\right), 3.49-3.54\left(\mathrm{~m}, 3 \mathrm{H}, \mathrm{NCH}_{2}\right.$ and $\left.\mathrm{CH}_{2} \mathrm{~N}\right), 3.84\left(\mathrm{~s}, 3 \mathrm{H}, \mathrm{OCH}_{3}\right), 3.90-3.94\left(\mathrm{~m}, 1 \mathrm{H}, \mathrm{NCH}_{2}\right), 6.12$ 
(s, $1 \mathrm{H}, \mathrm{CH}), 6.83(\mathrm{~d}, J=8.7 \mathrm{~Hz}, 1 \mathrm{H}, \operatorname{Ar} H), 6.91(\mathrm{~d}, J=8.6 \mathrm{~Hz}$, 2H, $\operatorname{ArH}), 7.41(\mathrm{~d}, J=8.6 \mathrm{~Hz}, 2 \mathrm{H}, \operatorname{ArH}), 7.49-7.51(\mathrm{~m}, 1 \mathrm{H}$, $\operatorname{ArH}$ ), 7.75 (s, $1 \mathrm{H}, \operatorname{ArH}$ ), 7.98-8.03 (m, 1H, ArH), 12.00 (br, $1 \mathrm{H}, \mathrm{NH}) ;{ }^{13} \mathrm{C}$ NMR $\left(125 \mathrm{MHz}, \mathrm{DMSO}-d_{6}+\mathrm{HClO}_{4}\right)(\delta$, ppm): 19.9, 38.8, 45.0, 55.8, 88.8, 93.7, 106.5, 114.0, 115.5, $120.1,126.2,130.4,130.4,133.1,137.8,138.6,155.1,156.3$, 161.5, 178.9, 192.2; HRMS (ESI-TOF, $[\mathrm{M}]^{+}$): calcd for $\mathrm{C}_{23} \mathrm{H}_{19} \mathrm{BrN}_{2} \mathrm{O}_{4}, 466.0523$; found, 466.0547.

9-Fluoro-5-(4-methylbenzoyl)-2,3,4,12a-tetrahydro$1 \mathrm{H}, 7 \mathrm{H}$-chromeno[3',2':5,6]pyrido-[1,2-a]pyrimidin-7-one (3bc). Isolated yield 86\%; yellow solid, mp $247-249{ }^{\circ} \mathrm{C}$; IR $(\mathrm{KBr})\left(\nu_{\max } \mathrm{cm}^{-1}\right): 3419,1650,1593,1499,1429,1352,1303$, 1256, 1188, 1119, 1061, 837, 759; ${ }^{1} \mathrm{H}$ NMR (500 MHz, DMSO- $\left.d_{6}+\mathrm{HClO}_{4}\right)(\delta, \mathrm{ppm}): 2.06-2.10\left(\mathrm{~m}, 2 \mathrm{H}, \mathrm{CH}_{2}\right), 2.26$ $\left(\mathrm{s}, 3 \mathrm{H}, \mathrm{ArCH}_{3}\right), 3.52-3.56\left(\mathrm{~m}, 2 \mathrm{H}, \mathrm{CH}_{2} \mathrm{~N}\right), 3.69-3.74(\mathrm{~m}, 2 \mathrm{H}$, $\left.\mathrm{NCH}_{2}\right), 6.32(\mathrm{~s}, 1 \mathrm{H}, \mathrm{CH}), 7.09-7.11(\mathrm{~m}, 1 \mathrm{H}, \mathrm{ArH}), 7.26-7.30$ (m, 4H, ArH), 7.39-7.42 (m, 3H, ArH), 11.59 (br, 1H, NH); ${ }^{13} \mathrm{C}$ NMR $\left(125 \mathrm{MHz}, \mathrm{DMSO}-d_{6}+\mathrm{HClO}_{4}\right)(\delta, \mathrm{ppm}): 19.2$, 21.3, 38.5, 44.8, 88.2, 93.0, 106.4, 112.0 (d, $J=23.8 \mathrm{~Hz}$ ), 120.4, $122.6(\mathrm{~d}, J=22.5 \mathrm{~Hz}), 125.2,128.0,129.1,137.0,138.1,139.7$, 146.7, 152.4, 155.5, 178.1, 191.1; HRMS (ESI-TOF, $[\mathrm{M}]^{+}$): calcd for $\mathrm{C}_{23} \mathrm{H}_{19} \mathrm{FN}_{2} \mathrm{O}_{3}, 390.1374$; found, 390.1388.

9-Chloro-5-(4-methylbenzoyl)-2,3,4,12a-tetrahydro$1 \mathrm{H}, 7 \mathrm{H}$-chromeno[3',2':5,6]pyrido-[1,2-a]pyrimidin-7-one (3bd). Isolated yield 90\%; yellow solid, mp 190-192 ${ }^{\circ} \mathrm{C}$; IR $(\mathrm{KBr})\left(\nu_{\max } \mathrm{cm}^{-1}\right): 3429,1583,1498,1415,1250,1167,1082$, 608; ${ }^{1} \mathrm{H}$ NMR (500 MHz, DMSO- $\left.d_{6}+\mathrm{HClO}_{4}\right)(\delta, \mathrm{ppm})$ : 2.05-2.13 (m, 2H, CH $\mathrm{CH}_{2}, 2.38\left(\mathrm{~s}, 3 \mathrm{H}, \mathrm{ArCH}_{3}\right), 3.55-3.72(\mathrm{~m}$, $4 \mathrm{H}, \mathrm{CH}_{2} \mathrm{~N}$ and $\left.\mathrm{NCH}_{2}\right), 6.31(\mathrm{~s}, 1 \mathrm{H}, \mathrm{CH}), 7.04(\mathrm{~d}, J=8.6 \mathrm{~Hz}$, 1H, $\mathrm{ArH}$ ), 7.23-7.28 (m, 4H, ArH), 7.42-7.51 (m, 2H, ArH), 7.64 (s, 1H, ArH), 12.07 (br, 1H, NH); ${ }^{13} \mathrm{C}$ NMR (125 MHz, DMSO- $\left.d_{6}+\mathrm{HClO}_{4}\right)(\delta, \mathrm{ppm}): 19.3,21.3,38.5,44.8,88.4$, 93.1, 106.2, 1120.3, 125.4, 126.1, 126.7, 128.0, 129.0, 134.8, 137.2, 138.0, 139.6, 154.7, 155.5, 177.8, 191.2; HRMS (ESITOF, $\left.[\mathrm{M}]^{+}\right)$: calcd for $\mathrm{C}_{23} \mathrm{H}_{19} \mathrm{ClN}_{2} \mathrm{O}_{3}, 406.1079$; found, 406.1078 .

9-Bromo-5-(4-methylbenzoyl)-2,3,4,12a-tetrahydro$1 \mathrm{H}, 7 \mathrm{H}$-chromeno $\left[3^{\prime}, 2^{\prime}: 5,6\right]$ pyrido-[1,2-a]pyrimidin-7-one (3be). Isolated yield 93\%; yellow solid, mp $244-246{ }^{\circ} \mathrm{C}$; IR $(\mathrm{KBr})\left(\nu_{\max } \mathrm{cm}^{-1}\right): 3426,1647,1588,1497,1255,1183,1138$, 1057, 756, 640; ${ }^{1} \mathrm{H}$ NMR (500 MHz, DMSO- $\left.d_{6}+\mathrm{CDCl}_{3}\right)(\delta$, ppm): 2.04-2.10 (m, 2H, $\left.\mathrm{CH}_{2}\right), 2.38$ (s, 3H, $\left.\mathrm{ArCH}_{3}\right), 3.52-$ $3.56\left(\mathrm{~m}, 2 \mathrm{H}, \mathrm{CH}_{2} \mathrm{~N}\right), 3.69-3.73\left(\mathrm{~m}, 2 \mathrm{H}, \mathrm{NCH}_{2}\right), 6.35(\mathrm{~s}, 1 \mathrm{H}$, $\mathrm{CH}$ ), 7.04 (d, $J=8.6 \mathrm{~Hz}, 1 \mathrm{H}, \mathrm{ArH}), 7.26-7.29$ (m, 4H, ArH), 7.40 (s, 1H, ArH), 7.69 (d, $J=8.5 \mathrm{~Hz}, 1 \mathrm{H}, \operatorname{ArH}), 7.77(\mathrm{~s}, 1 \mathrm{H}$, $\mathrm{ArH}), 11.58$ (br, $1 \mathrm{H}, \mathrm{NH}) ;{ }^{13} \mathrm{C}$ NMR (125 MHz, DMSO- $d_{6}+$ $\left.\mathrm{CDCl}_{3}\right)(\delta, \mathrm{ppm}): 19.2,21.3,38.2,44.9,88.4,93.1,106.1$, $114.3,121.0,125.9,128.0,129.1,137.2,137.8,138.1,139.7$, 155.2, 155.4, 177.7, 191.2; HRMS (ESI-TOF, $[\mathrm{M}]^{+}$): calcd for $\mathrm{C}_{23} \mathrm{H}_{19} \mathrm{BrN}_{2} \mathrm{O}_{3}, 450.0574$; found, 450.0576 .

5-Benzoyl-9-methyl-2,3,4, 12 a-tetrahydro- $1 \mathrm{H}, 7 \mathrm{H}$ chromeno[3',2':5,6]pyrido[1,2-a]pyrimi-din-7-one (3ca). Isolated yield 93\%; yellow solid, mp $209-211{ }^{\circ} \mathrm{C}$; IR (KBr) $\left(\nu_{\max }\right.$, $\left.\mathrm{cm}^{-1}\right): 3426,1653,1580,1500,1426,1340,1268,1224,1161$, 1068, 626; ${ }^{1} \mathrm{H}$ NMR $\left(500 \mathrm{MHz}, \mathrm{CDCl}_{3}\right)(\delta, \mathrm{ppm}): 2.03-2.14$ $\left(\mathrm{m}, 1 \mathrm{H}, \mathrm{CH}_{2}\right), 2.29$ (s, 3H, $\left.\mathrm{ArCH}_{3}\right), 3.38-3.50\left(\mathrm{~m}, 3 \mathrm{H}, \mathrm{NCH}_{2}\right.$ and $\left.\mathrm{CH}_{2} \mathrm{~N}\right), 3.89-3.95\left(\mathrm{~m}, 1 \mathrm{H}, \mathrm{NCH}_{2}\right), 6.06(\mathrm{~s}, 1 \mathrm{H}, \mathrm{CH})$, 6.81-6.85 (m, 1H, ArH), 7.22-7.26 (m, 1H, ArH), 7.38-7.41 (m, 5H, ArH), 7.63 (s, 1H, $\operatorname{ArH}$ ), 7.68 (s, 1H, ArH), 11.99 (br, $1 \mathrm{H}, \mathrm{NH}) ;{ }^{13} \mathrm{C}$ NMR $\left(125 \mathrm{MHz}, \mathrm{CDCl}_{3}\right)(\delta, \mathrm{ppm}): 19.9,21.0$, $38.7,44.8,88.3,93.4,108.3,117.8,124.3,127.6,128.3,128.6$, $130.1,132.3,136.3,137.3,140.9,154.4,156.3,180.6,192.3$;
HRMS (ESI-TOF, $[\mathrm{M}]^{+}$): calcd for $\mathrm{C}_{23} \mathrm{H}_{20} \mathrm{~N}_{2} \mathrm{O}_{3}, 372.1468$; found, 372.1479 .

5-Benzoyl-2,3,4, 12a-tetrahydro-1 H,7H-chromeno$\left[3^{\prime}, 2^{\prime}: 5,6\right]$ pyrido[1,2-a]pyrimidin-7-one (3cb). Isolated yield 89\%; yellow solid, mp $212-215{ }^{\circ} \mathrm{C}$; IR $(\mathrm{KBr})\left(\nu_{\max } \mathrm{cm}^{-1}\right)$ : $3429,1654,1601,1503,1340,1293,1256,1132,1071,1020$, 758; ${ }^{1} \mathrm{H} \mathrm{NMR}\left(500 \mathrm{MHz}, \mathrm{CDCl}_{3}\right)(\delta, \mathrm{ppm}): 2.03-2.16(\mathrm{~m}$, $\left.2 \mathrm{H}, \mathrm{CH}_{2}\right), 3.41-3.53\left(\mathrm{~m}, 3 \mathrm{H}, \mathrm{NCH}_{2}\right.$ and $\left.\mathrm{CH}_{2} \mathrm{~N}\right), 3.94-3.97$ $\left(\mathrm{m}, \mathrm{H}, \mathrm{NCH}_{2}\right), 6.12(\mathrm{~s}, 1 \mathrm{H}, \mathrm{CH}), 6.93(\mathrm{~d}, J=8.2 \mathrm{~Hz}, 1 \mathrm{H}$, $\operatorname{ArH}), 7.03-7.08(\mathrm{~m}, 1 \mathrm{H}, \mathrm{ArH}), 7.39-7.48$ (m, 6H, ArH), 7.65 (s, $1 \mathrm{H}, \operatorname{ArH}), 7.90$ (d, J = $7.8 \mathrm{~Hz}, 1 \mathrm{H}, \operatorname{ArH}), 11.99$ (br, $1 \mathrm{H}$, $\mathrm{NH}) ;{ }^{13} \mathrm{C}$ NMR $\left(125 \mathrm{MHz}, \mathrm{CDCl}_{3}\right)(\delta, \mathrm{ppm}): 19.9,38.8,44.9$, 88.4, 93.4, 108.1, 118.1, 122.8, 124.6, 127.8, 128.3, 128.7, 130.1, 135.4, 137.4, 140.8, 156.3, 156.4, 180.4, 192.4; HRMS (ESITOF, $\left.[\mathrm{M}]^{+}\right)$: calcd for $\mathrm{C}_{22} \mathrm{H}_{18} \mathrm{~N}_{2} \mathrm{O}_{3}, 358.1312$; found, 358.1320 .

5-Benzoyl-9-fluoro-2,3,4,12a-tetrahydro- $1 \mathrm{H}, 7 \mathrm{H}$ chromeno[3',2':5,6]pyrido[1,2-a]pyrimi-din-7-one (3cc). Isolated yield $85 \%$; yellow solid, mp $220-224{ }^{\circ} \mathrm{C}$; IR $(\mathrm{KBr})\left(\nu_{\max }\right.$ $\left.\mathrm{cm}^{-1}\right)$ : 3440, 1652, 1588, 1501, 1433, 1352, 1311, 1255, 1192, $1119,1061,1021,751,620 ;{ }^{1} \mathrm{H}$ NMR (500 MHz, DMSO-d $)$ $(\delta, \mathrm{ppm}): 2.00-2.08\left(\mathrm{~m}, 2 \mathrm{H}, \mathrm{CH}_{2}\right), 3.50-3.85\left(\mathrm{~m}, 4 \mathrm{H}, \mathrm{NCH}_{2}\right.$ and $\left.\mathrm{CH}_{2} \mathrm{~N}\right), 6.31(\mathrm{~s}, 1 \mathrm{H}, \mathrm{CH}), 7.08-7.11(\mathrm{~m}, 1 \mathrm{H}, \mathrm{ArH}), 7.36-$ 7.44 (m, 5H, ArH), 7.46-7.51 (m, 3H, ArH), 11.57 (br, 1H, $\mathrm{NH}) ;{ }^{13} \mathrm{C}$ NMR (125 MHz, DMSO- $\left.d_{6}\right)(\delta, \mathrm{ppm}): 19.2,38.5$, 44.8, 88.1, 93.0, 107.0, 106.6, 111.9 (d, $J=23.8 \mathrm{~Hz}$ ), 120.4, $122.6(\mathrm{~d}, J=23.8 \mathrm{~Hz}), 125.1,127.8,128.6,129.9,136.9,140.9$, 152.5 , 155.4, 156.6, 158.5, 178.1, 191.5; HRMS (ESI-TOF, $[\mathrm{M}]^{+}$): calcd for $\mathrm{C}_{22} \mathrm{H}_{17} \mathrm{FN}_{2} \mathrm{O}_{3}, 376.1218$; found, 376.1225.

5-Benzoyl-9-chloro-2, 3, 4, 12 a-tetrahydro- $1 \mathrm{H}, 7 \mathrm{H}$ chromeno[3',2':5,6]pyrido[1,2-a]pyrimi-din-7-one (3cd). Isolated yield $87 \%$; orange solid, $\mathrm{mp} 203-206{ }^{\circ} \mathrm{C}$; IR $(\mathrm{KBr})\left(\nu_{\max }\right.$, $\left.\mathrm{cm}^{-1}\right)$ : 3427, 1652, 1598, 1498, 1429, 1352, 1254, 1184, 1137, 1076, 625; ${ }^{1} \mathrm{H} \mathrm{NMR}\left(500 \mathrm{MHz}, \mathrm{CDCl}_{3}\right)(\delta, \mathrm{ppm}): 2.12-2.26$ $\left(\mathrm{m}, 2 \mathrm{H}, \mathrm{CH}_{2}\right), 3.51-3.62\left(\mathrm{~m}, 2 \mathrm{H}, \mathrm{NCH}_{2}\right.$ and $\left.\mathrm{CH}_{2} \mathrm{~N}\right), 3.98-$ $4.02\left(\mathrm{~m}, 1 \mathrm{H}, \mathrm{NCH}_{2}\right), 6.18(\mathrm{~s}, 1 \mathrm{H}, \mathrm{CH}), 6.96(\mathrm{~d}, J=8.7 \mathrm{~Hz}, 1 \mathrm{H}$, $\operatorname{ArH}), 7.35-7.51$ (m, 5H, ArH), 7.74 (s, 1H, ArH), 7.91-7.94 $(\mathrm{m}, 1 \mathrm{H}, \mathrm{ArH}), 12.07$ (br, $1 \mathrm{H}, \mathrm{NH}) ;{ }^{13} \mathrm{C}$ NMR $(125 \mathrm{MHz}$, $\left.\mathrm{CDCl}_{3}\right)(\delta, \mathrm{ppm}): 19.4,38.3,44.4,88.2,93.2,106.6,119.3$, $125.1,126.7,127.7,127.8,128.2,129.8,134.5,137.7,140.2$, 154.2, 155.8, 178.5, 192.2; HRMS (ESI-TOF, $[\mathrm{M}]^{+}$): calcd for $\mathrm{C}_{22} \mathrm{H}_{17} \mathrm{ClN}_{2} \mathrm{O}_{3}, 392.0922$; found, 392.0909 .

5-Benzoyl-9-bromo-2,3,4,12a-tetrahydro- $1 \mathrm{H}, 7 \mathrm{H}$ chromeno[3',2':5,6]pyrido[1,2-a]pyrimi-din-7-one (3ce). Isolated yield 90\%; orange solid, $\mathrm{mp} 207-209{ }^{\circ} \mathrm{C}$; IR $(\mathrm{KBr})\left(\nu_{\max }\right.$ $\left.\mathrm{cm}^{-1}\right): 3431,1652,1594,1501,1425,1345,1253,1184,1133$, 1070, 620; ${ }^{1} \mathrm{H}$ NMR (500 MHz, DMSO- $\left.d_{6}+\mathrm{CDCl}_{3}\right)(\delta$, ppm): $2.13-2.19\left(\mathrm{~m}, 2 \mathrm{H}, \mathrm{CH}_{2}\right), 3.51-3.57\left(\mathrm{~m}, 3 \mathrm{H}, \mathrm{NCH}_{2}\right.$ and $\left.\mathrm{CH}_{2} \mathrm{~N}\right), 3.95-3.96\left(\mathrm{~m}, 1 \mathrm{H}, \mathrm{NCH}_{2}\right), 6.14(\mathrm{~s}, 1 \mathrm{H}, \mathrm{CH}), 6.85(\mathrm{~d}$, $J=8.6 \mathrm{~Hz}, 1 \mathrm{H}, \operatorname{Ar} H), 7.39-7.43(\mathrm{~m}, 5 \mathrm{H}, \operatorname{ArH}), 7.50-7.53(\mathrm{~m}$, $1 \mathrm{H}, \operatorname{ArH}), 7.63$ (s, 1H, ArH), 7.95 (s, 1H, ArH), 11.95 (br, 1H, $\mathrm{NH}) ;{ }^{13} \mathrm{C}$ NMR $\left(125 \mathrm{MHz}, \mathrm{DMSO}-d_{6}+\mathrm{CDCl}_{3}\right)(\delta, \mathrm{ppm})$ : $19.7,38.7,44.9,88.5,93.6,106.8,115.2,120.2,125.9,128.2$, 128.2 , 128.6, 130.1, 137.7, 138.1, 140.6, 155.1, 156.1, 178.8, 192.4; HRMS (ESI-TOF, $[\mathrm{M}]^{+}$): calcd for $\mathrm{C}_{22} \mathrm{H}_{17} \mathrm{BrN}_{2} \mathrm{O}_{3}$, 436.0417; found, 436.0415 .

9-Fluoro-5-(4-fluorobenzoyl)-2,3,4,12a-tetrahydro-1H,7Hchromeno[3',2':5,6]pyrido[1,2-a]pyrimidin-7-one (3dc). Isolated yield $85 \%$; yellow solid, mp $236-239{ }^{\circ} \mathrm{C}$; IR ( $\left.\mathrm{KBr}\right)\left(\nu_{\max }\right.$ $\left.\mathrm{cm}^{-1}\right): 3423,1652,1600,1498,1436,1352,1311,1256,1155$, $1119,845,600 ;{ }^{1} \mathrm{H}$ NMR $\left(500 \mathrm{MHz}, \mathrm{DMSO}-d_{6}+\mathrm{HClO}_{4}\right)(\delta$, ppm): 2.00-2.08 (m, 2H, $\left.\mathrm{CH}_{2}\right), 3.52-3.60\left(\mathrm{~m}, 3 \mathrm{H}, \mathrm{NCH}_{2}\right.$ and $\left.\mathrm{CH}_{2} \mathrm{~N}\right), 3.79-3.83\left(\mathrm{~m}, 1 \mathrm{H}, \mathrm{NCH}_{2}\right), 6.31(\mathrm{~s}, 1 \mathrm{H}, \mathrm{CH}), 7.08-$ 
7.10 (m, 1H, ArH), 7.28-7.33 (m, 4H, ArH), 7.39-7.46 (m, $4 \mathrm{H}, \mathrm{ArH}), 11.52$ (br, $1 \mathrm{H}, \mathrm{NH}) ;{ }^{13} \mathrm{C}$ NMR (125 MHz, DMSO$\left.d_{6}+\mathrm{HClO}_{4}\right)(\delta, \mathrm{ppm}): 19.1,38.5,44.8,88.1,92.9,106.8,112.0$ $(\mathrm{d}, J=22.5 \mathrm{~Hz}), 115.5(\mathrm{~d}, J=21.3 \mathrm{~Hz}), 120.4,122.7$ (d, $J=$ $23.8 \mathrm{~Hz}$ ), 125.1, 130.4, 136.6, 137.3, 152.2, 155.3, 157.6 (d, $J=$ $240.0 \mathrm{~Hz}$ ), 163.0 (d, $J=247.5 \mathrm{~Hz}$ ), 178.2, 189.7; HRMS (ESITOF, $[\mathrm{M}]^{+}$): calcd for $\mathrm{C}_{22} \mathrm{H}_{16} \mathrm{~F}_{2} \mathrm{~N}_{2} \mathrm{O}_{3}, 394.1124$; found, 394.1122 .

9-Chloro-5-(4-fluorobenzoyl)-2,3,4,12a-tetrahydro- $1 \mathrm{H}, 7 \mathrm{H}$ chromeno[3', 2':5,6]pyrido[1,2-a]pyrimidin-7-one (3dd). Isolated yield $86 \%$; yellow solid, mp 224-226.5 ${ }^{\circ} \mathrm{C}$; IR ( $\mathrm{KBr}$ ) $\left(\nu_{\max } \mathrm{cm}^{-1}\right): 3428,1649,1600,1497,1426,1348,1255,1136$, 597; ${ }^{1} \mathrm{H}$ NMR (500 MHz, $\left.\mathrm{CDCl}_{3}\right)(\delta, \mathrm{ppm}): 2.04-2.21(\mathrm{~m}$, $\left.1 \mathrm{H}, \mathrm{CH}_{2}\right), 3.46-3.58\left(\mathrm{~m}, 3 \mathrm{H}, \mathrm{NCH}_{2}\right.$ and $\left.\mathrm{CH}_{2} \mathrm{~N}\right), 3.94-3.98$ $\left(\mathrm{m}, 1 \mathrm{H}, \mathrm{NCH}_{2}\right), 6.12(\mathrm{~s}, 1 \mathrm{H}, \mathrm{CH}), 6.89-6.91(\mathrm{~m}, 1 \mathrm{H}, \mathrm{ArH})$, 7.06-7.12 (m, 2H, ArH), 7.35-7.39 (s, 1H, ArH), 7.41-7.44 (m, 2H, ArH), 7.63 (s, 1H, ArH), 7.84-7.88 (m, 1H, ArH), 11.94 (br, $1 \mathrm{H}, \mathrm{NH}) ;{ }^{13} \mathrm{C}$ NMR $\left(125 \mathrm{MHz}, \mathrm{CDCl}_{3}\right)(\delta$, ppm): 19.9, 38.2, 45.0, 88.6, 93.6, 107.2, 115.7 (d, $J=21.3 \mathrm{~Hz}$ ), 119.7, $125.6,127.3,128.3,130.6,135.1,136.8,137.9,154.7,156.3$, $164.0(\mathrm{~d}, J=248.8 \mathrm{~Hz}), 179.1,191.3$; HRMS (ESI-TOF, $[\mathrm{M}]^{+}$): calcd for $\mathrm{C}_{22} \mathrm{H}_{16} \mathrm{ClFN}_{2} \mathrm{O}_{3}, 410.0828$; found, 410.0827 .

9-Bromo-5-(4-fluorobenzoyl)-2,3,4,12a-tetrahydro- $1 \mathrm{H}, 7 \mathrm{H}$ chromeno[3', 2':5,6]pyrido[1,2-a]pyrimidin-7-one (3de). Isolated yield $86 \%$; yellow solid, mp $220-222{ }^{\circ} \mathrm{C}$; IR ( $\left.\mathrm{KBr}\right)\left(\nu_{\max }\right.$ $\left.\mathrm{cm}^{-1}\right)$ : 3427, 1647, 1584, 1498, 1419, 1351, 1255, 1135, 646; ${ }^{1} \mathrm{H}$ NMR (500 MHz, $\left.\mathrm{CDCl}_{3}\right)(\delta, \mathrm{ppm}): 2.05-2.23(\mathrm{~m}, 2 \mathrm{H}$, $\left.\mathrm{CH}_{2}\right), 3.51-3.59\left(\mathrm{~m}, 3 \mathrm{H}, \mathrm{NCH}_{2}\right.$ and $\left.\mathrm{CH}_{2} \mathrm{~N}\right), 3.95-3.99(\mathrm{~m}$, $\left.1 \mathrm{H}, \mathrm{NCH}_{2}\right), 6.13(\mathrm{~s}, 1 \mathrm{H}, \mathrm{CH}), 6.84(\mathrm{~d}, J=8.7 \mathrm{~Hz}, 1 \mathrm{H}, \mathrm{ArH})$, 7.08-7.13 (m, 2H, ArH), 7.42-7.46 (m, 2H, ArH), 7.51-7.54 (m, 1H, ArH), 7.64 (s, 1H, ArH), 8.01 (s, 1H, ArH), 11.96 (br, $1 \mathrm{H}, \mathrm{NH}) ;{ }^{13} \mathrm{C}$ NMR $\left(125 \mathrm{MHz}, \mathrm{CDCl}_{3}\right)(\delta, \mathrm{ppm}): 19.9,38.8$, 45.0, 88.6, 93.6, 107.2, $115.8(\mathrm{~d}, J=21.3 \mathrm{~Hz}), 116.1,120.1$, $126.0,130.4,130.5,130.6,136.8,137.9,155.2,156.3,164.0$ (d, $J$ $=248.8 \mathrm{~Hz}), 179.0,191.3$; HRMS $\left(\right.$ ESI-TOF, $\left.[\mathrm{M}]^{+}\right)$: calcd for $\mathrm{C}_{22} \mathrm{H}_{16} \mathrm{BrFN}_{2} \mathrm{O}_{3}, 454.0323$; found, 454.0328 .

5-(4-Chlorobenzoyl)-9-fluoro-2,3,4,12a-tetrahydro- $1 \mathrm{H}, 7 \mathrm{H}$ chromeno[3',2':5,6]pyrido[1,2-a]pyrimidin-7-one (3ec). Isolated yield $84 \%$; yellow solid, mp $251-254{ }^{\circ} \mathrm{C}$; IR $(\mathrm{KBr})\left(\nu_{\max }\right.$ $\left.\mathrm{cm}^{-1}\right)$ : 3423, 1650, 1589, 1500, 1435, 1356, 1307, 1256, 1188, 1123, 1090, 841, 767; ${ }^{1} \mathrm{H}$ NMR (500 MHz, DMSO-d $d_{6}+$ $\left.\mathrm{HClO}_{4}\right)(\delta, \mathrm{ppm}): 2.07-2.11\left(\mathrm{~m}, 2 \mathrm{H}, \mathrm{CH}_{2}\right), 3.38-3.56(\mathrm{~m}$, $4 \mathrm{H}, \mathrm{NCH}_{2}$ and $\left.\mathrm{CH}_{2} \mathrm{~N}\right), 6.32(\mathrm{~s}, 1 \mathrm{H}, \mathrm{CH}), 7.10-7.13(\mathrm{~m}, 1 \mathrm{H}$, $\mathrm{ArH}$ ), 7.30 (s, 1H, $\mathrm{ArH}$ ), 7.39-7.44 (m, 4H, ArH), 7.52-7.55 (m, 2H, ArH), 11.49 (br, 1H, NH); ${ }^{13} \mathrm{C}$ NMR (125 MHz, DMSO- $\left.d_{6}+\mathrm{HClO}_{4}\right)(\delta, \mathrm{ppm}): 19.2,38.5,44.8,88.1,92.9$, $107.0,112.1,120.4,122.8,125.0,128.7,129.8,134.6,136.4$, 139.6, 151.5, 152.5, 155.4, 178.0, 189.5; HRMS (ESI-TOF, $[\mathrm{M}]^{+}$): calcd for $\mathrm{C}_{22} \mathrm{H}_{16} \mathrm{ClFN}_{2} \mathrm{O}_{3}, 410.0828$; found, 410.0848 .

9-Chloro-5-(4-chlorobenzoyl)-2,3,4,12a-tetrahydro-1H,7Hchromeno[3',2':5,6]pyrido[1,2-a]pyrimidin-7-one (3ed). Isolated yield $85 \%$; yellow solid, $\mathrm{mp} 237-240{ }^{\circ} \mathrm{C}$; IR $(\mathrm{KBr})\left(\nu_{\max }\right.$ $\left.\mathrm{cm}^{-1}\right)$ : 3427, 1648, 1588, 1497, 1423, 1353, 1254, 1182, 1136, 1091,$632 ;{ }^{1} \mathrm{H}$ NMR $\left(500 \mathrm{MHz}, \mathrm{DMSO}-d_{6}\right)(\delta$, ppm): 2.02$2.06\left(\mathrm{~m}, 2 \mathrm{H}, \mathrm{CH}_{2}\right), 3.50-3.54\left(\mathrm{~m}, 2 \mathrm{H}, \mathrm{CH}_{2} \mathrm{~N}\right), 3.67-3.71(\mathrm{~m}$, $\left.2 \mathrm{H}, \mathrm{NCH}_{2}\right), 6.32(\mathrm{~s}, 1 \mathrm{H}, \mathrm{CH}), 7.08(\mathrm{~d}, J=8.5 \mathrm{~Hz}, 1 \mathrm{H}, \operatorname{Ar} H)$, 7.26-7.30 (m, 1H, ArH), 7.39 (d, J = 7.5 Hz, 2H, ArH), 7.517.58 (m, 3H, ArH), 7.63 (s, 1H, ArH), 11.47 (br, $1 \mathrm{H}, \mathrm{NH}) ;{ }^{13} \mathrm{C}$ NMR (125 MHz, DMSO- $\left.d_{6}\right)(\delta, \mathrm{ppm}): 19.1,38.6,44.9,88.2$, 93.0, 106.8, 120.7, 125.3, 126.0, 126.7, 128.7, 129.8, 134.7, $135.1,136.6,139.6,154.9,155.3,177.9,189.6$; HRMS (ESITOF, $[\mathrm{M}]^{+}$): calcd for $\mathrm{C}_{22} \mathrm{H}_{16} \mathrm{Cl}_{2} \mathrm{~N}_{2} \mathrm{O}_{3}, 426.0532$; found, 426.0540
9-Bromo-5-(4-chlorobenzoyl)-2,3,4,12a-tetrahydro-1H,7Hchromeno $\left[3^{\prime}, 2^{\prime}: 5,6\right]$ pyrido[1,2-a]pyrimidin-7-one (3ee). Isolated yield $88 \%$; yellow solid, $\mathrm{mp} 236-239{ }^{\circ} \mathrm{C}$; IR $(\mathrm{KBr})\left(\nu_{\max }\right.$ $\left.\mathrm{cm}^{-1}\right): 3427,2499,1416,1249,1085,754,634 ;{ }^{1} \mathrm{H}$ NMR (500 $\left.\mathrm{MHz}, \mathrm{DMSO}-d_{6}+\mathrm{CDCl}_{3}+\mathrm{HClO}_{4}\right)(\delta, \mathrm{ppm}): 2.03-2.10(\mathrm{~m}$, $\left.2 \mathrm{H}, \mathrm{CH}_{2}\right), 3.52-3.56\left(\mathrm{~m}, 2 \mathrm{H}, \mathrm{CH}_{2} \mathrm{~N}\right), 3.69-3.73(\mathrm{~m}, 2 \mathrm{H}$, $\mathrm{NCH}_{2}$ ), 6.33 (s, 1H, CH), 7.03 (d, $\left.J=8.5 \mathrm{~Hz}, 1 \mathrm{H}, \mathrm{ArH}\right), 7.31$ (s, $1 \mathrm{H}, \operatorname{ArH}), 7.40$ (d, J=7.5 Hz, 2H, $\operatorname{ArH}), 7.53$ (d, $J=7.5 \mathrm{~Hz}$, $2 \mathrm{H}, \operatorname{Ar} H), 7.68(\mathrm{~d}, J=8.2 \mathrm{~Hz}, 1 \mathrm{H}, \operatorname{Ar} H), 7.78$ (s, $1 \mathrm{H}, \operatorname{Ar} H)$, 11.49 (br, $1 \mathrm{H}, \mathrm{NH}) ;{ }^{13} \mathrm{C}$ NMR $\left(125 \mathrm{MHz}\right.$, DMSO-d $d_{6}+\mathrm{CDCl}_{3}$ $\left.+\mathrm{HClO}_{4}\right)(\delta, \mathrm{ppm}): 19.2$, 38.6, 44.9, 88.2, 93.0, 106.7, 114.4, $121.0,125.8,128.7,129.1,129.8,134.7,136.5,137.9,139.6$, 155.3, 177.8, 189.6; HRMS (ESI-TOF, $[\mathrm{M}]^{+}$): calcd for $\mathrm{C}_{22} \mathrm{H}_{16} \mathrm{BrClN}_{2} \mathrm{O}_{3}$, 470.0027; found, 470.0031.

6-(4-Methoxybenzoyl)-10-methyl-1,2,3,4,5,13a-hexahydro-8H-chromeno $\left[3^{\prime}, 2^{\prime}: 5,6\right]$ pyrido-[1,2-a][1,3]diazepin-8one (3fa). Isolated yield $96 \%$; yellow solid, $\mathrm{mp} 202-204{ }^{\circ} \mathrm{C}$; IR $(\mathrm{KBr})\left(\nu_{\max }, \mathrm{cm}^{-1}\right): 3429,2927,1657,1570,1498,1425,1347$,

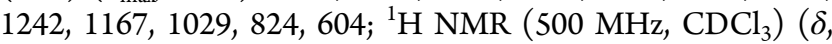
ppm): $2.00-2.06\left(\mathrm{~m}, 3 \mathrm{H}, \mathrm{CH}_{2}\right), 2.15-2.25\left(\mathrm{~m}, 1 \mathrm{H}, \mathrm{CH}_{2}\right), 2.31$ $\left(\mathrm{s}, 3 \mathrm{H}, \mathrm{ArCH}_{3}\right), 3.59-3.62\left(\mathrm{~m}, 2 \mathrm{H}, \mathrm{CH}_{2} \mathrm{~N}\right), 3.72-3.75(\mathrm{~m}, 1 \mathrm{H}$, $\left.\mathrm{NCH}_{2}\right), 3.83\left(\mathrm{~s}, 3 \mathrm{H}, \mathrm{OCH}_{3}\right), 4.10-4.15\left(\mathrm{~m}, 1 \mathrm{H}, \mathrm{NCH}_{2}\right), 6.13$ (s, 1H, CH), 6.83-6.85 (m, 1H, ArH), 6.89-6.91 (m, 2H, $\operatorname{ArH}), 7.24-7.28(\mathrm{~m}, 1 \mathrm{H}, \mathrm{ArH}), 7.41(\mathrm{~d}, J=8.3 \mathrm{~Hz}, 2 \mathrm{H}, \operatorname{ArH})$, 7.69 (s, 1H, ArH), 7.69 (s, 1H, ArH), 12.03 (br, 1H, NH); ${ }^{13} \mathrm{C}$ $\operatorname{NMR}\left(125 \mathrm{MHz}, \mathrm{CDCl}_{3}\right)(\delta, \mathrm{ppm}): 21.0,25.8,26.7,44.4,54.0$, 55.8, 91.3, 95.8, 109.2, 114.0, 118.0, 124.3, 127.6, 130.4, 132.1, 133.4, 136.3, 137.2, 154.5, 161.4, 162.8, 180.3, 192.0; HRMS (ESI-TOF, $[\mathrm{M}]^{+}$): calcd for $\mathrm{C}_{25} \mathrm{H}_{24} \mathrm{~N}_{2} \mathrm{O}_{4}, 416.1731$; found, 416.1740 .

6-(4-Methoxybenzoyl)-1,2,3,4,5, 13a-hexahydro-8Hchromeno[3',2':5,6]pyrido[1,2-a][1,3]-diazepin-8-one (3fb). Isolated yield 93\%; orange solid, mp 197-199 ${ }^{\circ} \mathrm{C}$; IR (KBr) $\left(\nu_{\max } \mathrm{cm}^{-1}\right): 3429,2932,1655,1571,1497,1333,1286,1237$, $1171,1117,1027,834 ;{ }^{1} \mathrm{H}$ NMR (500 MHz, DMSO- $d_{6}+$ $\left.\mathrm{CDCl}_{3}\right)(\delta, \mathrm{ppm}): 1.98-2.09\left(\mathrm{~m}, 4 \mathrm{H}, \mathrm{CH}_{2} \mathrm{CH}_{2}\right), 3.67-3.75$ $\left(\mathrm{m}, 3 \mathrm{H}, \mathrm{NCH}_{2}\right.$ and $\left.\mathrm{CH}_{2} \mathrm{~N}\right), 3.82\left(\mathrm{~s}, 3 \mathrm{H}, \mathrm{OCH}_{3}\right), 4.18-4.22$ $\left(\mathrm{m}, 1 \mathrm{H}, \mathrm{NCH}_{2}\right), 6.35(\mathrm{~s}, 1 \mathrm{H}, \mathrm{CH}), 6.98-7.01(\mathrm{~m}, 3 \mathrm{H}, \mathrm{ArH})$, 7.05-7.08 (m, $1 \mathrm{H}, \operatorname{ArH}), 7.35$ (d, $J=8.2 \mathrm{~Hz}, 2 \mathrm{H}, \operatorname{ArH}), 7.41$ (s, 1H, CH), 7.50-7.53 (m, 1H, ArH), $7.73(\mathrm{~d}, J=8.2 \mathrm{~Hz}, 1 \mathrm{H}$, $\mathrm{ArH}), 11.86(\mathrm{~s}, 1 \mathrm{H}, \mathrm{NH}) ;{ }^{13} \mathrm{C}$ NMR (125 MHz, DMSO-d ${ }_{6}+$ $\left.\mathrm{CDCl}_{3}\right): \delta=25.4,26.0,43.7,53.2,55.6,90.6,94.8,108.4,113.7$, $118.4,122.2,124.2,127.0,129.9,133.2,135.4,135.9,156.3$, 160.8, 161.7, 178.9, 190.4; HRMS (ESI-TOF, $[\mathrm{M}]^{+}$): calcd for $\mathrm{C}_{24} \mathrm{H}_{22} \mathrm{~N}_{2} \mathrm{O}_{4}, 402.1574$; found, 402.1582 .

10-Fluoro-6-(4-methoxybenzoyl)-1,2,3,4,5,13a-hexahydro-8H-chromeno[3',2':5,6]pyrido-[1,2-a][1,3]diazepin-8one (3fc). Isolated yield 90\%; yellow solid, $\mathrm{mp} \mathrm{208-210}{ }^{\circ} \mathrm{C}$; IR $(\mathrm{KBr})\left(\nu_{\max } \mathrm{cm}^{-1}\right): 3419,1648,1570,1488,1429,1343,1311$, $1253,1175,1111,1025,833 ;{ }^{1} \mathrm{H}$ NMR $(500 \mathrm{MHz}$, DMSO-d 6 + $\left.\mathrm{HClO}_{4}\right)(\delta, \mathrm{ppm}): 1.98-2.08\left(\mathrm{~m}, 4 \mathrm{H}, \mathrm{CH}_{2} \mathrm{CH}_{2}\right), 3.69-3.81$ $\left(\mathrm{m}, 3 \mathrm{H}, \mathrm{NCH}_{2}\right.$ and $\left.\mathrm{CH}_{2} \mathrm{~N}\right), 3.82\left(\mathrm{~s}, 3 \mathrm{H}, \mathrm{OCH}_{3}\right), 4.10-4.20$ $\left(\mathrm{m}, 1 \mathrm{H}, \mathrm{NCH}_{2}\right), 6.38(\mathrm{~s}, 1 \mathrm{H}, \mathrm{CH}), 7.01(\mathrm{~d}, J=8.1 \mathrm{~Hz}, 2 \mathrm{H}$, $\operatorname{ArH}), 7.09$ (d, $J=5.7 \mathrm{~Hz}, 1 \mathrm{H}, \operatorname{ArH}), 7.34-7.42$ (m, 5H, $\operatorname{ArH}$ ), $11.80(\mathrm{br}, 1 \mathrm{H}, \mathrm{NH}) ;{ }^{13} \mathrm{C}$ NMR $(125 \mathrm{MHz}$, DMSO-d $6+$ $\left.\mathrm{HClO}_{4}\right)(\delta, \mathrm{ppm}): 25.3,25.9,43.7,53.1,55.6,90.7,95.1,107.6$, $112.0,112.8,113.9,120.6,122.6,125.1,130.0,133.1,136.6$, 152.6, $157.4(\mathrm{~d}, J=237.5 \mathrm{~Hz}), 160.8,161.5,177.9,190.6$; HRMS (ESI-TOF, $[\mathrm{M}]^{+}$): calcd for $\mathrm{C}_{24} \mathrm{H}_{21} \mathrm{FN}_{2} \mathrm{O}_{4}, 420.1480$; found, 420.1483.

10-Chloro-6-(4-methoxybenzoyl)-1,2,3,4,5,13a-hexahydro-8H-chromeno[3',2':5,6]pyrido-[1,2-a][1,3]diazepin-8one (3fd). Isolated yield $91 \%$; yellow solid, mp $189-191{ }^{\circ} \mathrm{C}$; IR 
$(\mathrm{KBr})\left(\nu_{\max }, \mathrm{cm}^{-1}\right): 3429,1649,1571,1495,1423,1341,1253$, $1174,1128,1029,832 ;{ }^{1} \mathrm{H}$ NMR (500 $\left.\mathrm{MHz}, \mathrm{CDCl}_{3}\right)(\delta$, ppm): 2.03-2.20 (m, 4H, $\left.\mathrm{CH}_{2} \mathrm{CH}_{2}\right), 3.61-3.72\left(\mathrm{~m}, 3 \mathrm{H}, \mathrm{NCH}_{2}\right.$ and $\left.\mathrm{CH}_{2} \mathrm{~N}\right), 3.83\left(\mathrm{~s}, 2 \mathrm{H}, \mathrm{OCH}_{3}\right), 4.12-4.16\left(\mathrm{~m}, 1 \mathrm{H}, \mathrm{NCH}_{2}\right), 6.15$ (s, $1 \mathrm{H}, \mathrm{CH}), 6.87-6.91(\mathrm{~m}, 3 \mathrm{H}, \operatorname{ArH}), 7.36-7.41(\mathrm{~m}, 3 \mathrm{H}$, $\operatorname{ArH}), 7.71$ (s, $1 \mathrm{H}, \operatorname{ArH}), 7.85(\mathrm{~m}, 1 \mathrm{H}, \operatorname{Ar} H), 12.02$ (br, $1 \mathrm{H}$, $\mathrm{NH}) ;{ }^{13} \mathrm{C} \mathrm{NMR}\left(125 \mathrm{MHz}, \mathrm{CDCl}_{3}\right)(\delta, \mathrm{ppm}): 25.7,26.6,44.5$, 54.1, 55.8, 91.6, 96.1, 107.9, 114.0, 119.9, 125.6, 127.3, 128.0, $130.4,133.1,135.0,138.2,154.8,161.6,162.6,178.8,192.2$; HRMS (ESI-TOF, $[\mathrm{M}]^{+}$): calcd for $\mathrm{C}_{24} \mathrm{H}_{21} \mathrm{ClN}_{2} \mathrm{O}_{4}, 436.1184$; found, 436.1190.

10-Bromo-6-(4-methoxybenzoyl)-1,2,3,4,5,13a-hexahydro-8H-chromeno [3', 2':5,6]pyrido-[1,2-a][1,3]diazepin-8one (3fe). Isolated yield $93 \%$; yellow solid, $\mathrm{mp} 180-181{ }^{\circ} \mathrm{C}$; IR $(\mathrm{KBr})\left(\nu_{\max } \mathrm{cm}^{-1}\right): 3427,1652,1569,1496,1423,1347,1254$, $1173,1128,1028,824,601 ;{ }^{1} \mathrm{H} \mathrm{NMR}\left(500 \mathrm{MHz}, \mathrm{CDCl}_{3}\right)(\delta$, ppm): $2.06-2.26\left(\mathrm{~m}, 4 \mathrm{H}, \mathrm{CH}_{2} \mathrm{CH}_{2}\right), 3.59-3.79\left(\mathrm{~m}, 3 \mathrm{H}, \mathrm{NCH}_{2}\right.$ and $\left.\mathrm{CH}_{2} \mathrm{~N}\right), 3.84\left(\mathrm{~s}, 3 \mathrm{H}, \mathrm{OCH}_{3}\right), 4.10-4.14\left(\mathrm{~m}, 1 \mathrm{H}, \mathrm{NCH}_{2}\right)$, $6.17(\mathrm{~s}, 1 \mathrm{H}, \mathrm{CH}), 6.83(\mathrm{~d}, J=8.6 \mathrm{~Hz}, 1 \mathrm{H}, \operatorname{ArH}), 6.91(\mathrm{~d}, J=8.1$ $\mathrm{Hz}, 2 \mathrm{H}, \operatorname{ArH}), 7.41(\mathrm{~d}, J=8.1 \mathrm{~Hz}, 2 \mathrm{H}, \operatorname{ArH}), 7.50-7.52(\mathrm{~m}$, 1H, $\operatorname{ArH}), 7.72$ (s, 1H, $\operatorname{ArH}$ ), 8.00 (s, 1H, $\operatorname{ArH}$ ), 12.03 (br, 1H, $\mathrm{NH}) ;{ }^{13} \mathrm{C}$ NMR (125 MHz, $\left.\mathrm{CDCl}_{3}\right)(\delta, \mathrm{ppm}): 25.8,26.6,44.5$, 54.2, 55.8, 91.7, 96.1, 107.9, 114.0, 115.3, 120.3, 126.1, 130.4, 130.4, 133.1, 137.8, 138.2, 155.3, 161.6, 162.6, 178.7, 192.3; HRMS (ESI-TOF, $[\mathrm{M}]^{+}$): calcd for $\mathrm{C}_{24} \mathrm{H}_{21} \mathrm{BrN}_{2} \mathrm{O}_{4}, 480.0679$; found, 480.0714.

10-Fluoro-6-(4-methylbenzoyl)-1,2,3,4,5,13a-hexahydro8 H-chromeno[3',2':5,6]pyrido-[1,2-a][1,3]diazepin-8-one (3gc). Isolated yield 89\%; yellow solid, mp $218-222{ }^{\circ} \mathrm{C}$; IR $(\mathrm{KBr})\left(\nu_{\max } \mathrm{cm}^{-1}\right): 3423,1654,1568,1489,1434,1380,1325$, 1256, 1215, 1119, 1033, 1000, 929, 730; ${ }^{1} \mathrm{H}$ NMR (500 MHz, DMSO- $\left.d_{6}+\mathrm{HClO}_{4}\right)(\delta, \mathrm{ppm}): 1.03-2.10\left(\mathrm{~m}, 4 \mathrm{H}, \mathrm{CH}_{2} \mathrm{CH}_{2}\right)$, 2.37 (s, 3H, $\left.\mathrm{ArCH}_{3}\right), 3.69-3.76\left(\mathrm{~m}, 3 \mathrm{H}, \mathrm{NCH}_{2}\right.$ and $\left.\mathrm{CH}_{2} \mathrm{~N}\right)$, 4.10-4.27 (m, 1H, $\left.\mathrm{NCH}_{2}\right), 6.37(\mathrm{~s}, 1 \mathrm{H}, \mathrm{CH}), 7.08-7.11(\mathrm{~m}$, $1 \mathrm{H}, \mathrm{ArH}), 7.27-7.42(\mathrm{~m}, 7 \mathrm{H}, \mathrm{ArH}), 11.80(\mathrm{br}, 1 \mathrm{H}, \mathrm{NH}) ;{ }^{13} \mathrm{C}$ NMR $\left(125 \mathrm{MHz}, \mathrm{DMSO}-d_{6}+\mathrm{HClO}_{4}\right)(\delta, \mathrm{ppm}): 21.3,25.3$, 25.9, 43.7, 53.1, 90.6, 95.1, 107.8, 111.9 (d, $J=22.5 \mathrm{~Hz}$ ), 120.6, $122.6,125.0,128.0,129.1,136.5,138.0,139.8,152.6,157.4$ (d, $J$ $=240.0 \mathrm{~Hz}$ ), 161.4, 178.0, 191.2; HRMS (ESI-TOF, $[\mathrm{M}]^{+}$): calcd for $\mathrm{C}_{24} \mathrm{H}_{21} \mathrm{FN}_{2} \mathrm{O}_{3}$, 404.1531; found, 404.1539.

10-Chloro-6-(4-methylbenzoyl)-1,2,3,4,5,13a-hexahydro$8 \mathrm{H}$-chromeno[3',2':5,6]pyrido-[1,2-a][1,3]diazepin-8-one (3gd). Isolated yield 90\%; yellow solid, mp $219-221{ }^{\circ} \mathrm{C}$; IR $(\mathrm{KBr})\left(\nu_{\max } \mathrm{cm}^{-1}\right): 3428,1648,1570,1489,1420,1335,1250$, 1220, 1125, 771; ${ }^{1} \mathrm{H}$ NMR (500 MHz, $\left.\mathrm{CDCl}_{3}\right)(\delta, \mathrm{ppm})$ : 2.00-2.25 (m, 4H, $\left.\mathrm{CH}_{2} \mathrm{CH}_{2}\right), 2.38\left(\mathrm{~s}, 3 \mathrm{H}, \mathrm{ArCH}_{3}\right), 3.58-3.71$ $\left(\mathrm{m}, 3 \mathrm{H}, \mathrm{NCH}_{2} \mathrm{CH}_{2} \mathrm{~N}\right), 4.12-4.16\left(\mathrm{~m}, 1 \mathrm{H}, \mathrm{NCH}_{2}\right), 6.13(\mathrm{~s}, 1 \mathrm{H}$, $\mathrm{CH}), 6.87(\mathrm{~d}, J=8.6 \mathrm{~Hz}, 1 \mathrm{H}, \operatorname{ArH}), 7.19$ (d, J = 7.2 Hz, 2H, $\operatorname{ArH}$ ), 7.31-7.32 (m, 2H, ArH), 7.35-7.36 (m, 1H, ArH), 7.66 (s, 1H, ArH), 7.84 (s, 1H, ArH), 12.04 (br, 1H, NH); ${ }^{13} \mathrm{C}$ $\operatorname{NMR}\left(125 \mathrm{MHz}, \mathrm{CDCl}_{3}\right)(\delta, \mathrm{ppm}): 21.3,25.2,26.1,43.9,53.6$, 91.1, 95.6, 107.6, 119.4, 125.1, 126.8, 127.7, 128.0, 128.8, 134.5, 137.4, 137.6, 140.0, 154.4, 162.0, 178.3, 192.4; HRMS (ESITOF, $[\mathrm{M}]^{+}$): calcd for $\mathrm{C}_{24} \mathrm{H}_{21} \mathrm{ClN}_{2} \mathrm{O}_{3}, 420.1235$; found, 420.1253 .

10-Bromo-6-(4-methylbenzoyl)-1,2,3,4,5,13a-hexahydro$8 \mathrm{H}$-chromeno[3',2':5,6]pyrido-[1,2-a][1,3]diazepin-8-one (3ge). Isolated yield 92\%; orange solid, mp $236-237{ }^{\circ} \mathrm{C}$; IR $(\mathrm{KBr})\left(\nu_{\max } \mathrm{cm}^{-1}\right): 3427,1641,1572,1489,1417,1337,1221$, 1126, 647; ${ }^{1} \mathrm{H}$ NMR (500 MHz, $\mathrm{CDCl}_{3}$ ) $(\delta, \mathrm{ppm}): 2.00-2.34$ (m, 4H, $\mathrm{CH}_{2} \mathrm{CH}_{2}$ ), 2.38 (s, 3H, $\left.\mathrm{ArCH}_{3}\right), 3.59-3.74(\mathrm{~m}, 3 \mathrm{H}$, $\mathrm{NCH}_{2}$ and $\left.\mathrm{CH}_{2} \mathrm{~N}\right), 4.13-4.17\left(\mathrm{~m}, 1 \mathrm{H} 7 \mathrm{CH}_{2}\right), 6.14(\mathrm{~s}, 1 \mathrm{H}$, $\mathrm{CH})$, 6.74-6.76 (m, 1H, $\mathrm{ArH}), 7.15-7.20(\mathrm{~m}, 2 \mathrm{H}, \operatorname{Ar} H)$,
7.27-7.32 (m, 2H, ArH), 7.49-7.51 (m, 1H, ArH), 7.61 (s, $1 \mathrm{H}, \operatorname{ArH}), 7.99$ (s, 1H, ArH), $12.04(\mathrm{br}, 1 \mathrm{H}, \mathrm{NH}) ;{ }^{13} \mathrm{C} \mathrm{NMR}$ $\left(125 \mathrm{MHz} \mathrm{CDCl}_{3}\right)(\delta, \mathrm{ppm}): 21.8,25.7,26.6,44.5,54.1,91.6$, $96.2,108.0,115.3,120.3,126.0,128.5,129.0,129.1,130.4$, 137.9, 138.1, 140.6, 155.3, 162.6, 178.7, 192.9; HRMS (ESITOF, $[\mathrm{M}]^{+}$): calcd for $\mathrm{C}_{24} \mathrm{H}_{21} \mathrm{BrN}_{2} \mathrm{O}_{3}, 464.0730$; found, 464.0735 .

6-Benzoyl-10-methyl-1,2,3,4,5,13a-hexahydro-8Hchromeno[3',2':5,6]pyrido[1,2-a][1,3]-diazepin-8-one (3ha). Isolated yield 92\%; yellow solid, mp $227-230{ }^{\circ} \mathrm{C}$; IR ( $\mathrm{KBr}$ ) $\left(\nu_{\max } \mathrm{cm}^{-1}\right): 3428,1653,1567,1497,1423,1341,1273,1215$, 1161,$625 ;{ }^{1} \mathrm{H}$ NMR $\left(500 \mathrm{MHz}, \mathrm{CDCl}_{3}\right)(\delta, \mathrm{ppm}): 2.00-2.06$ $\left(\mathrm{m}, 2 \mathrm{H}, \mathrm{CH}_{2}\right), 2.20-2.24\left(\mathrm{~m}, 2 \mathrm{H}, \mathrm{CH}_{2}\right), 2.31\left(\mathrm{~s}, 1 \mathrm{H}, \mathrm{ArCH}_{3}\right)$, $3.58-3.60\left(\mathrm{~m}, 2 \mathrm{H}, \mathrm{CH}_{2} \mathrm{~N}\right), 3.74-3.76\left(\mathrm{~m}, 1 \mathrm{H}, \mathrm{NCH}_{2}\right), 4.12-$ $4.17\left(\mathrm{~m}, 1 \mathrm{H}, \mathrm{NCH}_{2}\right), 6.09-6.13(\mathrm{~m}, 1 \mathrm{H}, \mathrm{ArH}), 6.82-6.85$ (m, 1H, ArH), 7.24-7.26 (m, 1H, ArH), 7.38 (m, 5H, ArH), 7.587.62 (m, 1H, ArH), 7.68-7.69 (m, 1H, ArH), 12.05 (br, $1 \mathrm{H}$, $\mathrm{NH}) ;{ }^{13} \mathrm{C}$ NMR $\left(125 \mathrm{MHz}, \mathrm{CDCl}_{3}\right)(\delta, \mathrm{ppm}): 20.5,25.3,26.1$, 43.9, 53.5, 90.7, 95.3, 109.1, 117.5, 123.7, 127.1, 127.8, 128.2, 129.7, 131.6, 135.9, 136.4, 140.4, 154.0, 162.1, 179.9, 192.0; HRMS (ESI-TOF, $[\mathrm{M}]^{+}$): calcd for $\mathrm{C}_{24} \mathrm{H}_{22} \mathrm{~N}_{2} \mathrm{O}_{3}, 386.1625$; found, 386.1628 .

6-Benzoyl-1,2,3,4,5, 13a-hexahydro-8H-chromeno$\left[3^{\prime}, 2^{\prime}: 5,6\right]$ pyrido[1,2-a][1,3]diazepin-8-one (3hb). Isolated yield 91\%; orange solid, mp $172-174{ }^{\circ} \mathrm{C}$; IR $(\mathrm{KBr})\left(\nu_{\max }\right.$ $\left.\mathrm{cm}^{-1}\right)$ : 3427, 1576, 1499, 1417, 1333, 1280, 1224, 1119, 752; ${ }^{1} \mathrm{H}$ NMR $\left(500 \mathrm{MHz}, \mathrm{CDCl}_{3}\right)(\delta, \mathrm{ppm}): 2.01-2.04(\mathrm{~m}, 2 \mathrm{H}$, $\mathrm{CH}_{2}$ ), 2.18-2.31 (m, 2H, $\left.\mathrm{CH}_{2}\right), 3.56-3.59\left(\mathrm{~m}, 2 \mathrm{H}, \mathrm{NCH}_{2}\right)$, 3.70-3.74 (m, 1H, $\left.\mathrm{NCH}_{2}\right), 4.11-4.15\left(\mathrm{~m}, 1 \mathrm{H}, \mathrm{NCH}_{2}\right), 6.13(\mathrm{~s}$, $1 \mathrm{H}, \mathrm{CH}), 6.93(\mathrm{~d}, J=8.2 \mathrm{~Hz}, 1 \mathrm{H}, \mathrm{ArH}), 7.02-7.05(\mathrm{~m}, 1 \mathrm{H}$, $\operatorname{ArH}$ ), 7.36-7.39 (m, 6H, ArH), 7.61 (s, 1H, CH), 7.89 (d, J= $7.7 \mathrm{~Hz}, 1 \mathrm{H}, \mathrm{ArH}), 12.02$ (br, $1 \mathrm{H}, \mathrm{NH}) ;{ }^{13} \mathrm{C} \mathrm{NMR}(125 \mathrm{MHz}$, $\left.\mathrm{CDCl}_{3}\right)(\delta, \mathrm{ppm}): 25.8,26.6,44.4,53.9,91.3,95.8,109.3$, $118.2,122.6,124.5,127.9,128.3,128.7,130.2,135.4,137.0$, 140.9 , 156.6, 162.6, 180.2, 192.5; HRMS (ESI-TOF, $[\mathrm{M}]^{+}$): calcd for $\mathrm{C}_{23} \mathrm{H}_{20} \mathrm{~N}_{2} \mathrm{O}_{3}, 372.1468$; found, 372.1477.

6-Benzoyl-10-fluoro-1,2,3,4,5, 13 a-hexahydro-8Hchromeno[3',2':5,6]pyrido[1,2-a][1,3]-diazepin-8-one (3hc). Isolated yield $87 \%$; yellow solid, mp $169-172{ }^{\circ} \mathrm{C}$; IR ( $\mathrm{KBr}$ ) $\left(\nu_{\max } \mathrm{cm}^{-1}\right): 3427,1655,1569,1494,1435,1382,1337,1257$, $1219,1119,1033,783,622 ;{ }^{1} \mathrm{H}$ NMR (500 MHz, DMSO-d $)$ $(\delta, \mathrm{ppm}): 1.98-2.03\left(\mathrm{~m}, 4 \mathrm{H}, \mathrm{CH}_{2} \mathrm{CH}_{2}\right), 3.69-3.81(\mathrm{~m}, 3 \mathrm{H}$, $\mathrm{NCH}_{2}$ and $\left.\mathrm{CH}_{2} \mathrm{~N}\right), 4.24-4.27\left(\mathrm{~m}, 1 \mathrm{H}, \mathrm{NCH}_{2}\right), 6.38(\mathrm{~s}, 1 \mathrm{H}$, $\mathrm{CH}), 7.09-7.11(\mathrm{~m}, 1 \mathrm{H}, \mathrm{ArH}), 7.32$ (s, 1H, $\mathrm{ArH}), 7.37-7.51$ $(\mathrm{m}, 7 \mathrm{H}, \operatorname{ArH}), 11.79(\mathrm{br}, 1 \mathrm{H}, \mathrm{NH}) ;{ }^{13} \mathrm{C} \mathrm{NMR}(125 \mathrm{MHz}$, DMSO- $\left.d_{6}\right)(\delta, \mathrm{ppm}): 25.3,25.9,43.7,53.1,90.6,95.1,108.0$, $112.0(\mathrm{~d}, J=22.5 \mathrm{~Hz}), 120.6,122.7(\mathrm{~d}, J=23.8 \mathrm{~Hz}), 124.9$, $127.8,128.4,128.6,136.4,140.9,152.7,157.4(\mathrm{~d}, J=238.8 \mathrm{~Hz})$, 161.4, 178.0, 191.1; HRMS (ESI-TOF, $[\mathrm{M}]^{+}$): calcd for $\mathrm{C}_{23} \mathrm{H}_{19} \mathrm{FN}_{2} \mathrm{O}_{3}, 390.1374$; found, 390.1378 .

6-Benzoyl-10-chloro-1,2,3,4,5, 13 a-hexahydro-8Hchromeno[3',2':5,6]pyrido[1,2-a][1,3]-diazepin-8-one (3hd). Isolated yield $87 \%$; orange solid, mp $205-209{ }^{\circ} \mathrm{C}$; IR ( $\mathrm{KBr}$ ) $\left(\nu_{\max } \mathrm{cm}^{-1}\right): 3427,1654,1565,1497,1428,1340,1253,1220$, 1128,$623 ;{ }^{1} \mathrm{H}$ NMR $\left(500 \mathrm{MHz}, \mathrm{CDCl}_{3}\right)(\delta, \mathrm{ppm}): 2.00-2.05$ $\left(\mathrm{m}, 2 \mathrm{H}, \mathrm{CH}_{2}\right), 2.21-2.28\left(\mathrm{~m}, 2 \mathrm{H}, \mathrm{CH}_{2}\right), 3.56-3.60(\mathrm{~m}, 2 \mathrm{H}$, $\left.\mathrm{CH}_{2} \mathrm{~N}\right), 3.72-3.76\left(\mathrm{~m}, 1 \mathrm{H}, \mathrm{NCH}_{2}\right), 4.13-4.16(\mathrm{~m}, 1 \mathrm{H}$, $\left.\mathrm{NCH}_{2}\right), 6.12(\mathrm{~s}, 1 \mathrm{H}, \mathrm{CH}), 6.87(\mathrm{~d}, J=8.7 \mathrm{~Hz}, 1 \mathrm{H}, \operatorname{ArH})$, 7.35-7.40 (m, 6H, ArH), 7.62 (s, $1 \mathrm{H}, \operatorname{ArH}), 7.82-7.83(\mathrm{~m}$, $1 \mathrm{H}, \mathrm{ArH}), 12.02$ (br, $1 \mathrm{H}, \mathrm{NH}) ;{ }^{13} \mathrm{C} \mathrm{NMR}\left(125 \mathrm{MHz} \mathrm{CDCl}_{3}\right)$ $(\delta, \mathrm{ppm}): 25.7,26.6,44.4,54.1,91.5,96.1,108.3,119.9,125.5$, 127.2 , 128.0, 128.3, 128.7, 130.3, 135.1, 137.9, 140.7, 154.9, 
162.5, 178.9, 192.7; HRMS (ESI-TOF, $[\mathrm{M}]^{+}$): calcd for $\mathrm{C}_{23} \mathrm{H}_{19} \mathrm{ClN}_{2} \mathrm{O}_{3}, 406.1079$; found, 406.1090.

6-Benzoyl-10-bromo-1,2,3,4,5,13a-hexahydro-8Hchromeno[3',2':5,6]pyrido[1,2-a][1,3]-diazepin-8-one (3he). Isolated yield 90\%; tangerine solid, $\mathrm{mp} 236-238{ }^{\circ} \mathrm{C}$; IR $(\mathrm{KBr})\left(\nu_{\max } \mathrm{cm}^{-1}\right): 3427,1653,1563,1496,1428,1340,1254$, 1220, 1128, 619; ${ }^{1} \mathrm{H}$ NMR (500 $\left.\mathrm{MHz}, \mathrm{CDCl}_{3}\right)(\delta, \mathrm{ppm})$ : 1.89-2.21 (m, 4H, $\left.\mathrm{CH}_{2} \mathrm{CH}_{2}\right), 3.60-3.74\left(\mathrm{~m}, 3 \mathrm{H}, \mathrm{NCH}_{2}\right.$ and $\left.\mathrm{CH}_{2} \mathrm{~N}\right), 4.13-4.18\left(\mathrm{~m}, 1 \mathrm{H}, \mathrm{NCH}_{2}\right), 6.13(\mathrm{~s}, 1 \mathrm{H}, \mathrm{CH}), 6.81-$ $6.83(\mathrm{~m}, 1 \mathrm{H}, \mathrm{ArH}), 7.38-7.42(\mathrm{~m}, 5 \mathrm{H}, \operatorname{ArH}), 7.49-7.50(\mathrm{~m}$, $1 \mathrm{H}, \operatorname{ArH}), 7.62(\mathrm{~s}, 1 \mathrm{H}, \operatorname{ArH}), 7.97-7.99(\mathrm{~m}, 1 \mathrm{H}, \operatorname{ArH}), 12.04$ (br, $1 \mathrm{H}, \mathrm{NH}) ;{ }^{13} \mathrm{C} \mathrm{NMR}\left(125 \mathrm{MHz}, \mathrm{CDCl}_{3}\right)(\delta, \mathrm{ppm}): 25.7$, 26.6, 44.5, 54.1, 91.6, 96.1, 108.3, 115.3, 120.3, 126.0, 128.3, $128.7,129.0,130.3,137.9,137.9,140.7,155.4,162.5,178.7$, 192.8; HRMS (ESI-TOF, $[\mathrm{M}]^{+}$): calcd for $\mathrm{C}_{23} \mathrm{H}_{19} \mathrm{BrN}_{2} \mathrm{O}_{3}$, 450.0574; found, 450.0579 .

6-(4-Fluorobenzoyl)-10-methyl-1,2,3,4,5,13a-hexahydro$8 \mathrm{H}$-chromeno[3',2':5,6]pyrido-[1,2-a][1,3]diazepin-8-one (3ia). Isolated yield 89\%; yellow solid, mp $243-246{ }^{\circ} \mathrm{C}$; IR $(\mathrm{KBr})\left(\nu_{\max } \mathrm{cm}^{-1}\right): 3426,1654,1564,1497,1428,1341,1272$, $1215,1157,826,639 ;{ }^{1} \mathrm{H}$ NMR $\left(500 \mathrm{MHz}, \mathrm{CDCl}_{3}\right)(\delta, \mathrm{ppm})$ : 2.06-2.09 (m, 2H, CH$), 2.16-2.27\left(\mathrm{~m}, 2 \mathrm{H}, \mathrm{CH}_{2}\right), 2.31(\mathrm{~s}$, $\left.3 \mathrm{H}, \mathrm{ArCH}_{3}\right), 3.58-3.65\left(\mathrm{~m}, 2 \mathrm{H}, \mathrm{CH}_{2} \mathrm{~N}\right), 3.75-3.79(\mathrm{~m}, 1 \mathrm{H}$, $\left.\mathrm{NCH}_{2}\right), 4.16-4.21\left(\mathrm{~m}, 1 \mathrm{H}, \mathrm{NCH}_{2}\right), 6.12(\mathrm{~s}, 1 \mathrm{H}, \mathrm{CH}), 6.84(\mathrm{~d}$, $J=8.3 \mathrm{~Hz}, 1 \mathrm{H}, \mathrm{ArH}), 7.06-7.09$ (m, 2H, ArH), 7.25-7.27 (m, 1H, $\operatorname{ArH}), 7.41-7.44(\mathrm{~m}, 2 \mathrm{H}, \operatorname{ArH}), 7.57$ (s, 1H, ArH), 7.69 (s, $1 \mathrm{H}, \mathrm{ArH}), 11.99$ (br, $1 \mathrm{H}, \mathrm{NH}) ;{ }^{13} \mathrm{C}$ NMR $\left(125 \mathrm{MHz}, \mathrm{CDCl}_{3}\right)$ ( $\delta, \mathrm{ppm}):$ 20.9, 25.8, 26.6, 44.4, 54.0, 91.1, 95.7, 109.8, 115.7 $(\mathrm{d}, J=21.3 \mathrm{~Hz}), 118.0,124.1,127.6,130.6(\mathrm{~d}, J=7.5 \mathrm{~Hz})$, $132.2,136.5,137.0,154.5,162.6,163.0,165.0,180.4,191.1$; HRMS (ESI-TOF, $[\mathrm{M}]^{+}$): calcd for $\mathrm{C}_{24} \mathrm{H}_{21} \mathrm{FN}_{2} \mathrm{O}_{3}, 404.1531$; found, 404.1543.

6-(4-Fluorobenzoyl)-1,2,3,4,5, 13 a-hexahydro-8Hchromeno[3', $\left.2^{\prime}: 5,6\right]$ pyrido[1,2-a][1,3]-diazepin-8-one (3ib). Isolated yield $88 \%$; yellow solid, mp 204-207 ${ }^{\circ} \mathrm{C}$; IR ( $\mathrm{KBr}$ ) $\left(\nu_{\max } \mathrm{cm}^{-1}\right): 3427,1652,1574,1502,1325,1278,1228,1123$, 887, 754; ${ }^{1} \mathrm{H}$ NMR (500 MHz, $\left.\mathrm{CDCl}_{3}\right)(\delta, \mathrm{ppm}): 2.04-2.35$ (m, $\left.4 \mathrm{H}, \mathrm{CH}_{2} \mathrm{CH}_{2}\right), 3.58-3.65\left(\mathrm{~m}, 2 \mathrm{H}, \mathrm{CH}_{2} \mathrm{~N}\right), 3.74-3.79(\mathrm{~m}$, $\left.1 \mathrm{H}, \mathrm{NCH}_{2}\right), 4.16-4.20\left(\mathrm{~m}, 1 \mathrm{H}, \mathrm{NCH}_{2}\right), 6.16(\mathrm{~s}, 1 \mathrm{H}, \mathrm{CH}), 6.94$ (d, $J=8.2 \mathrm{~Hz}, 1 \mathrm{H}, \operatorname{ArH}), 7.04-7.09$ (m, 3H, ArH), 7.41-7.47 (m, 3H, ArH), 7.55 (s, 1H, CH), 7.90 (d, J=7.8 Hz, 1H, ArH), 11.99 (br, $1 \mathrm{H}, \mathrm{NH}) ;{ }^{13} \mathrm{C} \mathrm{NMR}\left(125 \mathrm{MHz}, \mathrm{CDCl}_{3}\right)(\delta$, ppm): 25.8, 26.6, 44.4, 54.0, 91.2, 95.7, 109.5, 115.7 (d, $J=21.3 \mathrm{~Hz})$, $118.2,122.7,124.5,127.9,130.5(\mathrm{~d}, J=6.3 \mathrm{~Hz}), 135.5,136.7$, 137.0, 156.6, 162.6, 164.0 (d, $J=6.3 \mathrm{~Hz}$ ), 180.2, 191.1; HRMS (ESI-TOF, $[\mathrm{M}]^{+}$): calcd for $\mathrm{C}_{23} \mathrm{H}_{19} \mathrm{FN}_{2} \mathrm{O}_{3}, 390.1374$; found, 390.1381 .

10-Fluoro-6-(4-fluorobenzoyl)-1,2,3,4,5,13a-hexahydro$8 \mathrm{H}$-chromeno[3',2':5,6]pyrido-[1,2-a][1,3]diazepin-8-one (3ic). Isolated yield 84\%; yellow solid, mp $187-189{ }^{\circ} \mathrm{C}$; IR $(\mathrm{KBr})\left(\nu_{\max } \mathrm{cm}^{-1}\right): 3426,1652,1569,1499,1436,1387,1341$, $1255,1222,1153,1111,831$; ${ }^{1} \mathrm{H}$ NMR (500 MHz, DMSO-d 6 ) $(\delta, \mathrm{ppm}): 2.02-2.07\left(\mathrm{~m}, 4 \mathrm{H}, \mathrm{CH}_{2} \mathrm{CH}_{2}\right), 3.68-3.80(\mathrm{~m}, 3 \mathrm{H}$, $\mathrm{NCH}_{2}$ and $\left.\mathrm{CH}_{2} \mathrm{~N}\right), 4.22-4.27\left(\mathrm{~m}, 1 \mathrm{H}, \mathrm{NCH}_{2}\right), 6.38(\mathrm{~s}, 1 \mathrm{H}$, $\mathrm{CH}), 7.08-7.12(\mathrm{~m}, 1 \mathrm{H}, \mathrm{ArH}), 7.28-7.46(\mathrm{~m}, 7 \mathrm{H}, \mathrm{CH}$ and $\mathrm{ArH}), 11.74$ (br, $1 \mathrm{H}, \mathrm{NH}) ;{ }^{13} \mathrm{C}$ NMR (125 MHz, DMSO-d $)$ $(\delta, \mathrm{ppm}): 25.3,25.9,43.7,53.1,90.5,95.1,108.2,111.9$ (d, $J=$ $22.5 \mathrm{~Hz}), 115.5(\mathrm{~d}, J=21.3 \mathrm{~Hz}), 120.6,122.8(\mathrm{~d}, J=22.5 \mathrm{~Hz})$, 125.0, 130.4, 136.1, 137.3, 152.7, 157.5 (d, $J=238.8 \mathrm{~Hz}$ ), 161.4, $163.0(\mathrm{~d}, J=246.3 \mathrm{~Hz}), 178.1,189.8$; HRMS (ESI-TOF, $[\mathrm{M}]^{+}$): calcd for $\mathrm{C}_{23} \mathrm{H}_{18} \mathrm{~F}_{2} \mathrm{~N}_{2} \mathrm{O}_{3}, 408.1280$; found, 408.1280.

10-Chloro-6-(4-fluorobenzoyl)-1,2,3,4,5,13a-hexahydro$8 H$-chromeno[3',2':5,6]pyrido-[1,2-a][1,3]diazepin-8-one (3id). Isolated yield $84 \%$; yellow solid, mp 232-234 ${ }^{\circ} \mathrm{C}$; IR $(\mathrm{KBr})\left(\nu_{\max } \mathrm{cm}^{-1}\right): 3427,1652,1563,1498,1428,1341,1254$, 1220, 1095, 1045, 596; ${ }^{1} \mathrm{H}$ NMR (500 MHz, $\left.\mathrm{CDCl}_{3}\right)(\delta$, ppm): 1.86-1.93 (m, 2H, CH $\mathrm{CH}_{2}$, 2.15-2.31 (m, $\left.2 \mathrm{H}, \mathrm{CH}_{2}\right), 3.60-3.65$ $\left(\mathrm{m}, 2 \mathrm{H}, \mathrm{CH}_{2} \mathrm{~N}\right), 3.75-3.79\left(\mathrm{~m}, 1 \mathrm{H}, \mathrm{NCH}_{2}\right), 4.17-4.20(\mathrm{~m}$, $\left.1 \mathrm{H}, \mathrm{NCH}_{2}\right), 6.15(\mathrm{~s}, 1 \mathrm{H}, \mathrm{CH}), 6.95-6.98(\mathrm{~m}, 1 \mathrm{H}, \operatorname{ArH}), 7.07-$ $7.10(\mathrm{~m}, 2 \mathrm{H}, \operatorname{ArH}), 7.36-7.44(\mathrm{~m}, 3 \mathrm{H}, \operatorname{ArH}), 7.59(\mathrm{~s}, 1 \mathrm{H}$, $\mathrm{ArH}), 7.84$ (s, 1H, ArH), 11.98 (br, $1 \mathrm{H}, \mathrm{NH}) ;{ }^{13} \mathrm{C}$ NMR (125 $\left.\mathrm{MHz}, \mathrm{CDCl}_{3}\right)(\delta, \mathrm{ppm}): 25.7,26.6,44.5,54.1,91.5,95.9$, $108.5,115.7$ (d, $J=21.3 \mathrm{~Hz}), 119.9,125.5,127.3,128.1,130.6$ $(\mathrm{d}, J=6.3 \mathrm{~Hz}), 135.2,136.8,137.5,154.9,162.5,164.0(\mathrm{~d}, J=$ $248.8 \mathrm{~Hz}$ ), 178.8, 191.3; HRMS (ESI-TOF, $[\mathrm{M}]^{+}$): calcd for $\mathrm{C}_{23} \mathrm{H}_{18} \mathrm{ClFN}_{2} \mathrm{O}_{3}, 424.0984$; found, 424.0999 .

10-Bromo-6-(4-fluorobenzoyl)-1,2,3,4,5,13a-hexahydro$8 H$-chromeno[3',2':5,6]pyrido-[1,2-a][1,3]diazepin-8-one (3ie). Isolated yield 87\%; yellow solid, mp $239-242{ }^{\circ} \mathrm{C}$; IR $(\mathrm{KBr})\left(\nu_{\max }, \mathrm{cm}^{-1}\right): 3427,1567,1498,1419,1341,1254,1220$, 1125, 647; ${ }^{1} \mathrm{H}$ NMR (500 MHz, DMSO- $\left.d_{6}+\mathrm{CDCl}_{3}\right)(\delta$, ppm): $2.06-2.12\left(\mathrm{~m}, 4 \mathrm{H}, \mathrm{CH}_{2} \mathrm{CH}_{2}\right), 3.60-3.80\left(\mathrm{~m}, 4 \mathrm{H}, \mathrm{NCH}_{2}\right.$ and $\left.\mathrm{CH}_{2} \mathrm{~N}\right), 6.20(\mathrm{~s}, 1 \mathrm{H}, \mathrm{CH}), 6.85-6.87(\mathrm{~m}, 1 \mathrm{H}, \mathrm{ArH}), 7.05-$ 7.09 (m, 2H, ArH), 7.37-7.41 (m, 2H, ArH), 7.49-7.51 (m, $1 \mathrm{H}, \operatorname{ArH}), 7.75$ (s, 1H, $\operatorname{ArH}), 7.81(\mathrm{~s}, 1 \mathrm{H}, \operatorname{ArH}), 11.83$ (br, $1 \mathrm{H}$, $\mathrm{NH}) ;{ }^{13} \mathrm{C}$ NMR (125 MHz, DMSO- $\left.d_{6}+\mathrm{CDCl}_{3}\right)(\delta, \mathrm{ppm})$ : $25.2,25.9,43.9,53.5,90.8,95.4,107.8,114.4,115.1$ (d, $J=20.0$ $\mathrm{Hz}), 115.4,115.5,120.3,125.5,129.4,130.1$ (d, $J=20.0 \mathrm{~Hz})$, 136.8, 137.5, 155.1, 161.8, 177.9, 190.2; HRMS (ESI-TOF, $[\mathrm{M}]^{+}$): calcd for $\mathrm{C}_{23} \mathrm{H}_{18} \mathrm{BrFN}_{2} \mathrm{O}_{3}, 468.0479$; found, 468.0494 .

10-Chloro-6-(4-chlorobenzoyl)-1,2,3,4,5,13a-hexahydro$8 \mathrm{H}$-chromeno[3',2':5,6]pyrido-[1,2-a][1,3]diazepin-8-one (3jc). Isolated yield 90\%; orange solid, mp $234-236{ }^{\circ} \mathrm{C}$; IR $(\mathrm{KBr})\left(\nu_{\max } \mathrm{cm}^{-1}\right): 3427,1649,1569,1489,1423,1379,1335$, 1250, 1220, 1126, 773; ${ }^{1} \mathrm{H}$ NMR (500 $\left.\mathrm{MHz} \mathrm{CDCl}_{3}\right)(\delta$, ppm): 2.05-2.10 (m, 2H, $\left.\mathrm{CH}_{2}\right), 2.22-2.30\left(\mathrm{~m}, 2 \mathrm{H}, \mathrm{CH}_{2}\right), 3.6-3.75$ $\left(\mathrm{m}, 3 \mathrm{H}, \mathrm{NCH}_{2}\right.$ and $\left.\mathrm{CH}_{2} \mathrm{~N}\right), 4.16-4.18\left(\mathrm{~m}, 1 \mathrm{H}, \mathrm{NCH}_{2}\right), 6.14$ $(\mathrm{s}, 1 \mathrm{H}, \mathrm{CH}), 6.88(\mathrm{~d}, J=8.7 \mathrm{~Hz}, 1 \mathrm{H}, \operatorname{ArH}), 7.19(\mathrm{~d}, J=7.8 \mathrm{~Hz}$, 2H, ArH), 7.26-7.28 (m, 1H, ArH), 7.31-7.32 (m, 1H, ArH), 7.36-7.38 (m, 1H, ArH), 7.67 (s, 1H, ArH), 7.84-7.86 (m, $1 \mathrm{H}, \mathrm{ArH}), 12.05$ (br, $1 \mathrm{H}, \mathrm{NH}) ;{ }^{13} \mathrm{C} \mathrm{NMR}\left(125 \mathrm{MHz}, \mathrm{CDCl}_{3}\right)$ $(\delta, \mathrm{ppm}): 25.2,26.1,44.0,53.6,91.1,95.6,107.6,119.4,125.1$, $126.8,127.5,127.9,128.9,134.6,137.3,137.6,140.1,154.4$, 162.1, 178.3, 192.5; HRMS (ESI-TOF, $[\mathrm{M}+\mathrm{H}]^{+}$): calcd for $\mathrm{C}_{23} \mathrm{H}_{19} \mathrm{Cl}_{2} \mathrm{~N}_{2} \mathrm{O}_{3}$, 441.0767; found, 441.0764 .

Characterization Data of Compounds 3'. 7-(2-Hydroxy5-methylbenzoyl)-9-(4-methoxy-benzoyl)-1,2,3,4tetrahydropyrido[1,2-a]pyrimidin-5-ium (3aa'). Isolated yield 99\%; light yellow solid, mp $212-214{ }^{\circ} \mathrm{C}$; IR ( $\left.\mathrm{KBr}\right)\left(\nu_{\max }\right.$, $\left.\mathrm{cm}^{-1}\right): 3254,3072,1727,1657,1592,1483,1358,1309,1252$, 1168, 1094, 786, 619; ${ }^{1} \mathrm{H}$ NMR (500 MHz, DMSO-d $d_{6}+$ $\left.\mathrm{HClO}_{4}\right)(\delta, \mathrm{ppm}): 2.14\left(\mathrm{~s}, 3 \mathrm{H}, \mathrm{CH}_{3}\right), 2.15\left(\mathrm{~m}, 2 \mathrm{H}, \mathrm{CH}_{2}\right), 3.54$ $\left(\mathrm{m}, 2 \mathrm{H}, \mathrm{NCH}_{2}\right), 3.78\left(\mathrm{~s}, 3 \mathrm{H}, \mathrm{OCH}_{3}\right), 4.42\left(\mathrm{~m}, 2 \mathrm{H}, \mathrm{NCH}_{2}\right)$, 6.81-6.83 (m, 1H, ArH), 7.01-7.03 (m, 2H, ArH), 7.16-7.19 (m, 2H, ArH), 7.69-7.72 (m, 2H, ArH), $7.98(\mathrm{~s}, 1 \mathrm{H}, \mathrm{N}=\mathrm{CH})$, $8.47(\mathrm{~s}, 1 \mathrm{H}, \mathrm{C}=\mathrm{CH}), 9.83(\mathrm{~s}, 1 \mathrm{H}, \mathrm{OH}) ;{ }^{13} \mathrm{C} \mathrm{NMR}(125 \mathrm{MHz}$, DMSO- $\left.d_{6}+\mathrm{HClO}_{4}\right)(\delta, \mathrm{ppm}): 17.5,20.0,39.9,52.4,55.9$, $114.4,117.1,119.2,120.9,122.7,128.9,129.0,130.8,132.7$, 135.6, 145.0, 146.7, 151.7, 154.8, 164.0, 191.4, 192.2; HRMS $\left(\right.$ ESI-TOF, $[\mathrm{M}]^{+}$): calcd for $\mathrm{C}_{24} \mathrm{H}_{23} \mathrm{~N}_{2} \mathrm{O}_{4}, 403.1647$; found, 403.1660.

7-(2-Hydroxybenzoyl)-9-(4-methoxybenzoyl)-1,2,3,4tetrahydropyrido[1,2-a]pyrimidin-5-ium (3ab'). Isolated yield 99\%; yellow solid, $\mathrm{mp} 214-216{ }^{\circ} \mathrm{C}$; IR $(\mathrm{KBr})\left(\nu_{\max }, \mathrm{cm}^{-1}\right)$ : 3271, 3078, 1661, 1596, 1492, 1311, 1248, 1169, 1093, 775, 620; ${ }^{1} \mathrm{H}$ NMR (500 MHz, DMSO-d $\left.6+\mathrm{HClO}_{4}\right)(\delta, \mathrm{ppm}): 2.19$ 
(m, 2H, $\left.\mathrm{CH}_{2}\right), 3.56\left(\mathrm{~m}, 2 \mathrm{H}, \mathrm{NCH}_{2}\right), 3.86\left(\mathrm{~s}, 3 \mathrm{H}, \mathrm{OCH}_{3}\right), 4.49$ (m, 2H, $\left.\mathrm{NCH}_{2}\right), 6.93-6.99(\mathrm{~m}, 2 \mathrm{H}, \mathrm{ArH}), 7.11-7.12(\mathrm{~m}, 2 \mathrm{H}$, $\operatorname{ArH}$ ), 7.40-7.45 (m, 2H, ArH), 7.79-7.80 (m, 2H, ArH), 8.03 $(\mathrm{s}, 1 \mathrm{H}, \mathrm{N}=\mathrm{CH}), 8.64(\mathrm{~s}, 1 \mathrm{H}, \mathrm{C}=\mathrm{CH}), 9.86(\mathrm{~s}, 1 \mathrm{H}, \mathrm{OH}) ;{ }^{13} \mathrm{C}$ NMR $\left(125 \mathrm{MHz}, \mathrm{DMSO}-d_{6}+\mathrm{HClO}_{4}\right)(\delta, \mathrm{ppm}): 17.6,40.1$, 52.4, 56.1, 114.6, 117.1, 119.8, 120.0, 120.9, 123.8, 128.8, 131.0, 132.8, 134.5, 144.3, 146.8, 151.5, 156.6, 164.2, 191.1, 191.7; HRMS (ESI-TOF, $[\mathrm{M}]^{+}$): calcd for $\mathrm{C}_{23} \mathrm{H}_{21} \mathrm{~N}_{2} \mathrm{O}_{4}, 389.1490$; found, 389.1496 .

7-(5-Fluoro-2-hydroxybenzoyl)-9-(4-methoxybenzoyl)1,2,3,4-tetrahydropyrido[1,2-a]-pyrimidin-5-ium (3ac'). Isolated yield 99\%; light yellow solid, mp $224-226{ }^{\circ} \mathrm{C}$; IR ( $\mathrm{KBr}$ ) $\left(\nu_{\max } \mathrm{cm}^{-1}\right): 3261,3075,1660,1604,1479,1425,1319,1263$, $1163,1093,788,621 ;{ }^{1} \mathrm{H}$ NMR (500 MHz, DMSO-d $d_{6}+$ $\left.\mathrm{HClO}_{4}\right)(\delta, \mathrm{ppm}): 2.18\left(\mathrm{~m}, 2 \mathrm{H}, \mathrm{CH}_{2}\right), 3.55\left(\mathrm{~m}, 2 \mathrm{H}, \mathrm{NCH}_{2}\right)$, $3.85\left(\mathrm{~s}, 3 \mathrm{H}, \mathrm{OCH}_{3}\right), 4.48\left(\mathrm{~m}, 2 \mathrm{H}, \mathrm{NCH}_{2}\right), 6.96-6.99(\mathrm{~m}, 1 \mathrm{H}$, $\operatorname{ArH}), 7.09-7.11(\mathrm{~m}, 2 \mathrm{H}, \operatorname{ArH}), 7.17-7.19(\mathrm{~m}, 1 \mathrm{H}, \operatorname{ArH})$, 7.25-7.28 (m, 1H, ArH), 7.78-7.80 (m, 2H, ArH), 8.03 (s, $1 \mathrm{H}, \mathrm{N}=\mathrm{CH}), 8.63(\mathrm{~s}, 1 \mathrm{H}, \mathrm{C}=\mathrm{CH}), 9.86(\mathrm{~s}, 1 \mathrm{H}, \mathrm{OH}) ;{ }^{13} \mathrm{C}$ NMR $\left(125 \mathrm{MHz}, \mathrm{DMSO}-d_{6}+\mathrm{HClO}_{4}\right)(\delta, \mathrm{ppm}): 18.1,40.6$, 52.9, 56.6, 115.1, 116.8, 117.0, 119.0, 120.6, 121.0, 121.3, 121.5, $125.0,129.3,133.3,144.4,147.6,152.1,153.2,155.0,156.9$, 164.8, 190.2, 192.1; HRMS (ESI-TOF, $[\mathrm{M}]^{+}$): calcd for $\mathrm{C}_{23} \mathrm{H}_{20} \mathrm{FN}_{2} \mathrm{O}_{4}$, 407.1396; found, 407.1408.

7-(5-Chloro-2-hydroxybenzoyl)-9-(4-methoxybenzoyl)1,2,3,4-tetrahydropyrido[1,2-a]-pyrimidin-5-ium (3ad'). Isolated yield $99 \%$; yellow solid, mp $144-146{ }^{\circ} \mathrm{C}$; IR $(\mathrm{KBr})\left(\nu_{\max }\right.$ $\left.\mathrm{cm}^{-1}\right)$ : 3250, 3077, 1658, 1590, 1464, 1420, 1318, 1227, 1173, 1093, 787, 622; ${ }^{1} \mathrm{H} \mathrm{NMR}\left(500 \mathrm{MHz}, \mathrm{DMSO}-d_{6}+\mathrm{HClO}_{4}\right)(\delta$, ppm): $2.17\left(\mathrm{~m}, 2 \mathrm{H}, \mathrm{CH}_{2}\right), 3.55\left(\mathrm{~m}, 2 \mathrm{H}, \mathrm{NCH}_{2}\right), 3.84(\mathrm{~s}, 3 \mathrm{H}$, $\left.\mathrm{OCH}_{3}\right), 4.46\left(\mathrm{~m}, 2 \mathrm{H}, \mathrm{NCH}_{2}\right), 6.98(\mathrm{~m}, 1 \mathrm{H}, \mathrm{ArH}), 7.10(\mathrm{~m}, 2 \mathrm{H}$, $\operatorname{ArH}), 7.35(\mathrm{~m}, 1 \mathrm{H}, \operatorname{ArH}), 7.43(\mathrm{~m}, 1 \mathrm{H}, \operatorname{ArH}), 7.78(\mathrm{~m}, 2 \mathrm{H}$, $\mathrm{ArH}), 8.01(\mathrm{~s}, 1 \mathrm{H}, \mathrm{N}=\mathrm{CH}), 8.60(\mathrm{~s}, 1 \mathrm{H}, \mathrm{C}=\mathrm{CH}), 9.88(\mathrm{~s}$, $1 \mathrm{H}, \mathrm{OH}) ;{ }^{13} \mathrm{C}$ NMR $\left(125 \mathrm{MHz}, \mathrm{DMSO}-d_{6}+\mathrm{HClO}_{4}\right)(\delta$, ppm): 17.6, 40.1, 52.4, 56.1, 114.6, 119.0, 119.8, 120.6, 123.5, $125.6,128.8,129.7,132.8,133.6,144.2,147.1,151.7,155.0$, 164.2, 189.6, 191.8; HRMS (ESI-TOF, $[\mathrm{M}]^{+}$): calcd for $\mathrm{C}_{23} \mathrm{H}_{20} \mathrm{ClN}_{2} \mathrm{O}_{4}, 423.1101$; found, 423.1102 .

7-(5-Bromo-2-hydroxybenzoyl)-9-(4-methoxybenzoyl)1,2,3,4-tetrahydropyrido[1,2-a]-pyrimidin-5-ium (3ae'). Isolated yield 99\%; light yellow solid, mp $254-255{ }^{\circ} \mathrm{C}$; IR ( $\mathrm{KBr}$ ) $\left(\nu_{\max } \mathrm{cm}^{-1}\right): 3255,3078,1659,1592,1463,1418,1316,1227$, $1172,1093,789,622 ;{ }^{1} \mathrm{H}$ NMR $\left(500 \mathrm{MHz}, \mathrm{DMSO}-d_{6}+\right.$ $\left.\mathrm{HClO}_{4}\right)(\delta, \mathrm{ppm}): 2.16\left(\mathrm{~m}, 2 \mathrm{H}, \mathrm{CH}_{2}\right), 3.54\left(\mathrm{~m}, 2 \mathrm{H}, \mathrm{NCH}_{2}\right)$, $3.82\left(\mathrm{~s}, 3 \mathrm{H}, \mathrm{OCH}_{3}\right), 4.44\left(\mathrm{~m}, 2 \mathrm{H}, \mathrm{NCH}_{2}\right), 6.90-6.92(\mathrm{~m}, 1 \mathrm{H}$, $\operatorname{ArH}), 7.06-7.08(\mathrm{~m}, 2 \mathrm{H}, \operatorname{ArH}), 7.44(\mathrm{~s}, 1 \mathrm{H}, \operatorname{ArH}), 7.50-7.52$ (m, 1H, ArH), 7.73-7.75 (m, 2H, ArH), $7.99(\mathrm{~s}, 1 \mathrm{H}, \mathrm{N}=\mathrm{CH})$, $8.58(\mathrm{~s}, 1 \mathrm{H}, \mathrm{C}=\mathrm{CH}), 9.87(\mathrm{~s}, 1 \mathrm{H}, \mathrm{OH}) ;{ }^{13} \mathrm{C}$ NMR $(125 \mathrm{MHz}$, DMSO- $\left.d_{6}+\mathrm{HClO}_{4}\right)(\delta, \mathrm{ppm}): 17.5,40.0,52.4,56.0,110.9$, $114.5,119.4,119.6,120.5,126.1,128.8,132.5,132.8,136.4$, 144.3, 147.0, 151.7, 155.4, 164.1, 189.5, 191.8; HRMS (ESITOF, $\left.[\mathrm{M}]^{+}\right)$: calcd for $\mathrm{C}_{23} \mathrm{H}_{20} \mathrm{BrN}_{2} \mathrm{O}_{4}, 467.0595$; found, 467.0614 .

7-(5-Fluoro-2-hydroxybenzoyl)-9-(4-methylbenzoyl)1,2,3,4-tetrahydropyrido[1,2-a]-pyrimidin-5-ium (3bc'). Isolated yield 99\%; light yellow solid, mp $232-234{ }^{\circ} \mathrm{C}$; IR ( $\mathrm{KBr}$ ) $\left(\nu_{\max } \mathrm{cm}^{-1}\right): 3279,3074,1660,1610,1480,1429,1319,1272$, 1220, 1092, 782, 621; ${ }^{1} \mathrm{H}$ NMR (500 MHz, DMSO- $d_{6}+$ $\left.\mathrm{HClO}_{4}\right)(\delta, \mathrm{ppm}): 2.17\left(\mathrm{~m}, 2 \mathrm{H}, \mathrm{CH}_{2}\right), 2.36\left(\mathrm{~s}, 3 \mathrm{H}, \mathrm{CH}_{3}\right), 3.57$ $\left(\mathrm{m}, 2 \mathrm{H}, \mathrm{NCH}_{2}\right), 4.46\left(\mathrm{~m}, 2 \mathrm{H}, \mathrm{NCH}_{2}\right), 6.94-6.96(\mathrm{~m}, 1 \mathrm{H}$, ArH), 7.15-7.17 (m, 1H, ArH), 7.17-7.19 (m, 1H, ArH), 7.23 (m, 1H, ArH), 7.35-7.36 (m, 2H, ArH), 7.63-7.65 (m, 2H, $\mathrm{ArH}), 8.07(\mathrm{~s}, 1 \mathrm{H}, \mathrm{N}=\mathrm{CH}), 8.59(\mathrm{~s}, 1 \mathrm{H}, \mathrm{C}=\mathrm{CH}), 10.01(\mathrm{~s}$,
$1 \mathrm{H}, \mathrm{OH}) ;{ }^{13} \mathrm{C}$ NMR $\left(125 \mathrm{MHz}, \mathrm{DMSO}-d_{6}+\mathrm{HClO}_{4}\right)(\delta$, ppm): 17.5, 21.5, 40.1, 52.4, 116.2, 116.4, 118.6, 119.2, 120.5, $121.1,124.3,129.7,130.2,133.8,144.9,145.0,147.6,151.8$, 152.7, 154.5, 189.6, 193.4; HRMS (ESI-TOF, $[\mathrm{M}]^{+}$): calcd for $\mathrm{C}_{23} \mathrm{H}_{20} \mathrm{FN}_{2} \mathrm{O}_{3}, 391.1447$; found, 391.1463 .

7-(5-Chloro-2-hydroxybenzoyl)-9-(4-methylbenzoyl)1,2,3,4-tetrahydropyrido[1,2-a]-pyrimidin-5-ium (3bd'). Isolated yield $99 \%$; yellow solid, mp $137-139{ }^{\circ} \mathrm{C}$; IR $(\mathrm{KBr})\left(\nu_{\max }\right.$ $\left.\mathrm{cm}^{-1}\right): 3274,1660,1593,1468,1410,1241,1096,779,623 ;{ }^{1} \mathrm{H}$ NMR $\left(500 \mathrm{MHz}, \mathrm{DMSO}_{-} d_{6}+\mathrm{HClO}_{4}\right)(\delta, \mathrm{ppm}): 2.16(\mathrm{~m}, 2 \mathrm{H}$, $\left.\mathrm{CH}_{2}\right), 2.34\left(\mathrm{~s}, 3 \mathrm{H}, \mathrm{CH}_{3}\right), 3.56\left(\mathrm{~m}, 2 \mathrm{H}, \mathrm{NCH}_{2}\right), 4.44(\mathrm{~m}, 2 \mathrm{H}$, $\left.\mathrm{NCH}_{2}\right)$, 6.94-6.96 (m, 1H, $\left.\operatorname{ArH}\right), 7.31-7.39(\mathrm{~m}, 4 \mathrm{H}, \operatorname{ArH})$, 7.61-7.62 (m, 2H, $\operatorname{ArH}), 8.57(\mathrm{~s}, 1 \mathrm{H}, \mathrm{N}=\mathrm{CH}), 8.57(\mathrm{~s}, 1 \mathrm{H}$, $\mathrm{C}=\mathrm{CH}), 10.01(\mathrm{~s}, 1 \mathrm{H}, \mathrm{OH}) ;{ }^{13} \mathrm{C}$ NMR $\left(125 \mathrm{MHz}, \mathrm{DMSO}-d_{6}\right.$ $\left.+\mathrm{HClO}_{4}\right)(\delta, \mathrm{ppm}): 17.4,21.5,40.1,52.4,119.0,120.4,123.5$, $125.3,129.7,130.0,133.6,133.8,144.8,145.1,147.6,151.8$, 155.1, 189.5, 193.4; HRMS (ESI-TOF, $[\mathrm{M}]^{+}$): calcd for $\mathrm{C}_{23} \mathrm{H}_{20} \mathrm{ClN}_{2} \mathrm{O}_{3}$, 407.1151; found, 407.1163.

7-(5-Bromo-2-hydroxybenzoyl)-9-(4-methylbenzoyl)1,2,3,4-tetrahydropyrido[1,2-a]-pyrimidin-5-ium (3be'). Isolated yield 99\%; white solid, mp $230-232{ }^{\circ} \mathrm{C}$; IR (KBr) $\left(\nu_{\max }\right.$, $\left.\mathrm{cm}^{-1}\right)$ : 3242, 3083, 1662, 1619, 1461, 1316, 1221, 1091, 780, 621; ${ }^{1} \mathrm{H}$ NMR (500 MHz, DMSO- $\left.d_{6}+\mathrm{CDCl}_{3}+\mathrm{HClO}_{4}\right)(\delta$, ppm): $2.21\left(\mathrm{~m}, 2 \mathrm{H}, \mathrm{CH}_{2}\right), 2.39\left(\mathrm{~s}, 3 \mathrm{H}, \mathrm{CH}_{3}\right), 3.62(\mathrm{~m}, 2 \mathrm{H}$, $\left.\mathrm{NCH}_{2}\right), 4.50\left(\mathrm{~m}, 2 \mathrm{H}, \mathrm{NCH}_{2}\right), 6.90-6.92(\mathrm{~m}, 1 \mathrm{H}, \mathrm{ArH}), 7.33-$ 7.34 (m, 2H, ArH), 7.43-7.46 (m, 2H, ArH), 7.63-7.65 (m, $2 \mathrm{H}, \mathrm{ArH}), 8.09(\mathrm{~s}, 1 \mathrm{H}, \mathrm{N}=\mathrm{CH}), 8.65(\mathrm{~s}, 1 \mathrm{H}, \mathrm{C}=\mathrm{CH}), 10.09$ $(\mathrm{s}, 1 \mathrm{H}, \mathrm{OH}) ;{ }^{13} \mathrm{C}$ NMR $\left(125 \mathrm{MHz}, \mathrm{DMSO}-d_{6}+\mathrm{CDCl}_{3}+\right.$ $\left.\mathrm{HClO}_{4}\right)(\delta, \mathrm{ppm}): 17.7,21.7,40.1,52.4,112.0,119.1,119.4$, $120.7,125.7,129.7,130.2,132.6,133.7,136.4,144.8,145.1$, 147.5, 151.8, 155.7, 189.1, 193.1; HRMS (ESI-TOF, $[\mathrm{M}]^{+}$): calcd for $\mathrm{C}_{23} \mathrm{H}_{20} \mathrm{BrN}_{2} \mathrm{O}_{3}, 451.0646$; found, 451.0653 .

9-Benzoyl-7-(2-hydroxy-5-methylbenzoyl)-1,2,3,4tetrahydropyrido[1,2-a]pyrimidin-5-ium (3ca'). Isolated yield 99\%; white solid, $\mathrm{mp} 208-210{ }^{\circ} \mathrm{C}$; IR $(\mathrm{KBr})\left(\nu_{\max } \mathrm{cm}^{-1}\right)$ : 3266, 3069, 1660, 1592, 1484, 1315, 1224, 1162, 1092, 768, $625 ;{ }^{1} \mathrm{H}$ NMR $\left(500 \mathrm{MHz}, \mathrm{DMSO}-d_{6}+\mathrm{HClO}_{4}\right)(\delta, \mathrm{ppm}): 2.16$ $\left(\mathrm{s}, 3 \mathrm{H}, \mathrm{CH}_{3}\right), 2.18\left(\mathrm{~m}, 2 \mathrm{H}, \mathrm{CH}_{2}\right), 3.59\left(\mathrm{~m}, 2 \mathrm{H}, \mathrm{NCH}_{2}\right), 4.47$ $\left(\mathrm{m}, 2 \mathrm{H}, \mathrm{NCH}_{2}\right), 6.83-6.84(\mathrm{~m}, 1 \mathrm{H}, \operatorname{ArH}), 7.16(\mathrm{~s}, 1 \mathrm{H}, \operatorname{ArH})$, 7.19-7.21 (m, 1H, ArH), 7.53-7.56 (m, 2H, ArH), 7.64-7.67 (m, 1H, ArH), 7.71-7.72 (m, 2H, ArH), $8.06(\mathrm{~s}, 1 \mathrm{H}, \mathrm{N}=\mathrm{CH})$, $8.60(\mathrm{~s}, 1 \mathrm{H}, \mathrm{C}=\mathrm{CH}), 10.10(\mathrm{~s}, 1 \mathrm{H}, \mathrm{OH}) ;{ }^{13} \mathrm{C} \mathrm{NMR}(125$ $\left.\mathrm{MHz}, \mathrm{DMSO}-d_{6}+\mathrm{HClO}_{4}\right)(\delta, \mathrm{ppm}): 17.5,20.0,40.1,52.5$, $117.1,118.4,120.9,123.0,128.9,129.1,129.9,130.8,133.8$, 135.4, 136.6, 146.3, 147.4, 151.8, 154.6, 191.1, 194.1; HRMS $\left(\right.$ ESI-TOF, $[\mathrm{M}]^{+}$): calcd for $\mathrm{C}_{23} \mathrm{H}_{21} \mathrm{~N}_{2} \mathrm{O}_{3}, 373.1541$; found, 373.1554.

9-Benzoyl-7-(2-hydroxybenzoyl)-1,2,3,4-tetrahydropyrido[1,2-a]pyrimidin-5-ium (3cb'). Isolated yield 99\%; white solid, mp $226-228{ }^{\circ} \mathrm{C}$; IR $(\mathrm{KBr})\left(\nu_{\max } \mathrm{cm}^{-1}\right): 3425,3286,2355$, 1662 , 1604, 1487, 1444, 1317, 1278, 1235, 1092, 764; ${ }^{1} \mathrm{H}$ NMR $\left(500 \mathrm{MHz}, \mathrm{DMSO}-d_{6}+\mathrm{HClO}_{4}\right)(\delta, \mathrm{ppm}): 2.18\left(\mathrm{~m}, 2 \mathrm{H}, \mathrm{CH}_{2}\right)$, $3.59\left(\mathrm{~m}, 2 \mathrm{H}, \mathrm{NCH}_{2}\right), 4.46\left(\mathrm{~m}, 2 \mathrm{H}, \mathrm{NCH}_{2}\right), 6.88-6.94(\mathrm{~m}, 2 \mathrm{H}$, $\operatorname{Ar} H)$, 7.36-7.40 (m, 2H, $\operatorname{ArH}), 7.52-7.55(\mathrm{~m}, 2 \mathrm{H}, \operatorname{Ar} H)$, 7.63-7.66 (m, 1H, ArH), 7.69-7.70 (m, 2H, ArH), 8.07 (s, $1 \mathrm{H}, \mathrm{N}=\mathrm{CH}), 8.58(\mathrm{~s}, 1 \mathrm{H}, \mathrm{C}=\mathrm{CH}), 10.11(\mathrm{~s}, 1 \mathrm{H}, \mathrm{OH}) ;{ }^{13} \mathrm{C}$ NMR (125 MHz, DMSO-d $\left.d_{6}+\mathrm{HClO}_{4}\right)(\delta, \mathrm{ppm}): 17.4,40.0$, $52.5,117.1,118.4,120.0,123.3,129.1,129.8,130.9,133.8$, 134.7, 136.6, 146.4, 147.5, 151.9, 156.7, 191.1, 194.3; HRMS $\left(\right.$ ESI-TOF, $[\mathrm{M}]^{+}$): calcd for $\mathrm{C}_{22} \mathrm{H}_{19} \mathrm{~N}_{2} \mathrm{O}_{3}, 359.1385$; found, 359.1390.

9-Benzoyl-7-(5-fluoro-2-hydroxybenzoyl)-1,2,3,4tetrahydropyrido[1,2-a]pyrimidin-5-ium $\left(3 c c^{\prime}\right)$. Isolated yield 
99\%; light yellow solid, mp $214-218{ }^{\circ} \mathrm{C}$; IR ( $\left.\mathrm{KBr}\right)\left(\nu_{\max }\right.$ $\left.\mathrm{cm}^{-1}\right)$ : 3294, 3077, 1661, 1589, 1482, 1430, 1329, 1274, 1222, 1164, 1092, 761, 623; ${ }^{1} \mathrm{H}$ NMR (500 MHz, DMSO-d $d_{6}+$ $\left.\mathrm{HClO}_{4}\right)(\delta, \mathrm{ppm}): 2.17\left(\mathrm{~m}, 2 \mathrm{H}, \mathrm{CH}_{2}\right), 3.58\left(\mathrm{~m}, 2 \mathrm{H}, \mathrm{NCH}_{2}\right)$, $4.43\left(\mathrm{~m}, 2 \mathrm{H}, \mathrm{NCH}_{2}\right), 6.89-6.92(\mathrm{~m}, 1 \mathrm{H}, \mathrm{ArH}), 7.11-7.13(\mathrm{~m}$, $2 \mathrm{H}, \operatorname{ArH}), 7.17-7.19$ (m, 1H, $\operatorname{ArH}), 7.50-7.53(\mathrm{~m}, 2 \mathrm{H}, \operatorname{ArH})$, 7.61-7.68 (m, 3H, ArH), $8.06(\mathrm{~s}, 1 \mathrm{H}, \mathrm{N}=\mathrm{CH}), 8.55(\mathrm{~s}, 1 \mathrm{H}$, $\mathrm{C}=\mathrm{CH}), 10.11(\mathrm{~s}, 1 \mathrm{H}, \mathrm{OH}) ;{ }^{13} \mathrm{C}$ NMR $\left(125 \mathrm{MHz}, \mathrm{DMSO}-d_{6}\right.$ $\left.+\mathrm{HClO}_{4}\right)(\delta, \mathrm{ppm}): 17.4,40.9,52.5,116.2,116.4,118.6,120.4$, $121.0,121.2,123.9,129.1,129.8,133.8,136.5,146.2,147.8$, 152.0, 152.7, 154.4, 156.3, 189.8, 194.3; HRMS (ESI-TOF, $[\mathrm{M}]^{+}$): calcd for $\mathrm{C}_{22} \mathrm{H}_{18} \mathrm{FN}_{2} \mathrm{O}_{3}, 377.1290$; found, 377.1303.

9-Benzoyl-7-(5-chloro-2-hydroxybenzoyl)-1,2,3,4tetrahydropyrido[1,2-a]pyrimidin-5-ium $\left(3 \mathrm{~cd}^{\prime}\right)$. Isolated yield 99\%; white solid, mp $131-133{ }^{\circ} \mathrm{C}$; IR $(\mathrm{KBr})\left(\nu_{\max } \mathrm{cm}^{-1}\right)$ : 3288, 1659, 1591, 1466, 1409, 1231, 1093, 763, 627; ${ }^{1} \mathrm{H}$ NMR $\left(500 \mathrm{MHz}, \mathrm{DMSO}-d_{6}+\mathrm{HClO}_{4}\right)(\delta, \mathrm{ppm}): 2.19\left(\mathrm{~m}, 2 \mathrm{H}, \mathrm{CH}_{2}\right)$, $3.59\left(\mathrm{~m}, 2 \mathrm{H}, \mathrm{NCH}_{2}\right), 4.48\left(\mathrm{~m}, 2 \mathrm{H}, \mathrm{NCH}_{2}\right), 6.96-6.98(\mathrm{~m}, 1 \mathrm{H}$, $\mathrm{ArH}), 7.33(\mathrm{~m}, 1 \mathrm{H}, \mathrm{ArH}), 7.39-7.41(\mathrm{~m}, 1 \mathrm{H}, \mathrm{ArH}), 7.55-7.58$ (m, 2H, ArH), 7.67-7.69 (m, 1H, ArH), 7.72-7.74 (m, 2H, $\operatorname{ArH}), 8.07(\mathrm{~s}, 1 \mathrm{H}, \mathrm{N}=\mathrm{CH}), 8.66(\mathrm{~s}, 1 \mathrm{H}, \mathrm{C}=\mathrm{CH}), 10.12(\mathrm{~s}$, $1 \mathrm{H}, \mathrm{NH}) ;{ }^{13} \mathrm{C}$ NMR $\left(125 \mathrm{MHz}, \mathrm{DMSO}-d_{6}+\mathrm{HClO}_{4}\right)(\delta$, ppm): 17.5, 40.2, 52.5, 118.8, 118.9, 120.4, 123.5, 125.5, 129.2, $129.7,129.9,133.6,133.9,136.5,145.7,147.8,151.8,155.0$, 189.4, 193.9; HRMS (ESI-TOF, $[\mathrm{M}]^{+}$): calcd for $\mathrm{C}_{22} \mathrm{H}_{18} \mathrm{ClN}_{2} \mathrm{O}_{3}$, 393.0995; found, 393.1008.

9-Benzoyl-7-(5-bromo-2-hydroxybenzoyl)-1,2,3,4tetrahydropyrido[1,2-a]pyrimidin-5-ium (3ce'). Isolated yield 99\%; light yellow solid, mp $227-229{ }^{\circ} \mathrm{C}$; IR (KBr) ( $\nu_{\max }$ $\left.\mathrm{cm}^{-1}\right): 3268,3077,1660,1591,1463,1319,1221,1090,764$, 624; ${ }^{1} \mathrm{H}$ NMR $\left(500 \mathrm{MHz}, \mathrm{DMSO}-d_{6}+\mathrm{HClO}_{4}\right)(\delta, \mathrm{ppm}): 2.17$ $\left(\mathrm{m}, 2 \mathrm{H}, \mathrm{CH}_{2}\right), 3.58\left(\mathrm{~m}, 2 \mathrm{H}, \mathrm{NCH}_{2}\right), 4.43\left(\mathrm{~m}, 2 \mathrm{H}, \mathrm{NCH}_{2}\right)$, 6.87-6.88 (m, 1H, ArH), $7.40(\mathrm{~s}, 1 \mathrm{H}, \operatorname{ArH}), 7.45-7.47(\mathrm{~m}$, 1H, $\operatorname{ArH}), 7.51-7.54(\mathrm{~m}, 2 \mathrm{H}, \operatorname{ArH}), 7.63-7.67$ (m, 3H, $\operatorname{ArH})$, $8.04(\mathrm{~s}, 1 \mathrm{H}, \mathrm{N}=\mathrm{CH}), 8.56(\mathrm{~s}, 1 \mathrm{H}, \mathrm{C}=\mathrm{CH}), 10.12(\mathrm{~s}, 1 \mathrm{H}$, $\mathrm{OH}) ;{ }^{13} \mathrm{C}$ NMR $\left(125 \mathrm{MHz}, \mathrm{DMSO}-d_{6}+\mathrm{HClO}_{4}\right)(\delta, \mathrm{ppm}):$ 17.4 , 40.0, 52.5, 110.9, 118.3, 119.4, 120.4, 125.7, 129.1, 129.8, $132.5,133.8,136.5,146.2,147.7,152.0,155.4,189.4,194.3$; HRMS (ESI-TOF, $[\mathrm{M}]^{+}$): calcd for $\mathrm{C}_{22} \mathrm{H}_{18} \mathrm{BrN}_{2} \mathrm{O}_{3}, 437.0490$; found, 437.0504.

7-(5-Fluoro-2-hydroxybenzoyl)-9-(4-fluorobenzoyl)1,2,3,4-tetrahydropyrido[1,2-a]pyri-midin-5-ium (3dc'). Isolated yield 99\%; light yellow solid, mp $213-215{ }^{\circ} \mathrm{C}$; IR ( $\mathrm{KBr}$ ) $\left(\nu_{\max } \mathrm{cm}^{-1}\right): 3294,3075,1661,1596,1487,1352,1226,1160$, 1091, 786, 614; ${ }^{1} \mathrm{H}$ NMR (500 MHz, DMSO-d $\left.d_{6}+\mathrm{HClO}_{4}\right)(\delta$, ppm): $2.19\left(\mathrm{~m}, 2 \mathrm{H}, \mathrm{CH}_{2}\right), 3.59\left(\mathrm{~m}, 2 \mathrm{H}, \mathrm{NCH}_{2}\right), 4.49(\mathrm{~m}, 2 \mathrm{H}$, $\left.\mathrm{NCH}_{2}\right)$, 6.96-6.98 (m, 1H, $\left.\mathrm{ArH}\right), 7.16-7.17(\mathrm{~m}, 1 \mathrm{H}, \mathrm{ArH})$, 7.24-7.28 (m, 1H, ArH), 7.37-7.40 (m, 2H, ArH), 7.84-7.87 $(\mathrm{m}, 2 \mathrm{H}, \operatorname{Ar} H), 8.08(\mathrm{~s}, 1 \mathrm{H}, \mathrm{N}=\mathrm{CH}), 8.66(\mathrm{~s}, 1 \mathrm{H}, \mathrm{C}=\mathrm{CH})$, $9.99(\mathrm{~s}, 1 \mathrm{H}, \mathrm{OH}) ;{ }^{13} \mathrm{C}$ NMR $\left(125 \mathrm{MHz}, \mathrm{DMSO}-d_{6}+\mathrm{HClO}_{4}\right)$ $(\delta, \mathrm{ppm}): 17.5,40.2,52.5,116.2,116.4,118.5,119.3,120.5$, $121.0,124.4,133.2,145.1,147.7,151.7,152.7,154.6,156.4$, 164.5, 166.5, 189.5, 192.2; HRMS (ESI-TOF, $[\mathrm{M}]^{+}$): calcd for $\mathrm{C}_{22} \mathrm{H}_{17} \mathrm{~F}_{2} \mathrm{~N}_{2} \mathrm{O}_{3}$, 395.1196; found, 395.1216.

7-(5-Chloro-2-hydroxybenzoyl)-9-(4-fluorobenzoyl)1,2,3,4-tetrahydropyrido[1,2-a]pyri-midin-5-ium (3dd'). Isolated yield 99\%; light yellow solid, mp $126-129^{\circ} \mathrm{C}$; IR ( $\mathrm{KBr}$ ) $\left(\nu_{\max } \mathrm{cm}^{-1}\right): 3276,3080,1659,1592,1468,1410,1232,1161$, $1093,786,619 ;{ }^{1} \mathrm{H}$ NMR $\left(500 \mathrm{MHz}, \mathrm{DMSO}-d_{6}+\mathrm{HClO}_{4}\right)(\delta$, ppm): $2.18\left(\mathrm{~m}, 2 \mathrm{H}, \mathrm{CH}_{2}\right), 3.59\left(\mathrm{~m}, 2 \mathrm{H}, \mathrm{NCH}_{2}\right), 4.48(\mathrm{~m}, 2 \mathrm{H}$, $\left.\mathrm{NCH}_{2}\right), 6.96-6.98(\mathrm{~m}, 1 \mathrm{H}, \mathrm{ArH}), 7.33-7.42(\mathrm{~m}, 4 \mathrm{H}, \mathrm{ArH})$, 7.81-7.84 (m, 2H, ArH), $8.05(\mathrm{~s}, 1 \mathrm{H}, \mathrm{N}=\mathrm{CH}), 8.65(\mathrm{~s}, 1 \mathrm{H}$, $\mathrm{C}=\mathrm{CH}), 10.01(\mathrm{~s}, 1 \mathrm{H}, \mathrm{OH}) ;{ }^{13} \mathrm{C}$ NMR $\left(125 \mathrm{MHz}, \mathrm{DMSO}-d_{6}\right.$
$\left.+\mathrm{HClO}_{4}\right)(\delta, \mathrm{ppm}): 17.5,40.2,52.5,116.2,116.4,118.9,120.5$, 123.5 , 125.5, 129.7, 133.1, 133.6, 145.3, 147.7, 151.7, 155.0, 164.5, 166.5, 189.4, 192.3; HRMS (ESI-TOF, $[\mathrm{M}]^{+}$): calcd for $\mathrm{C}_{22} \mathrm{H}_{17} \mathrm{ClFN}_{2} \mathrm{O}_{3}, 411.0901$; found, 411.0910 .

7-(5-Bromo-2-hydroxybenzoyl)-9-(4-fluorobenzoyl)1,2,3,4-tetrahydropyrido[1,2-a]pyri-midin-5-ium (3de'). Isolated yield 99\%; yellow solid, mp $139-141{ }^{\circ} \mathrm{C}$; IR $(\mathrm{KBr})\left(\nu_{\max }\right.$ $\left.\mathrm{cm}^{-1}\right)$ : 3354, 1660, 1593, 1466, 1407, 1233, 1094, 787, 620; ${ }^{1} \mathrm{H}$ NMR $\left(500 \mathrm{MHz}, \mathrm{DMSO}-d_{6}+\mathrm{HClO}_{4}\right)(\delta, \mathrm{ppm}): 2.18(\mathrm{~m}, 2 \mathrm{H}$, $\left.\mathrm{CH}_{2}\right), 3.58\left(\mathrm{~m}, 2 \mathrm{H}, \mathrm{NCH}_{2}\right), 4.47\left(\mathrm{~m}, 2 \mathrm{H}, \mathrm{NCH}_{2}\right), 6.90-6.92$ (m, 1H, ArH), 7.35-7.38 (m, 2H, ArH), 7.43 (s, 1H, ArH), 7.51-7.53 (m, 1H, ArH), 7.80-7.83 (m, 2H, ArH), 8.04 (s, $1 \mathrm{H}, \mathrm{N}=\mathrm{CH}), 8.63(\mathrm{~s}, 1 \mathrm{H}, \mathrm{C}=\mathrm{CH}), 10.00(\mathrm{~s}, 1 \mathrm{H}, \mathrm{OH}) ;{ }^{13} \mathrm{C}$ NMR $\left(125 \mathrm{MHz}, \mathrm{DMSO}-d_{6}+\mathrm{HClO}_{4}\right)(\delta, \mathrm{ppm}): 17.5,41.5$, $52.5,110.9,116.2,116.4,118.9,119.3,120.4,126.0,132.5$, $133.1,136.5,145.3,147.6,151.7,155.4,164.5,166.5,189.3$, 192.4; HRMS (ESI-TOF, $[\mathrm{M}]^{+}$): calcd for $\mathrm{C}_{22} \mathrm{H}_{17} \mathrm{BrFN}_{2} \mathrm{O}_{3}$, 455.0396; found, 455.0406.

9-(4-Chlorobenzoyl)-7-(5-fluoro-2-hydroxybenzoyl)1,2,3,4-tetrahydropyrido[1,2-a]pyri-midin-5-ium (3ec'). Isolated yield 99\%; yellow solid, $\mathrm{mp} 145-147{ }^{\circ} \mathrm{C}$; IR $(\mathrm{KBr})\left(\nu_{\max }\right.$, $\left.\mathrm{cm}^{-1}\right)$ : 3272, 3082, 1661, 1589, 1484, 1430, 1267, 1215, 1161, 1093, 785, 623; ${ }^{1} \mathrm{H}$ NMR (500 MHz, DMSO-d $\left.6+\mathrm{HClO}_{4}\right)(\delta$, ppm): $2.16\left(\mathrm{~m}, 2 \mathrm{H}, \mathrm{CH}_{2}\right), 3.56\left(\mathrm{~m}, 2 \mathrm{H}, \mathrm{CH}_{2}\right), 4.44(\mathrm{~m}, 2 \mathrm{H}$, $\left.\mathrm{CH}_{2}\right)$, 6.91-6.94 (m, 1H, ArH), 7.11-7.13 (m, 2H, $\left.\mathrm{ArH}\right)$, 7.19-7.22 (m, 1H, ArH), 7.55-7.57 (m, 2H, ArH), 7.70-7.72 $(\mathrm{m}, 2 \mathrm{H}, \operatorname{Ar} H), 8.05(\mathrm{~s}, 1 \mathrm{H}, \mathrm{N}=\mathrm{CH}), 8.58(\mathrm{~s}, 1 \mathrm{H}, \mathrm{C}=\mathrm{CH})$, $10.01(\mathrm{~s}, 1 \mathrm{H}, \mathrm{OH}) ;{ }^{13} \mathrm{C} \mathrm{NMR}\left(125 \mathrm{MHz}, \mathrm{DMSO}-d_{6}+\mathrm{HClO}_{4}\right)$ $(\delta, \mathrm{ppm}): 17.4,40.1,52.5,116.3,116.4,118.6,120.5,121.0$, $121.1,124.1,129.2,131.8,135.2,138.9,145.6,147.8,151.8$, $152.7,154.5,156.5,189.5,192.8$; HRMS (ESI-TOF, $[\mathrm{M}]^{+}$): calcd for $\mathrm{C}_{22} \mathrm{H}_{17} \mathrm{ClFN}_{2} \mathrm{O}_{3}, 411.0901$; found, 411.0914 .

7-(5-Chloro-2-hydroxybenzoyl)-9-(4-chlorobenzoyl)1,2,3,4-tetrahydropyrido[1,2-a]pyri-midin-5-ium (3ed'). Isolated yield 99\%; yellow solid, mp $226-229{ }^{\circ} \mathrm{C}$; IR $(\mathrm{KBr})\left(\nu_{\max }\right.$ $\left.\mathrm{cm}^{-1}\right): 3259,3084,1663,1465,1318,1219,1090,783,624 ;{ }^{1} \mathrm{H}$ NMR $\left(500 \mathrm{MHz}, \mathrm{DMSO}_{-} d_{6}+\mathrm{HClO}_{4}\right)(\delta, \mathrm{ppm}): 2.18(\mathrm{~m}, 2 \mathrm{H}$, $\left.\mathrm{CH}_{2}\right), 3.58\left(\mathrm{~m}, 2 \mathrm{H}, \mathrm{NCH}_{2}\right), 4.47\left(\mathrm{~m}, 2 \mathrm{H}, \mathrm{NCH}_{2}\right), 6.96-6.97$ (m, 1H, ArH), 7.33 (s, 1H, ArH), 7.41-7.42 (m, 1H, ArH), 7.60-7.62 (m, 2H, ArH), 7.74-7.75 (m, 2H, ArH), 8.06 (s, $1 \mathrm{H}, \mathrm{N}=\mathrm{CH}), 8.65(\mathrm{~s}, 1 \mathrm{H}, \mathrm{C}=\mathrm{CH}), 10.04(\mathrm{~s}, 1 \mathrm{H}, \mathrm{OH}) ;{ }^{13} \mathrm{C}$ NMR $\left(125 \mathrm{MHz}, \mathrm{DMSO}-d_{6}+\mathrm{HClO}_{4}\right)(\delta, \mathrm{ppm}): 17.5,40.2$, $52.5,119.8,120.5,123.5,125.4,129.2,129.8,131.8,133.7$, 135.3, 139.0, 145.5, 147.9, 151.7, 155.1, 189.5, 192.7; HRMS (ESI-TOF, $[\mathrm{M}]^{+}$): calcd for $\mathrm{C}_{22} \mathrm{H}_{17} \mathrm{Cl}_{2} \mathrm{~N}_{2} \mathrm{O}_{3}, 427.0605$; found, 427.0613.

7-(5-Bromo-2-hydroxybenzoyl)-9-(4-chlorobenzoyl)1,2,3,4-tetrahydropyrido[1,2-a]pyri-midin-5-ium (3ee'). Isolated yield 99\%; yellow solid, $\mathrm{mp} 230-232{ }^{\circ} \mathrm{C}$; IR $(\mathrm{KBr})\left(\nu_{\max }\right.$ $\left.\mathrm{cm}^{-1}\right): 3257,3084,1663,1588,1463,1316,1220,1091,784$, 623; ${ }^{1} \mathrm{H}$ NMR (500 MHz, DMSO-d $\left.6+\mathrm{HClO}_{4}\right)(\delta, \mathrm{ppm}): 2.25$ $\left(\mathrm{m}, 2 \mathrm{H}, \mathrm{CH}_{2}\right), 3.65\left(\mathrm{~m}, 2 \mathrm{H}, \mathrm{NCH}_{2}\right), 4.44\left(\mathrm{~m}, 2 \mathrm{H}, \mathrm{NCH}_{2}\right)$, 6.78-6.80 (m, 1H, ArH), 7.33-7.39 (m, 3H, ArH), $7.53(\mathrm{~s}$, $1 \mathrm{H}, \operatorname{ArH}), 7.58-7.68(\mathrm{~m}, 2 \mathrm{H}, \operatorname{ArH}), 8.08(\mathrm{~s}, 1 \mathrm{H}, \mathrm{N}=\mathrm{CH})$, $8.33(\mathrm{~s}, 1 \mathrm{H}, \mathrm{C}=\mathrm{CH}), 10.10(\mathrm{~s}, 1 \mathrm{H}, \mathrm{OH}) ;{ }^{13} \mathrm{C} \mathrm{NMR}(125$ $\left.\mathrm{MHz}, \mathrm{DMSO}-d_{6}+\mathrm{HClO}_{4}\right)(\delta, \mathrm{ppm}): 17.4,39.8,52.6,111.3$, $117.9,119.7,120.9,122.5,129.1,131.1,133.2,134.6,138.0$, 139.6, 146.3, 147.3, 152.2, 157.8, 190.4, 193.7; HRMS (ESITOF, $[\mathrm{M}]^{+}$): calcd for $\mathrm{C}_{22} \mathrm{H}_{17} \mathrm{BrClN}_{2} \mathrm{O}_{3}, 471.0100$; found, 471.0113.

8-(2-Hydroxy-5-methylbenzoyl)-10-(4-methoxybenzoyl)2,3,4,5-tetrahydro-1H-pyrido-[1,2-a][1,3]diazepin-6-ium $\left(3 f a^{\prime}\right)$. Isolated yield $99 \%$; light yellow solid, mp $189-191{ }^{\circ} \mathrm{C}$; 
IR $(\mathrm{KBr})\left(\nu_{\max }, \mathrm{cm}^{-1}\right): 3282,3078,1648,1590,1482,1311$, 1260, 1168, 1092, 789, 620; ${ }^{1} \mathrm{H}$ NMR (500 MHz, DMSO-d $d_{6}+$ $\left.\mathrm{HClO}_{4}\right)(\delta, \mathrm{ppm}): 2.04-2.05\left(\mathrm{~m}, 2 \mathrm{H}, \mathrm{NCH}_{2}\right), 2.17(\mathrm{~m}, 2 \mathrm{H}$, $\left.\mathrm{NCH}_{2}\right), 2.17\left(\mathrm{~s}, 3 \mathrm{H}, \mathrm{CH}_{3}\right), 3.81\left(\mathrm{~s}, 3 \mathrm{H}, \mathrm{OCH}_{3}\right), 3.81(\mathrm{~m}, 2 \mathrm{H}$, $\left.\mathrm{CH}_{2}\right), 4.68\left(\mathrm{~m}, 2 \mathrm{H}, \mathrm{CH}_{2}\right), 6.83-6.85(\mathrm{~m}, 1 \mathrm{H}, \mathrm{ArH}), 7.04-7.06$ (m, 2H, ArH), 7.18-7.22 (m, 2H, ArH), 7.75-7.77 (m, 2H, $\operatorname{ArH}), 7.98(\mathrm{~s}, 1 \mathrm{H}, \mathrm{N}=\mathrm{CH}), 8.63(\mathrm{~s}, 1 \mathrm{H}, \mathrm{C}=\mathrm{CH}), 9.53(\mathrm{~s}$, $1 \mathrm{H}, \mathrm{OH}) ;{ }^{13} \mathrm{C}$ NMR $\left(125 \mathrm{MHz}, \mathrm{DMSO}-d_{6}+\mathrm{HClO}_{4}\right)(\delta$, ppm): 20.1, 23.6, 24.0, 44.8, 56.0, 57.8, 114.4, 117.1, 121.6, $122.6,123.0,128.9,130.9,132.9,135.5,144.7,148.1,154.7$, 156.2, 164.1, 191.1, 192.2; HRMS (ESI-TOF, $[\mathrm{M}]^{+}$): calcd for $\mathrm{C}_{25} \mathrm{H}_{25} \mathrm{~N}_{2} \mathrm{O}_{4}$, 417.1803; found, 417.1821.

8-(2-Hydroxybenzoyl)-10-(4-methoxybenzoyl)-2,3,4,5-tetrahydro-1H-pyrido[1,2-a][1,3]-diazepin-6-ium (3f $\left.b^{\prime}\right)$. Isolated yield 99\%; yellow solid, mp $265-267{ }^{\circ} \mathrm{C}$; IR (KBr) $\left(\nu_{\max }\right.$ $\left.\mathrm{cm}^{-1}\right)$ : 3305, 3078, 1646, 1590, 1492, 1447, 1316, 1166, 1093, 776,$621 ;{ }^{1} \mathrm{H}$ NMR $\left(500 \mathrm{MHz}, \mathrm{DMSO}-d_{6}+\mathrm{HClO}_{4}\right)(\delta$, ppm): $2.06\left(\mathrm{~m}, 2 \mathrm{H}, \mathrm{NCH}_{2}\right), 2.16\left(\mathrm{~m}, 2 \mathrm{H}, \mathrm{NCH}_{2}\right), 3.80\left(\mathrm{~m}, 2 \mathrm{H}, \mathrm{CH}_{2}\right)$, $3.82\left(\mathrm{~s}, 3 \mathrm{H}, \mathrm{OCH}_{3}\right), 4.69\left(\mathrm{~m}, 2 \mathrm{H}, \mathrm{CH}_{2}\right), 6.92-6.96(\mathrm{~m}, 2 \mathrm{H}$, $\mathrm{ArH}$ ), 7.06-7.07 (m, 2H, $\operatorname{ArH}), 7.39-7.41$ (m, 2H, $\mathrm{ArH}$ ), 7.75-7.77 (m, 2H, ArH), $8.01(\mathrm{~s}, 1 \mathrm{H}, \mathrm{N}=\mathrm{CH}), 8.66(\mathrm{~s}, 1 \mathrm{H}$, $\mathrm{C}=\mathrm{CH}), 9.54(\mathrm{~s}, 1 \mathrm{H}, \mathrm{OH}) ;{ }^{13} \mathrm{C}$ NMR $\left(125 \mathrm{MHz}\right.$, DMSO- $d_{6}+$ $\left.\mathrm{HClO}_{4}\right)(\delta, \mathrm{ppm}): 23.6,23.9,44.8,56.0,57.8,114.5,117.1$, $120.0,121.7,122.5,123.5,128.8,131.1,132.9,134.7,144.6$, 148.2, 156.2, 156.8, 164.2, 191.0, 192.2; HRMS (ESI-TOF, $[\mathrm{M}]^{+}$): calcd for $\mathrm{C}_{24} \mathrm{H}_{23} \mathrm{~N}_{2} \mathrm{O}_{4}, 403.1647$; found, 403.1658 .

8-(5-Fluoro-2-hydroxybenzoyl)-10-(4-methoxybenzoyl)2,3,4,5-tetrahydro-1H-pyrido[1,2-a][1,3]diazepin-6-ium $\left(3 \mathrm{fc}^{\prime}\right)$. Isolated yield 99\%; yellow solid, $\mathrm{mp} 141-143{ }^{\circ} \mathrm{C}$; IR $(\mathrm{KBr})\left(\nu_{\max } \mathrm{cm}^{-1}\right): 3411,3078,1650,1591,1480,1260,1171$, 1094, 790, 618; ${ }^{1} \mathrm{H}$ NMR (500 MHz, DMSO-d $\left.6+\mathrm{HClO}_{4}\right)(\delta$, ppm): 2.06-2.07 (m, 2H, $\left.\mathrm{NCH}_{2}\right), 2.16\left(\mathrm{~m}, 2 \mathrm{H}, \mathrm{NCH}_{2}\right), 3.81$ $\left(\mathrm{m}, 2 \mathrm{H}, \mathrm{CH}_{2}\right), 3.85\left(\mathrm{~s}, 3 \mathrm{H}, \mathrm{OCH}_{3}\right), 4.71\left(\mathrm{~m}, 2 \mathrm{H}, \mathrm{CH}_{2}\right), 6.96-$ $6.98(\mathrm{~m}, 1 \mathrm{H}, \mathrm{ArH}), 7.09-7.10(\mathrm{~m}, 2 \mathrm{H}, \mathrm{ArH}), 7.19-7.20(\mathrm{~m}$, 1H, $\operatorname{ArH}$ ), 7.25-7.29 (m, 1H, ArH), 7.79-7.81 (m, 2H, ArH), $8.03(\mathrm{~s}, 1 \mathrm{H}, \mathrm{N}=\mathrm{CH}), 8.71(\mathrm{~s}, 1 \mathrm{H}, \mathrm{C}=\mathrm{CH}), 9.50(\mathrm{~s}, 1 \mathrm{H}, \mathrm{OH})$; ${ }^{13} \mathrm{C}$ NMR (125 MHz, DMSO- $\left.d_{6}+\mathrm{HClO}_{4}\right)(\delta, \mathrm{ppm}): 23.7$, 24.0, 44.8, 56.1, 57.7, 114.5, 116.3, 116.5, 118.6, 120.9, 121.1, $122.1,122.3,124.4,128.8,133.0,143.9,148.5,152.8,154.5$, 156.2, 156.2, 164.3, 189.5, 191.9; HRMS (ESI-TOF, $[\mathrm{M}]^{+}$): calcd for $\mathrm{C}_{24} \mathrm{H}_{22} \mathrm{FN}_{2} \mathrm{O}_{4}, 421.1553$; found, 421.1569.

8-(5-Chloro-2-hydroxybenzoyl)-10-(4-methoxybenzoyl)2,3,4,5-tetrahydro-1H-pyrido-[1,2-a][1,3]diazepin-6-ium $\left(3 f^{\prime}\right)$. Isolated yield 99\%; light yellow solid, mp $150-152{ }^{\circ} \mathrm{C}$; IR $(\mathrm{KBr})\left(\nu_{\max } \mathrm{cm}^{-1}\right): 3396,1645,1595,1466,1318,1262$, $1172,1092,787,622 ;{ }^{1} \mathrm{H}$ NMR (500 MHz, DMSO- $d_{6}+$ $\left.\mathrm{HClO}_{4}\right)(\delta, \mathrm{ppm}): 2.05\left(\mathrm{~m}, 2 \mathrm{H}, \mathrm{NCH}_{2}\right), 2.14\left(\mathrm{~m}, 2 \mathrm{H}, \mathrm{NCH}_{2}\right)$, $3.81\left(\mathrm{~s}, 3 \mathrm{H}, \mathrm{OCH}_{3}\right), 4.67\left(\mathrm{~m}, 2 \mathrm{H}, \mathrm{CH}_{2}\right), 6.94-6.95(\mathrm{~m}, 1 \mathrm{H}$, ArH), 7.04-7.06 (m, 2H, ArH), 7.33 (m, 1H, ArH), 7.37-7.39 (m, 1H, ArH), 7.73-7.75 (m, 2H, ArH), $7.99(\mathrm{~s}, 1 \mathrm{H}, \mathrm{N}=\mathrm{CH})$, $8.64(\mathrm{~s}, 1 \mathrm{H}, \mathrm{C}=\mathrm{CH}), 9.57(\mathrm{~s}, 1 \mathrm{H}, \mathrm{OH}) ;{ }^{13} \mathrm{C} \mathrm{NMR}(125 \mathrm{MHz}$, DMSO- $\left.d_{6}+\mathrm{HClO}_{4}\right)(\delta, \mathrm{ppm}): 23.6,23.9,44.8,56.0,57.8$, $114.4,119.0,121.6,122.0,123.5,125.3,128.8,129.7,132.9$, 133.7, 144.5, 148.5, 155.1, 156.3, 164.2, 189.4, 192.2; HRMS $\left(\right.$ ESI-TOF, $\left.[\mathrm{M}]^{+}\right)$: calcd for $\mathrm{C}_{24} \mathrm{H}_{22} \mathrm{ClN}_{2} \mathrm{O}_{4}, 437.1257$; found, 437.1267.

8-(5-Bromo-2-hydroxybenzoyl)-10-(4-methoxybenzoyl)2,3,4,5-tetrahydro-1H-pyrido[1,2-a][1,3]diazepin-6-ium $\left(3 \mathrm{fe}^{\prime}\right)$. Isolated yield 99\%; yellow solid, $\mathrm{mp} 131-133{ }^{\circ} \mathrm{C}$; IR $(\mathrm{KBr})\left(\nu_{\max } \mathrm{cm}^{-1}\right): 3405,3080,1649,1590,1463,1408,1320$, 1228, 1171, 1093, 790, 621; ${ }^{1} \mathrm{H}$ NMR (500 MHz, DMSO-d $d_{6}+$ $\left.\mathrm{HClO}_{4}\right)(\delta, \mathrm{ppm}): 2.04-2.05\left(\mathrm{~m}, 2 \mathrm{H}, \mathrm{NCH}_{2}\right), 2.15(\mathrm{~m}, 2 \mathrm{H}$, $\left.\mathrm{NCH}_{2}\right), 3.81\left(\mathrm{~m}, 2 \mathrm{H}, \mathrm{CH}_{2}\right), 3.82\left(\mathrm{~s}, 3 \mathrm{H}, \mathrm{OCH}_{3}\right), 4.68(\mathrm{~m}, 2 \mathrm{H}$,
$\mathrm{CH}_{2}$ ), 6.90-6.92 (m, 1H, ArH), 7.06-7.07 (m, 1H, ArH), 7.45 (s, 1H, $\operatorname{ArH}), 7.50-7.52(\mathrm{~m}, 2 \mathrm{H}, \operatorname{ArH}), 7.74-7.76(\mathrm{~m}, 2 \mathrm{H}$, $\mathrm{ArH}), 7.99(\mathrm{~s}, 1 \mathrm{H}, \mathrm{N}=\mathrm{CH}), 8.67(\mathrm{~s}, 1 \mathrm{H}, \mathrm{C}=\mathrm{CH}), 9.56(\mathrm{~s}$, $1 \mathrm{H}, \mathrm{OH}) ;{ }^{13} \mathrm{C}$ NMR $\left(125 \mathrm{MHz}, \mathrm{DMSO}-d_{6}+\mathrm{HClO}_{4}\right)(\delta$, ppm): 23.6, 24.0, 44.8, 56.0, 57.8, 110.8, 114.5, 119.4, 121.7, $122.0,126.0,128.7,132.5,132.9,136.5,144.3,148.5,155.5$, 156.3, 164.2, 189.3, 192.1; HRMS (ESI-TOF, $[\mathrm{M}]^{+}$): calcd for $\mathrm{C}_{24} \mathrm{H}_{22} \mathrm{BrN}_{2} \mathrm{O}_{4}$, 481.0752; found, 481.0764 .

8-(5-Fluoro-2-hydroxybenzoyl)-10-(4-methylbenzoyl)2,3,4,5-tetrahydro-1H-pyrido[1,2-a][1,3]diazepin-6-ium $\left(3 g c^{\prime}\right)$. Isolated yield $99 \%$; yellow solid, $\mathrm{mp} 130-132{ }^{\circ} \mathrm{C}$; IR $(\mathrm{KBr})\left(\nu_{\max } \mathrm{cm}^{-1}\right): 3376,3079,1652,1581,1482,1433,1267$, 1224, 1094, 785, 620; ${ }^{1} \mathrm{H}$ NMR (500 MHz, DMSO-d $d_{6}+$ $\left.\mathrm{HClO}_{4}\right)(\delta, \mathrm{ppm}): 2.07\left(\mathrm{~m}, 2 \mathrm{H}, \mathrm{NCH}_{2}\right), 2.14-2.15(\mathrm{~m}, 2 \mathrm{H}$, $\left.\mathrm{NCH}_{2}\right), 2.37$ (s, 3H, CH $), 3.83\left(\mathrm{~m}, 2 \mathrm{H}, \mathrm{CH}_{2}\right), 4.70(\mathrm{~m}, 2 \mathrm{H}$, $\left.\mathrm{CH}_{2}\right), 6.94-6.96(\mathrm{~m}, 1 \mathrm{H}, \mathrm{ArH}), 7.16-7.18(\mathrm{~m}, 1 \mathrm{H}, \mathrm{ArH})$, 7.23-7.27 (m, 1H, ArH), 7.35-7.36 (m, 2H, ArH), 7.66-7.67 $(\mathrm{m}, 2 \mathrm{H}, \mathrm{ArH}), 8.06(\mathrm{~s}, 1 \mathrm{H}, \mathrm{N}=\mathrm{CH}), 8.69(\mathrm{~s}, 1 \mathrm{H}, \mathrm{C}=\mathrm{CH})$, $9.71(\mathrm{~s}, 1 \mathrm{H}, \mathrm{OH}) ;{ }^{13} \mathrm{C}$ NMR $\left(125 \mathrm{MHz}, \mathrm{DMSO}-d_{6}+\mathrm{HClO}_{4}\right)$ $(\delta, \mathrm{ppm}): 21.5,23.6,24.0,44.9,57.8,116.3,116.5,118.6,120.9$, $121.1,121.4,122.0,124.2,129.7,130.4,133.8,144.9,145.0$, 149.0, 152.8, 154.5, 156.4, 189.4, 193.6; HRMS (ESI-TOF, $\left.[\mathrm{M}]^{+}\right)$: calcd for $\mathrm{C}_{24} \mathrm{H}_{22} \mathrm{FN}_{2} \mathrm{O}_{3}, 405.1603$; found, 405.1624.

8-(5-Chloro-2-hydroxybenzoyl)-10-(4-methylbenzoyl)2,3,4,5-tetrahydro-1H-pyrido[1,2-a][1,3]diazepin-6-ium $\left(3 \mathrm{gd}^{\prime}\right)$. Isolated yield $99 \%$; light yellow solid, mp $194-196{ }^{\circ} \mathrm{C}$; IR $(\mathrm{KBr})\left(\nu_{\max } \mathrm{cm}^{-1}\right): 3395,1079,1649,1468,1407,1319$, $1228,1177,1096,783,624 ;{ }^{1} \mathrm{H}$ NMR $\left(500 \mathrm{MHz}, \mathrm{DMSO}-d_{6}+\right.$ $\left.\mathrm{HClO}_{4}\right)(\delta, \mathrm{ppm}): 2.07\left(\mathrm{~m}, 2 \mathrm{H}, \mathrm{NCH}_{2}\right), 2.07\left(\mathrm{~m}, 2 \mathrm{H}, \mathrm{NCH}_{2}\right)$, $2.38\left(\mathrm{~s}, 3 \mathrm{H}, \mathrm{CH}_{3}\right), 3.84\left(\mathrm{~m}, 2 \mathrm{H}, \mathrm{CH}_{2}\right), 6.97-6.98(\mathrm{~m}, 1 \mathrm{H}$, $\operatorname{ArH})$, 7.36-7.38 (m, 3H, $\operatorname{ArH}), 7.41-7.43(\mathrm{~m}, 1 \mathrm{H}, \operatorname{ArH})$, 7.67-7.68 (m, 2H, $\operatorname{ArH}), 8.05(\mathrm{~s}, 1 \mathrm{H}, \mathrm{N}=\mathrm{CH}), 8.72(\mathrm{~s}, 1 \mathrm{H}$, $\mathrm{C}=\mathrm{CH}), 9.72(\mathrm{~s}, 1 \mathrm{H}, \mathrm{OH}) ;{ }^{13} \mathrm{C}$ NMR $\left(125 \mathrm{MHz}, \mathrm{DMSO}-d_{6}+\right.$ $\left.\mathrm{HClO}_{4}\right)(\delta, \mathrm{ppm}): 21.6,23.7,24.0,44.9,57.8,119.1,121.4$, $122.0,123.5,125.4,129.7,130.4,133.7,144.8,145.0,148.9$, 155.2, 156.3, 189.3, 193.5; HRMS (ESI-TOF, $[\mathrm{M}]^{+}$): calcd for $\mathrm{C}_{24} \mathrm{H}_{22} \mathrm{ClN}_{2} \mathrm{O}_{3}, 421.1308$; found, 421.1319 .

8-(5-Bromo-2-hydroxybenzoyl)-10-(4-methylbenzoyl)2,3,4,5-tetrahydro-1H-pyrido[1,2-a][1,3]diazepin-6-ium $\left(3 g e^{\prime}\right)$. Isolated yield $99 \%$; light yellow solid, mp $140-142{ }^{\circ} \mathrm{C}$; IR $(\mathrm{KBr})\left(\nu_{\max } \mathrm{cm}^{-1}\right): 3292,3077,1649,1584,1464,1404$, $1317,1227,1176,1093 ;{ }^{1} \mathrm{H}$ NMR (500 MHz, DMSO- $d_{6}+$ $\left.\mathrm{HClO}_{4}\right)(\delta, \mathrm{ppm}): 2.04\left(\mathrm{~m}, 2 \mathrm{H}, \mathrm{NCH}_{2}\right), 2.16\left(\mathrm{~m}, 2 \mathrm{H}, \mathrm{NCH}_{2}\right)$, $2.36\left(\mathrm{~s}, 3 \mathrm{H}, \mathrm{CH}_{3}\right), 3.84\left(\mathrm{~m}, 2 \mathrm{H}, \mathrm{CH}_{2}\right), 4.69\left(\mathrm{~m}, 2 \mathrm{H}, \mathrm{CH}_{2}\right)$, 6.90-6.92 (m, 1H, ArH), 7.35-7.37 (m, 2H, ArH), 7.45 (s, $1 \mathrm{H}, \operatorname{ArH}), 7.50-7.52(\mathrm{~m}, 1 \mathrm{H}, \operatorname{ArH}), 7.64-7.66(\mathrm{~m}, 2 \mathrm{H}, \operatorname{ArH})$, $8.04(\mathrm{~s}, 1 \mathrm{H}, \mathrm{N}=\mathrm{CH}), 8.69(\mathrm{~s}, 1 \mathrm{H}, \mathrm{C}=\mathrm{CH}), 9.75(\mathrm{~s}, 1 \mathrm{H}, \mathrm{OH})$; ${ }^{13} \mathrm{C}$ NMR (125 MHz, DMSO-d $\left.d_{6}+\mathrm{HClO}_{4}\right)(\delta, \mathrm{ppm}): 21.5$, 23.7, 24.0, 44.9, 57.8, 110.9, 119.5, 121.2, 122.0, 125.9, 129.7, $130.3,132.6,133.7,136.5,145.0,149.0,155.6,156.4,189.2$, 193.6; HRMS (ESI-TOF, $[\mathrm{M}]^{+}$): calcd for $\mathrm{C}_{24} \mathrm{H}_{22} \mathrm{BrN}_{2} \mathrm{O}_{3}$, 465.0803; found, 465.0814.

10-Benzoyl-8-(2-hydroxy-5-methylbenzoyl)-2,3,4,5-tetrahydro-1H-pyrido[1,2-a][1,3]-diazepin-6-ium (3ha'). Isolated yield 99\%; light yellow solid, mp $206-208{ }^{\circ} \mathrm{C}$; IR $(\mathrm{KBr})\left(\nu_{\max }\right.$, $\left.\mathrm{cm}^{-1}\right): 3290,1650,1585,1482,1348,1227,1092,782,621 ;{ }^{1} \mathrm{H}$ NMR (500 MHz, DMSO- $\left.d_{6}+\mathrm{HClO}_{4}\right)(\delta, \mathrm{ppm}): 2.07(\mathrm{~m}, 2 \mathrm{H}$, $\left.\mathrm{NCH}_{2}\right), 2.14\left(\mathrm{~m}, 2 \mathrm{H}, \mathrm{NCH}_{2}\right), 2.14\left(\mathrm{~s}, 3 \mathrm{H}, \mathrm{CH}_{3}\right), 3.84(\mathrm{~m}, 2 \mathrm{H}$, $\left.\mathrm{CH}_{2}\right), 4.66\left(\mathrm{~m}, 2 \mathrm{H}, \mathrm{CH}_{2}\right), 6.80-6.82(\mathrm{~m}, 1 \mathrm{H}, \mathrm{ArH}), 7.17-7.19$ (m, 2H, ArH), 7.49-7.52 (m, 2H, ArH), $7.62(\mathrm{~m}, 1 \mathrm{H}, \operatorname{ArH})$, 7.68-7.70 (m, 2H, $\operatorname{ArH}), 8.04(\mathrm{~s}, 1 \mathrm{H}, \mathrm{N}=\mathrm{CH}), 8.61(\mathrm{~s}, 1 \mathrm{H}$, $\mathrm{C}=\mathrm{CH}), 9.91(\mathrm{~s}, 1 \mathrm{H}, \mathrm{OH}) ;{ }^{13} \mathrm{C}$ NMR $\left(125 \mathrm{MHz}, \mathrm{DMSO}-d_{6}+\right.$ $\left.\mathrm{HClO}_{4}\right)(\delta, \mathrm{ppm}): 20.0,21.5,23.6,23.9,44.8,57.8,117.2$, 
$120.8,122.4,122.8,128.9,129.7,130.3,130.9,133.8,135.6$, 144.9, 145.7, 148.5, 154.9, 156.4, 191.1, 193.9; HRMS (ESITOF, $[\mathrm{M}]^{+}$): calcd for $\mathrm{C}_{24} \mathrm{H}_{23} \mathrm{~N}_{2} \mathrm{O}_{3}, 387.1698$; found, 387.1709 .

10-Benzoyl-8-(2-hydroxybenzoyl)-2,3,4,5-tetrahydro-1H-

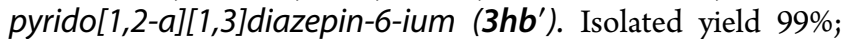
white solid, mp $233-234{ }^{\circ} \mathrm{C}$; IR $(\mathrm{KBr})\left(\nu_{\max } \mathrm{cm}^{-1}\right): 3418$, 3018, 1651, 1591, 1449, 1318, 1234, 1094, 994, 766; ${ }^{1} \mathrm{H}$ NMR $\left(500 \mathrm{MHz}, \mathrm{DMSO}-d_{6}+\mathrm{CDCl}_{3}+\mathrm{HClO}_{4}\right)(\delta, \mathrm{ppm}): 1.84(\mathrm{~m}$, $\left.2 \mathrm{H}, \mathrm{NCH}_{2}\right), 1.93\left(\mathrm{~m}, 2 \mathrm{H}, \mathrm{NCH}_{2}\right), 3.58\left(\mathrm{~m}, 2 \mathrm{H}, \mathrm{CH}_{2}\right), 4.36(\mathrm{~m}$, 2H, $\left.\mathrm{CH}_{2}\right), 6.53-6.59(\mathrm{~m}, 2 \mathrm{H}, \mathrm{ArH}), 7.03-7.06(\mathrm{~m}, 1 \mathrm{H}, \mathrm{ArH})$, 7.12-7.17 (m, 3H, ArH), 7.23-7.29 (m, 1H, $\operatorname{ArH}), 7.34-7.35$ $(\mathrm{m}, 2 \mathrm{H}, \operatorname{Ar} H), 8.86(\mathrm{~s}, 1 \mathrm{H}, \mathrm{N}=\mathrm{CH}), 8.19(\mathrm{~s}, 1 \mathrm{H}, \mathrm{C}=\mathrm{CH})$, $9.79(\mathrm{~s}, 1 \mathrm{H}, \mathrm{OH}) ;{ }^{13} \mathrm{C}$ NMR $\left(125 \mathrm{MHz}\right.$, DMSO-d $6+\mathrm{CDCl}_{3}+$ $\left.\mathrm{HClO}_{4}\right)(\delta$, ppm): 23.4, 23.6, 44.6, 58.0, 117.3, 119.5, 128.5, $119.5,120.5,122.5,128.5,129.4,131.2,133.2,135.3,135.9$, $146.5,148.3,156.3,158.4,191.1,194.6$; HRMS (ESI-TOF, $\left.[\mathrm{M}]^{+}\right)$: calcd for $\mathrm{C}_{23} \mathrm{H}_{21} \mathrm{~N}_{2} \mathrm{O}_{3}, 373.1541$; found, 373.1546.

10-Benzoyl-8-(5-fluoro-2-hydroxybenzoyl)-2,3,4,5-tetrahydro-1H-pyrido[1,2-a][1,3]-diazepin-6-ium (3hc'). Isolated yield 99\%; yellow solid, mp $131-133{ }^{\circ} \mathrm{C}$; IR ( $\left.\mathrm{KBr}\right)\left(\nu_{\max }\right.$ $\left.\mathrm{cm}^{-1}\right): 3279,3079,1652,1580,1483,1435,1323,1266,1221$, $1158,1093,778,625 ;{ }^{1} \mathrm{H}$ NMR (500 MHz, DMSO- $d_{6}+$ $\left.\mathrm{HClO}_{4}\right)(\delta, \mathrm{ppm}): 2.08\left(\mathrm{~m}, 2 \mathrm{H}, \mathrm{NCH}_{2}\right), 2.16-2.17(\mathrm{~m}, 2 \mathrm{H}$, $\left.\mathrm{NCH}_{2}\right), 3.85\left(\mathrm{~m}, 2 \mathrm{H}, \mathrm{CH}_{2}\right), 4.71\left(\mathrm{~m}, 2 \mathrm{H}, \mathrm{CH}_{2}\right), 6.93-6.96(\mathrm{~m}$, $1 \mathrm{H}, \operatorname{ArH}), 7.16-7.18(\mathrm{~m}, 1 \mathrm{H}, \operatorname{ArH}), 7.23-7.26(\mathrm{~m}, 1 \mathrm{H}, \mathrm{ArH})$, 7.54-7.57 (m, 2H, ArH), 7.67-7.70 (m, 2H, ArH), 7.74-7.76 $(\mathrm{m}, 2 \mathrm{H}, \operatorname{Ar} H), 8.08(\mathrm{~s}, 1 \mathrm{H}, \mathrm{N}=\mathrm{CH}), 8.73(\mathrm{~s}, 1 \mathrm{H}, \mathrm{C}=\mathrm{CH})$, $9.84(\mathrm{~s}, 1 \mathrm{H}, \mathrm{OH}) ;{ }^{13} \mathrm{C}$ NMR $\left(125 \mathrm{MHz}, \mathrm{DMSO}-d_{6}+\mathrm{HClO}_{4}\right)$ $(\delta, \mathrm{ppm}): 23.6,24.0,44.9,57.8,116.2,116.4,118.6,120.9$, $121.1,121.9,124.3,129.1,130.1,134.0,136.5,145.7,149.2$, 152.7, 154.5, 156.4, 189.4, 194.2; HRMS (ESI-TOF, $[\mathrm{M}]^{+}$): calcd for $\mathrm{C}_{23} \mathrm{H}_{20} \mathrm{FN}_{2} \mathrm{O}_{3}, 391.1447$; found, 391.1466.

10-Benzoyl-8-(5-chloro-2-hydroxybenzoyl)-2,3,4,5-tetrahydro-1H-pyrido[1,2-a][1,3]-diazepin-6-ium (3hd'). Isolated yield 99\%; white solid, mp $189-191{ }^{\circ} \mathrm{C}$; IR (KBr) ( $\nu_{\max }$ $\left.\mathrm{cm}^{-1}\right)$ : 3282, 3081, 1651, 1587, 1466, 1327, 1224, 1173, 1093, 771,$626 ;{ }^{1} \mathrm{H}$ NMR $\left(500 \mathrm{MHz}, \mathrm{DMSO}-d_{6}+\mathrm{HClO}_{4}\right)(\delta, \mathrm{ppm})$ : $2.08\left(\mathrm{~m}, 2 \mathrm{H}, \mathrm{NCH}_{2}\right), 2.16\left(\mathrm{~m}, 2 \mathrm{H}, \mathrm{NCH}_{2}\right), 3.85\left(\mathrm{~m}, 2 \mathrm{H}, \mathrm{CH}_{2}\right)$, $4.69\left(\mathrm{~m}, 2 \mathrm{H}, \mathrm{CH}_{2}\right), 6.94-6.96(\mathrm{~m}, 1 \mathrm{H}, \mathrm{ArH}), 7.33(\mathrm{~s}, 3 \mathrm{H}$, $\operatorname{Ar} H), 7.38-7.40(\mathrm{~m}, 1 \mathrm{H}, \operatorname{ArH}), 7.53-7.56(\mathrm{~m}, 2 \mathrm{H}, \mathrm{ArH})$, 7.65-7.68 (m, 1H, $\operatorname{ArH}), 7.72-7.73(\mathrm{~m}, 2 \mathrm{H}, \operatorname{ArH}), 8.06(\mathrm{~s}$, $1 \mathrm{H}, \mathrm{N}=\mathrm{CH}), 8.71(\mathrm{~s}, 1 \mathrm{H}, \mathrm{C}=\mathrm{CH}), 9.89(\mathrm{~s}, 1 \mathrm{H}, \mathrm{OH}) ;{ }^{13} \mathrm{C}$ NMR (125 MHz, DMSO- $\left.d_{6}+\mathrm{HClO}_{4}\right)(\delta, \mathrm{ppm}): 23.6,24.0$, $44.9,57.9,119.0,120.6,121.9,123.5,125.3,129.1,129.7,130.0$, 133.7, 133.9, 136.5, 145.8, 149.2, 155.1, 156.5, 189.3, 194.3; HRMS (ESI-TOF, $[\mathrm{M}]^{+}$): calcd for $\mathrm{C}_{23} \mathrm{H}_{20} \mathrm{ClN}_{2} \mathrm{O}_{3}, 407.1151$; found, 407.1162.

10-Benzoyl-8-(5-bromo-2-hydroxybenzoyl)-2,3,4,5-tetrahydro-1H-pyrido[1,2-a][1,3]-diazepin-6-ium (3he'). Isolated yield 99\%; yellow solid, mp $142-143{ }^{\circ} \mathrm{C}$; IR $(\mathrm{KBr})\left(\nu_{\max }\right.$ $\left.\mathrm{cm}^{-1}\right): 3276,3082,1650,1581,1464,1402,1318,1225,1093$, 773,$623 ;{ }^{1} \mathrm{H}$ NMR $\left(500 \mathrm{MHz}, \mathrm{DMSO}-d_{6}+\mathrm{HClO}_{4}\right)(\delta, \mathrm{ppm})$ : $2.08\left(\mathrm{~m}, 2 \mathrm{H}, \mathrm{NCH}_{2}\right), 2.17\left(\mathrm{~m}, 2 \mathrm{H}, \mathrm{NCH}_{2}\right), 3.86\left(\mathrm{~m}, 2 \mathrm{H}, \mathrm{CH}_{2}\right)$, $4.71\left(\mathrm{~m}, 2 \mathrm{H}, \mathrm{CH}_{2}\right), 6.91-6.93(\mathrm{~m}, 1 \mathrm{H}, \mathrm{ArH}), 7.45(\mathrm{~s}, 1 \mathrm{H}$, $\operatorname{ArH}), 7.51-7.53(\mathrm{~m}, 1 \mathrm{H}, \operatorname{Ar} H), 7.56-7.58(\mathrm{~m}, 2 \mathrm{H}, \operatorname{ArH})$, 7.67-7.70 (m, 1H, ArH), 7.74-7.75 (m, 2H, ArH), 8.06 (s, $1 \mathrm{H}, \mathrm{N}=\mathrm{CH}), 8.74(\mathrm{~s}, 1 \mathrm{H}, \mathrm{C}=\mathrm{CH}), 9.85(\mathrm{~s}, 1 \mathrm{H}, \mathrm{OH}) ;{ }^{13} \mathrm{C}$ NMR (125 MHz, DMSO- $\left.d_{6}+\mathrm{HClO}_{4}\right)(\delta, \mathrm{ppm}): 23.7,24.0$, $44.9,57.8,110.8,119.4,120.8,121.9,126.0,129.1,130.1,132.6$, 134.0, 136.5, 145.7, 149.2, 155.5, 156.4, 189.2, 194.2; HRMS $\left(\right.$ ESI-TOF, $[\mathrm{M}]^{+}$): calcd for $\mathrm{C}_{23} \mathrm{H}_{20} \mathrm{BrN}_{2} \mathrm{O}_{3}, 451.0646$; found, 451.0656 .
10-(4-Fluorobenzoyl)-8-(2-hydroxy-5-methylbenzoyl)2,3,4,5-tetrahydro-1H-pyrido[1,2-a][1,3]diazepin-6-ium $\left(3 i a^{\prime}\right)$. Isolated yield $99 \%$; light yellow solid, mp $130-133{ }^{\circ} \mathrm{C}$; IR $(\mathrm{KBr})\left(\nu_{\max } \mathrm{cm}^{-1}\right): 3281,3080,1652,1588,1486,1343$, 1227, 1159, 1093, 788, 618; ${ }^{1} \mathrm{H}$ NMR (500 MHz, DMSO- $d_{6}+$ $\left.\mathrm{HClO}_{4}\right)(\delta, \mathrm{ppm}): 2.06\left(\mathrm{~m}, 2 \mathrm{H}, \mathrm{NCH}_{2}\right), 2.13\left(\mathrm{~m}, 2 \mathrm{H}, \mathrm{NCH}_{2}\right)$, $2.14\left(\mathrm{~s}, 3 \mathrm{H}, \mathrm{CH}_{3}\right), 3.82\left(\mathrm{~m}, 2 \mathrm{H}, \mathrm{CH}_{2}\right), 4.64\left(\mathrm{~m}, 2 \mathrm{H}, \mathrm{CH}_{2}\right)$, 6.79-6.81 (m, 1H, ArH), 7.17-7.19 (m, 2H, ArH), 7.25-7.29 (m, 2H, $\mathrm{ArH}), 7.75-7.78(\mathrm{~m}, 2 \mathrm{H}, \mathrm{ArH}), 8.01(\mathrm{~s}, 1 \mathrm{H}, \mathrm{N}=\mathrm{CH})$, $8.58(\mathrm{~s}, 1 \mathrm{H}, \mathrm{C}=\mathrm{CH}), 9.78(\mathrm{~s}, 1 \mathrm{H}, \mathrm{OH}) ;{ }^{13} \mathrm{C}$ NMR $(125 \mathrm{MHz}$, DMSO- $\left.d_{6}+\mathrm{HClO}_{4}\right)(\delta, \mathrm{ppm}): 19.9,23.5,23.9,44.8,58.0$, $116.0,116.2,117.1,120.3,122.4,129.0,130.9,133.0,133.1$, 135.7, 146.2, 148.6, 155.0, 156.4, 164.3, 166.3, 191.1, 193.2; HRMS (ESI-TOF, $[\mathrm{M}]^{+}$): calcd for $\mathrm{C}_{24} \mathrm{H}_{22} \mathrm{FN}_{2} \mathrm{O}_{3}, 405.1603$; found, 405.1618 .

10-(4-Fluorobenzoyl)-8-(2-hydroxybenzoyl)-2,3,4,5-tetrahydro-1H-pyrido[1,2-a][1,3]-diazepin-6-ium (3ib'). Isolated yield 99\%; light yellow solid, mp $248-249{ }^{\circ} \mathrm{C}$; IR ( $\mathrm{KBr}$ ) $\left(\nu_{\max } \mathrm{cm}^{-1}\right): 3295,3079,1651,1591,1489,1450,1317,1233$, $1154,1092,780,619 ;{ }^{1} \mathrm{H}$ NMR (500 MHz, DMSO-d $d_{6}+$ $\left.\mathrm{HClO}_{4}\right)(\delta, \mathrm{ppm}): 2.07-2.09\left(\mathrm{~m}, 2 \mathrm{H}, \mathrm{NCH}_{2}\right), 2.17-2.18(\mathrm{~m}$, $\left.2 \mathrm{H}, \mathrm{NCH}_{2}\right), 3.86\left(\mathrm{~m}, 2 \mathrm{H}, \mathrm{CH}_{2}\right), 4.74\left(\mathrm{~m}, 2 \mathrm{H}, \mathrm{CH}_{2}\right), 6.93-6.99$ (m, 2H, ArH), 7.39-7.45 (m, 4H, ArH), 7.87-7.89 (m, 2H, $\mathrm{ArH}), 8.06(\mathrm{~s}, 1 \mathrm{H}, \mathrm{N}=\mathrm{CH}), 8.76(\mathrm{~s}, 1 \mathrm{H}, \mathrm{C}=\mathrm{CH}), 9.65(\mathrm{~s}$, $1 \mathrm{H}, \mathrm{OH}) ;{ }^{13} \mathrm{C}$ NMR $\left(125 \mathrm{MHz}, \mathrm{DMSO}-d_{6}+\mathrm{HClO}_{4}\right)(\delta$, ppm): 23.7, 24.0, 44.9, 57.8, 116.2, 116.4, 117.1, 120.0, 121.3, $122.4,123.6,131.1,133.3,134.6,145.3,148.8,164.6,166.6$, $190.8,192.5$; HRMS (ESI-TOF, $[\mathrm{M}]^{+}$): calcd for $\mathrm{C}_{23} \mathrm{H}_{20} \mathrm{FN}_{2} \mathrm{O}_{3}, 391.1447$; found, 391.1462 .

8-(5-Fluoro-2-hydroxybenzoyl)-10-(4-fluorobenzoyl)2,3,4,5-tetrahydro-1H-pyrido[1,2-a][1,3]diazepin-6-ium (3ic'). Isolated yield 99\%; light yellow solid, mp 217-219 ${ }^{\circ} \mathrm{C}$; IR $(\mathrm{KBr})\left(\nu_{\max } \mathrm{cm}^{-1}\right): 3298,3076,1654,1597,1482,1345$, 1227, 1154, 1092, 786, 617; ${ }^{1} \mathrm{H}$ NMR (500 MHz, DMSO-d $d_{6}+$ $\left.\mathrm{HClO}_{4}\right)(\delta, \mathrm{ppm}): 2.07\left(\mathrm{~m}, 2 \mathrm{H}, \mathrm{NCH}_{2}\right), 2.16\left(\mathrm{~m}, 2 \mathrm{H}, \mathrm{NCH}_{2}\right)$, $3.83\left(\mathrm{~m}, 2 \mathrm{H}, \mathrm{CH}_{2}\right), 4.68\left(\mathrm{~m}, 2 \mathrm{H}, \mathrm{CH}_{2}\right), 6.93-6.95(\mathrm{~m}, 1 \mathrm{H}$, $\operatorname{ArH}), 7.13-7.16(\mathrm{~m}, 1 \mathrm{H}, \operatorname{ArH}), 7.22-7.23(\mathrm{~m}, 1 \mathrm{H}, \operatorname{ArH})$, 7.32-7.35 (m, 2H, ArH), 7.81-7.83 (m, 2H, ArH), 8.05 (s, $1 \mathrm{H}, \mathrm{N}=\mathrm{CH}), 8.68(\mathrm{~s}, 1 \mathrm{H}, \mathrm{C}=\mathrm{CH}), 9.72(\mathrm{~s}, 1 \mathrm{H}, \mathrm{OH}) ;{ }^{13} \mathrm{C}$ NMR (125 MHz, DMSO- $\left.d_{6}+\mathrm{HClO}_{4}\right)(\delta, \mathrm{ppm}): 23.6,23.9$, 44.9, 57.9, 107.2, 116.1, 116.3, 116.4, 118.6, 121.0, 121.1, 122.0, $124.1,133.1,145.4,149.1,152.7,154.5,156.3,164.5,166.5$, 189.4, 192.7; HRMS (ESI-TOF, $[\mathrm{M}]^{+}$): calcd for $\mathrm{C}_{23} \mathrm{H}_{19} \mathrm{~F}_{2} \mathrm{~N}_{2} \mathrm{O}_{3}$, 409.1353; found, 409.1369 .

8-(5-Chloro-2-hydroxybenzoyl)-10-(4-fluorobenzoyl)2,3,4,5-tetrahydro-1H-pyrido[1,2-a][1,3]diazepin-6-ium (3id'). Isolated yield 99\%; yellow solid, mp 218-220 ${ }^{\circ} \mathrm{C}$; IR $(\mathrm{KBr})\left(\nu_{\max } \mathrm{cm}^{-1}\right): 3292,3078,1652,1590,1467,1404,1326$, $1226,1163,1094,787,619 ;{ }^{1} \mathrm{H}$ NMR (500 MHz, DMSO-d $d_{6}+$ $\left.\mathrm{HClO}_{4}\right)(\delta, \mathrm{ppm}): 2.07\left(\mathrm{~m}, 2 \mathrm{H}, \mathrm{NCH}_{2}\right), 2.15-2.16(\mathrm{~m}, 2 \mathrm{H}$, $\left.\mathrm{NCH}_{2}\right), 3.84\left(\mathrm{~m}, 2 \mathrm{H}, \mathrm{CH}_{2}\right), 4.69\left(\mathrm{~m}, 2 \mathrm{H}, \mathrm{CH}_{2}\right), 6.94-6.96(\mathrm{~m}$, 1H, $\operatorname{ArH}$ ), 7.32-7.35 (m, 3H, ArH), 7.38-7.39 (m, 1H, ArH), 7.80-7.83 (m, 2H, ArH), $8.03(\mathrm{~s}, 1 \mathrm{H}, \mathrm{N}=\mathrm{CH}), 8.69(\mathrm{~s}, 1 \mathrm{H}$, $\mathrm{C}=\mathrm{CH}), 9.74(\mathrm{~s}, 1 \mathrm{H}, \mathrm{OH}) ;{ }^{13} \mathrm{C}$ NMR $\left(125 \mathrm{MHz}, \mathrm{DMSO}-d_{6}+\right.$ $\left.\mathrm{HClO}_{4}\right)(\delta, \mathrm{ppm}): 23.6,23.9,44.9,57.9,116.1,116.3,119.0$, $120.9,121.9,123.5,125.2,129.7,133.1,133.7,145.4,149.1$, 155.1, 156.4, 164.5, 166.5, 189.2, 192.8; HRMS (ESI-TOF, $[\mathrm{M}]^{+}$): calcd for $\mathrm{C}_{23} \mathrm{H}_{19} \mathrm{ClFN}_{2} \mathrm{O}_{3}, 425.1057$; found, 425.1072.

8-(5-Bromo-2-hydroxybenzoyl)-10-(4-fluorobenzoyl)2,3,4,5-tetrahydro-1H-pyrido[1,2-a][1,3]diazepin-6-ium (3ie'). Isolated yield 99\%; light yellow solid, mp $134-136{ }^{\circ} \mathrm{C}$; IR $(\mathrm{KBr})\left(\nu_{\max } \mathrm{cm}^{-1}\right): 3406,3082,1650,1588,1466,1405$, $1229,1162,1094,789,618 ;{ }^{1} \mathrm{H}$ NMR (500 MHz, DMSO- $d_{6}+$ 
$\left.\mathrm{HClO}_{4}\right)(\delta, \mathrm{ppm}): 2.03\left(\mathrm{~m}, 2 \mathrm{H}, \mathrm{NCH}_{2}\right), 2.07\left(\mathrm{~m}, 2 \mathrm{H}, \mathrm{NCH}_{2}\right)$, $3.83\left(\mathrm{~m}, 2 \mathrm{H}, \mathrm{CH}_{2}\right), 4.68\left(\mathrm{~m}, 2 \mathrm{H}, \mathrm{CH}_{2}\right), 6.89-6.91(\mathrm{~m}, 1 \mathrm{H}$, $\operatorname{ArH}), 7.32-7.36$ (m, 2H, $\operatorname{ArH}), 7.43$ (s, 1H, $\operatorname{ArH}), 7.49-7.51$ $(\mathrm{m}, 1 \mathrm{H}, \mathrm{ArH}), 7.80-7.83(\mathrm{~m}, 2 \mathrm{H}, \mathrm{ArH}), 8.02(\mathrm{~s}, 1 \mathrm{H}, \mathrm{N}=\mathrm{CH})$, $8.69(\mathrm{~s}, 1 \mathrm{H}, \mathrm{C}=\mathrm{CH}), 9.73(\mathrm{~s}, 1 \mathrm{H}, \mathrm{OH}) ;{ }^{13} \mathrm{C}$ NMR $(125 \mathrm{MHz}$, DMSO-d $\left.d_{6}+\mathrm{HClO}_{4}\right)(\delta, \mathrm{ppm}): 23.6,24.0,44.9,57.9,110.9$, $116.1,116.3,119.4,120.9,121.9,125.9,132.6,133.1,136.5$, 145.4, 149.1, 155.5, 156.4, 164.4, 166.5, 189.1, 192.7; HRMS (ESI-TOF, $[\mathrm{M}]^{+}$): calcd for $\mathrm{C}_{23} \mathrm{H}_{19} \mathrm{BrFN}_{2} \mathrm{O}_{3}, 469.0552$; found, 469.0564 .

8-(5-Chloro-2-hydroxybenzoyl)-10-(4-chlorobenzoyl)2,3,4,5-tetrahydro-1H-pyrido[1,2-a][1,3]diazepin-6-ium $\left(3 \mathbf{j c}^{\prime}\right)$. Isolated yield 99\%; yellow solid, $\mathrm{mp} 120-123{ }^{\circ} \mathrm{C}$; IR $(\mathrm{KBr})\left(\nu_{\max } \mathrm{cm}^{-1}\right): 3081,1649,1583,1467,1408,1228,1178$, 1093, 783, 621; ${ }^{1} \mathrm{H}$ NMR (500 MHz, DMSO- $\left.d_{6}+\mathrm{HClO}_{4}\right)(\delta$, ppm): $2.06\left(\mathrm{~m}, 2 \mathrm{H}, \mathrm{NCH}_{2}\right), 2.17\left(\mathrm{~m}, 2 \mathrm{H}, \mathrm{NCH}_{2}\right), 3.99(\mathrm{~m}$, $\left.2 \mathrm{H}, \mathrm{CH}_{2}\right), 4.72\left(\mathrm{~m}, 2 \mathrm{H}, \mathrm{CH}_{2}\right), 6.98-6.99(\mathrm{~m}, 1 \mathrm{H}, \mathrm{ArH}), 7.38-$ $7.45(\mathrm{~m}, 4 \mathrm{H}, \operatorname{ArH}), 7.68-7.69(\mathrm{~m}, 2 \mathrm{H}, \operatorname{ArH}), 8.06(\mathrm{~s}, 1 \mathrm{H}, \mathrm{N}=$ $\mathrm{CH}), 8.74(\mathrm{~s}, 1 \mathrm{H}, \mathrm{C}=\mathrm{CH}), 9.68(\mathrm{~s}, 1 \mathrm{H}, \mathrm{OH}) ;{ }^{13} \mathrm{C}$ NMR $(125$ $\left.\mathrm{MHz}, \mathrm{DMSO}-d_{6}+\mathrm{HClO}_{4}\right)(\delta, \mathrm{ppm}): 23.7,24.0,44.9,57.7$, $119.1,121.6,122.0,123.5,125.5,129.7,130.4,133.7,144.6$, 145.0, 148.9, 155.2, 156.3, 189.3, 193.4; HRMS (ESI-TOF, $[\mathrm{M}]^{+}$): calcd for $\mathrm{C}_{23} \mathrm{H}_{19} \mathrm{Cl}_{2} \mathrm{~N}_{2} \mathrm{O}_{3}, 441.0762$; found, 441.0773.

\section{ASSOCIATED CONTENT}

\section{S Supporting Information}

The Supporting Information is available free of charge on the ACS Publications website at DOI: 10.1021/acsomega.6b00545.

Colorimetric screening of the fluorescence for compounds 3, spectroscopic and electrochemical properties of the screened fluorescent molecules, geometries for all optimized fluorescent molecules and ring-opening counterparts, and ${ }^{1} \mathrm{H}$ NMR and ${ }^{13} \mathrm{C}$ NMR spectra of compounds 3 and $\mathbf{3}^{\prime}$ (PDF)

X-ray crystallographic data (CCDC 908921 and 1032134) (CIF)

\section{AUTHOR INFORMATION}

\section{Corresponding Authors}

*E-mail: frankz.c.liu@outlook.com (Z.-C.L.).

*E-mail: zhjihong2000@yahoo.com.cn (J.-H.Z.).

*E-mail: yansj@ynu.edu.cn (S.-J.Y.).

*E-mail: linjun@ynu.edu.cn. Phone/Fax: +86 87165031633 (J.L.).

\section{ORCID}

Zhi-Cheng Liu: 0000-0002-8577-3349

Jun Lin: 0000-0002-2087-6013

\section{Author Contributions}

${ }^{\#}$ F.-C.Y. and X.-R.L. contributed equally.

\section{Notes}

The authors declare no competing financial interest.

\section{ACKNOWLEDGMENTS}

This work was supported by the Program for Changiiang Scholars and Innovative Research Team in University (no. IRT13095), the National Natural Science Foundation of China (nos. U1202221, 21262042, 21362042, 81260501, and 21662042), and the Reserve Talent Foundation of Yunnan Province for Middle-aged and Young Academic and Technical Leaders (no. 2012HB001). We also thank Profs. Ying Zhou and Guang-Can Wang for their helpful discussion and suggestions.

\section{DEDICATION}

This work is dedicated to the memory of Prof. Zhi-Tang Huang (1928-2016).

\section{REFERENCES}

(1) Lam, M. H.-W.; Law, G.-L.; Lee, C.-S.; Wong, K.-L. Organic Molecules for Optical Imaging. In The Chemistry of Molecular Imaging; Long, N., Wong, W.-T., Eds.; John Wiley \& Sons: Hoboken, 2015; pp 245-274.

(2) Peña, B.; Barhoumi, R.; Burghardt, R. C.; Turro, C.; Dunbar, K. R. Confocal Fluorescence Microscopy Studies of a FluorophoreLabeled Dirhodium Compound: Visualizing Metal-Metal Bonded Molecules in Lung Cancer (A549) Cells. J. Am. Chem. Soc. 2014, 136, $7861-7864$.

(3) Lai, J.; Shah, B. P.; Garfunkel, E.; Lee, K.-B. Versatile Fluorescence Resonance Energy Transfer-Based Mesoporous Silica Nanoparticles for Real-Time Monitoring of Drug Release. ACS Nano 2013, 7, 2741-2750.

(4) Hoffmann, S.; Vystrčilová, L.; Ulbrich, K.; Etrych, T.; Caysa, H.; Mueller, T.; Mäder, K. Dual Fluorescent HPMA Copolymers for Passive Tumor Targeting with $\mathrm{pH}$-Sensitive Drug Release: Synthesis and Characterization of Distribution and Tumor Accumulation in Mice by Noninvasive Multispectral Optical Imaging. Biomacromolecules 2012, 13, 652-663.

(5) Plass, T.; Schultz, C. Covalent Labeling of Biomolecules in Living Cells. In Advanced Fluorescence Reporters in Chemistry and Biology III: Applications in Sensing and Imaging; Demchenko, A. P., Ed.; Springer: Heidelberg, 2011; pp 225-262.

(6) Alford, R.; Simpson, H. M.; Duberman, J.; Hill, G. C.; Ogawa, M.; Regino, C.; Kobayashi, H.; Choyke, P. L. Toxicity of Organic Fluorophores Used in Molecular Imaging: Literature Review. Mol. Imaging 2009, 8, 341-354.

(7) Silva, L. N.; Zimmer, K. R.; Macedo, A. J.; Trentin, D. S. Plant Natural Products Targeting Bacterial Virulence Factors. Chem. Rev. 2016, 116, 9162-9236.

(8) Elshahawi, S. I.; Shaaban, K. A.; Kharel, M. K.; Thorson, J. S. A Comprehensive Review of Glycosylated Bacterial Natural Products. Chem. Soc. Rev. 2015, 44, 7591-7697.

(9) Donner, C. D. Naphthopyranones-Isolation, Bioactivity, Biosynthesis and Synthesis. Nat. Prod. Rep. 2015, 32, 578-604.

(10) Blunt, J. W.; Copp, B. R.; Keyzers, R. A.; Munro, M. H. G.; Prinsep, M. R. Marine Natural Products. Nat. Prod. Rep. 2015, 32, 116-211.

(11) Winter, D. K.; Sloman, D. L.; Porco, J. A., Jr. Polycyclic Xanthone Natural Products: Structure, Biological Activity and Chemical Synthesis. Nat. Prod. Rep. 2013, 30, 382-391.

(12) Masters, K.-S.; Bräse, S. Xanthones from Fungi, Lichens, and Bacteria: The Natural Products and Their Synthesis. Chem. Rev. 2012, 112, 3717-3776.

(13) Song, G.-P.; Li, S.-M.; Si, H.-Z.; Li, Y.-B.; Li, Y.-S.; Fan, J.-H.; Liang, Q.-Q.; He, H.-B.; Ye, H.-M.; Cui, Z.-N. Synthesis and Bioactivity of Novel Xanthone and Thioxanthonel-Rhamnopyranosides. RSC Adv. 2015, 5, 36092-36103.

(14) Zhang, X.; Li, X.; Sun, H.; Wang, X.; Zhao, L.; Gao, Y.; Liu, X.; Zhang, S.; Wang, Y.; Yang, Y.; Zeng, S.; Guo, Q.; You, Q. Garcinia Xanthones as Orally Active Antitumor Agents. J. Med. Chem. 2013, 56, 276-292.

(15) Koh, J.-J.; Zou, H.; Lin, S.; Lin, H.; Soh, R. T.; Lim, F. H.; Koh, W. L.; Li, J.; Lakshminarayanan, R.; Verma, C.; Tan, D. T. H.; Cao, D.; Beuerman, R. W.; Liu, S. Nonpeptidic Amphiphilic Xanthone Derivatives: Structure-Activity Relationship and Membrane-Targeting Properties. J. Med. Chem. 2016, 59, 171-193.

(16) Coqueiro, A.; Choi, Y. H.; Verpoorte, R.; Gupta, K. B. S. S.; De Mieri, M.; Hamburger, M.; Young, M. C. M.; Stapleton, P.; Gibbons, S.; Bolzani, V. d. S. Antistaphylococcal Prenylated Acylphoroglucinol and Xanthones from Kielmeyeravariabilis. J. Nat. Prod. 2016, 79, 470476. 
(17) Zhang, H.; Tao, L.; Fu, W.-W.; Liang, S.; Yang, Y.-F.; Yuan, Q.H.; Yang, D.-J.; Lu, A.-P.; Xu, H.-X. Prenylated Benzoylphloroglucinols and Xanthones from the Leaves of Garciniaoblongifolia with Antienteroviral Activity. J. Nat. Prod. 2014, 77, 1037-1046.

(18) Parish, C. A.; Smith, S. K.; Calati, K.; Zink, D.; Wilson, K.; Roemer, T.; Jiang, B.; Xu, D.; Bills, G.; Platas, G.; Peláez, F.; Díez, M. T.; Tsou, N.; McKeown, A. E.; Ball, R. G.; Powles, M. A.; Yeung, L.; Liberator, P.; Harris, G. Isolation and Structure Elucidation of Parnafungins, Antifungal Natural Products that Inhibit mRNA Polyadenylation. J. Am. Chem. Soc. 2008, 130, 7060-7066.

(19) Gobbi, S.; Hu, Q.; Zimmer, C.; Engel, M.; Belluti, F.; Rampa, A.; Hartmann, R. W.; Bisi, A. Exploiting the Chromone Scaffold for the Development of Inhibitors of Corticosteroid Biosynthesis. J. Med. Chem. 2016, 59, 2468-2477.

(20) Xu, W.-J.; Li, R.-J.; Quasie, O.; Yang, M.-H.; Kong, L.-Y.; Luo, J. Polyprenylated Tetraoxygenated Xanthones from the Roots of Hypericummonogynum and Their Neuroprotective Activities. J. Nat. Prod. 2016, 79, 1971-1981.

(21) Wang, A.; Liu, Q.; Ye, Y.; Wang, Y.; Lin, L. Identification of Hepatoprotective Xanthones from the Pericarps of Garciniamangosta$n a$, Guided with tert-Butyl Hydroperoxide Induced Oxidative Injury in HL-7702 Cells. Food Funct. 2015, 6, 3013-3021.

(22) Rujirawanich, J.; Kim, S.; Ma, A.-J.; Butler, J. R.; Wang, Y.; Wang, C.; Rosen, M.; Posner, B.; Nijhawan, D.; Ready, J. M. Synthesis and Biological Evaluation of Kibdelone $\mathrm{C}$ and Its Simplified Derivatives. J. Am. Chem. Soc. 2016, 138, 10561-10570.

(23) Miao, J.; Cui, H.; Jin, J.; Lai, F.; Wen, H.; Zhang, X.; Ruda, G. F.; Chen, X.; Yin, D. Development of 3-Alkyl-6-methoxy-7-hydroxychromones (AMHCs) from Natural Isoflavones, A New Class of Fluorescent Scaffolds for Biological Imaging. Chem. Commun. 2015, 51, 881-884.

(24) Maity, D.; Sarkar, B.; Maiti, S.; Govindaraju, T. A Highly Selective Reaction-Based Two-Photon Probe for Copper(I) in Aqueous Media. ChemPlusChem 2013, 78, 785-788.

(25) Umemoto, S.; Im, S.; Zhang, J.; Hagihara, M.; Murata, A.; Harada, Y.; Fukuzumi, T.; Wazaki, T.; Sasaoka, S.-I.; Nakatani, K. Structure-Activity Studies on the Fluorescent Indicator in a Displacement Assay for the Screening of Small Molecules Binding to RNA. Chem.-Eur. J. 2012, 18, 9999-10008.

(26) Ghosh, K. K.; Ha, H.-H.; Kang, N.-Y.; Chandran, Y.; Chang, Y.T. Solid Phase Combinatorial Synthesis of a Xanthone Library Using Click Chemistry and Its Application to an Embryonic Stem Cell Probe. Chem. Commun. 2011, 47, 7488-7490.

(27) Frisch, M. J.; Trucks, G. W.; Schlegel, H. B.; Scuseria, G. E.; Robb, M. A.; Cheeseman, J. R.; Montgomery, J. A., Jr.; Vreven, T.; Kudin, K. N.; Burant, J. C.; Millam, J. M.; Iyengar, S. S.; Tomasi, J.; Barone, V.; Mennucci, B.; Cossi, M.; Scalmani, G.; Rega, N.; Petersson, G. A.; Nakatsuji, H.; Hada, M.; Ehara, M.; Toyota, K.; Fukuda, R.; Hasegawa, J.; Ishida, M.; Nakajima, T.; Honda, Y.; Kitao, O.; Nakai, H.; Klene, M.; Li, X.; Knox, J. E.; Hratchian, H. P.; Cross, J. B.; Bakken, V.; Adamo, C.; Jaramillo, J.; Gomperts, R.; Stratmann, R. E.; Yazyev, O.; Austin, A. J.; Cammi, R.; Pomelli, C.; Ochterski, J. W.; Ayala, P. Y.; Morokuma, K.; Voth, G. A.; Salvador, P.; Dannenberg, J. J.; Zakrzewski, V. G.; Dapprich, S.; Daniels, A. D.; Strain, M. C.; Farkas, O.; Malick, D. K.; Rabuck, A. D.; Raghavachari, K.; Foresman, J. B.; Ortiz, J. V.; Cui, Q.; Baboul, A. G.; Clifford, S.; Cioslowski, J.; Stefanov, B. B.; Liu, G.; Liashenko, A.; Piskorz, P.; Komaromi, I.; Martin, R. L.; Fox, D. J.; Keith, T.; Al-Laham, M. A.; Peng, C. Y.; Nanayakkara, A.; Challacombe, M.; Gill, P. M. W.; Johnson, B.; Chen, W.; Wong, M. W.; Gonzalez, C.; Pople, J. A. Gaussian 03, Revision D.01; Gaussian, Inc.: Wallingford, CT, 2004.

(28) Becke, A. D. Density-Functional Thermochemistry. III. The Role of Exact Exchange. J. Chem. Phys. 1993, 98, 5648-5652.

(29) Lee, C.; Yang, W.; Parr, R. G. Development of the Colle-Salvetti Correlation-Energy Formula into a Functional of the Electron Density. Phys. Rev. B: Condens. Matter Mater. Phys. 1988, 37, 785-789.

(30) Miehlich, B.; Savin, A.; Stoll, H.; Preuss, H. Results Obtained with the Correlation Energy Density Functionals of Becke and Lee, Yang and Parr. Chem. Phys. Lett. 1989, 157, 200-206.
(31) Hariharan, P. C.; Pople, J. A. The Influence of Polarization Functions on Molecular Orbital Hydrogenation Energies. Theor. Chim. Acta 1973, 28, 213-222.

(32) Chen, X.-B.; Liu, X.-M.; Huang, R.; Yan, S.-J.; Lin, J. ThreeComponent Synthesis of Indanone-Fused Spirooxindole Derivatives. Eur. J. Org. Chem. 2013, 4607-4613. 